\title{
Rheumatologists' daily practice performance : a study with incognito standardized patients
}

Citation for published version (APA):

Gorter, S. L. (2003). Rheumatologists' daily practice performance : a study with incognito standardized patients. [Doctoral Thesis, Maastricht University]. Datawyse / Universitaire Pers Maastricht. https://doi.org/10.26481/dis.20031003sg

Document status and date:

Published: 01/01/2003

DOI:

$10.26481 /$ dis.20031003sg

Document Version:

Publisher's PDF, also known as Version of record

\section{Please check the document version of this publication:}

- A submitted manuscript is the version of the article upon submission and before peer-review. There can be important differences between the submitted version and the official published version of record.

People interested in the research are advised to contact the author for the final version of the publication, or visit the DOI to the publisher's website.

- The final author version and the galley proof are versions of the publication after peer review.

- The final published version features the final layout of the paper including the volume, issue and page numbers.

Link to publication

\footnotetext{
General rights rights.

- You may freely distribute the URL identifying the publication in the public portal. please follow below link for the End User Agreement:

www.umlib.nl/taverne-license

Take down policy

If you believe that this document breaches copyright please contact us at:

repository@maastrichtuniversity.nl

providing details and we will investigate your claim.
}

Copyright and moral rights for the publications made accessible in the public portal are retained by the authors and/or other copyright owners and it is a condition of accessing publications that users recognise and abide by the legal requirements associated with these

- Users may download and print one copy of any publication from the public portal for the purpose of private study or research.

- You may not further distribute the material or use it for any profit-making activity or commercial gain

If the publication is distributed under the terms of Article $25 \mathrm{fa}$ of the Dutch Copyright Act, indicated by the "Taverne" license above, 
Rheumatologists' Daily Practice Performance 
Simone Leonie Gorter, Maastricht 2003

ISBN 90-5278-393-4

Universitaire Pers Mastricht

Omslagillustratie: Annelies Weegels-Don Griot

Druk: Datawyse / Universitaire Pers Maastricht 


\section{Rheumatologists" Daily Practice Performance}

a study with incognito standardized patients

\section{PROEFSCHRIFT}

ter verkrijging van de graad van doctor

aan de Universiteit Maastricht,

op gezag van de Rector Magnificus,

Prof. Dr. A.C. Nieuwenhuijzen Kruseman,

volgens het besluit van het College van Decanen, in het openbaar te verdedigen

op vrijdag 3 oktober 2003 om 12.00 uur

door

Simone Leonie Gorter

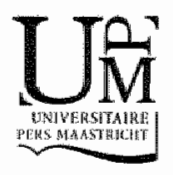




\section{Promotores}

Prof.dr. D.M.F.M. van der Heijde

Prof.dr. A.J.J.A. Scherpbier

Co-promotor

Dr. $J$ J. Rethans

Beoordelingscommissie

Prof.dr. H.F.P. Hillen (voorzitter)

Prof.dr. B.A.C. Dijkmans (Vrije Universiteit Amsterdam)

Prof.dr. C.P. van Schayck

Dr. H.A.P. Wolfhagen

Prof.dr. R.P. Zwierstra (Rijksuniversiteit Groningen)

The study presented in this thesis was performed at the Care and Public Health Research institute (CAPHRI. Which participates in the Netherlands School of Primary Care Research (accredited by the Royal Netherlands Academy of Arts and Sciences (KNAWI).

Hhe study was made possible by grant from the Dutch Arthritis Association. Grant No $97-2-201$.

The printing of this thesis was suppoted by Amgen BV, Astrazeneca BV, Aventis Pharma BV and Glaxosmithkline BW. 
Les hommes, ils s' enfoument dans les rapides, mais ils ne savent plus ce qu'ils cherchent.

(d'après: Le petit prince. Antoine de Saint Exupéry, 1946) 



\section{Contents}

Chapter 1 General Introduction 9

Chapter 2 Developing case-specific checklists for standardized patient-based assessments in internal medicine:

A review of the literature

Chapter 3 How to introduce incognito standardized patients into outpatient clinics of specialists in rheumatology

Chapter 4 Rheumatologists' performance in daily practice

Chapter 5 Rheumatologists" variation in actual daily practice:

Chapter 6 Psoriatic Arthritis: Performance of rheumatologists in daily practice. A study with incognito standardized patients

Chapter 7 Reproducibility of clinical performance assessment in practice using incognito standardized patients

Chapter 8 The role of a computerized case-based testing procedure in practice performance assessment

Chapter 9 Doctor-patient interaction: standardized patients' reflections from inside the rheumatological office

Chapter 10 Conclusions and recommendations for further research

Chapter 11 Summary

Chapter 12 Samenvatting

Dankwoord 

Chapter

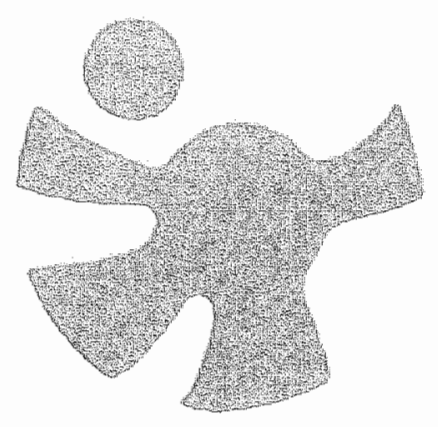

General introduction 
This is a study assessing variation in health care provided by a large number of rheumatologists, by using incognito standardized patients (SPs) visiting rheumatologists working in secondary care settings. It also investigates the feasibility and reproducibility of introducing incognito SPS into secondary care settings.

In this introduction, firstly, the reasons why this study was started will be discussed. Thereafter the SP-method will be introduced briefly and the role of variation in performance in this study will be discussed. At the end of this introduction the different research questions will be presented and a description of the content of this thesis will be provided to the reader.

\section{Why this study?}

During the last decades, the proportional increase of the aging population. increasing demands for health care from patients, and rapid growth in expensive medical technologies cause an increase in health care costs and constraining forces on manpower in health care. Managing this growth appears to be a problem as illustrated by increasing waiting lists for patients and continuing debates about budgets. Priorities have to be set. In making best choices, quality of care plays a major role. There are several stakeholders playing in the field of health care. These are patients, health care providers (physicians, nurses, professional organizations), insurance companies and legislative authorities. Several motives and forces influence each of these parties. This calls for a detailed insight into the acts or motives of each of the parties involved. While recognizing that each party is important, in this study the emphasis is put on the clinical activities of physicians in the health care setting. The study foresees in getting data about physician's performance in daily clinical practice. The reason is that these data on performance and especially on variation in performance will be a valuable source for discussions among professionals on the appropriateness of care they provide. The development of guidelines could then be concentrated on what is really going on in actual practice and hence might have more influence on changing practice behavior whenever needed. In addition, in the future, targeted continuing medical education might be organized if performance on a certain subject seems to be substandard. Ideally, after an educational intervention has taken place, repeated assessments to control for the desired improvement in daily practice performance should occur.' 


\section{Assuring performance}

Assessing real practice performance can be done using direct and indirect methods. ${ }^{2}$ Direct measures observe the actual patient-physician encounter by for example observation in practice with video or audio equipment ${ }^{3}$ or with the standardized patient approach. ${ }^{45}$ With indirect methods only results of daily doctormatient practice performance can be found, such as morbidity or complication rates. patient satisfaction, prescriptions or records from patients and registration of certain practice activities by physicians. ${ }^{5}$ Indirect methods are easier to administer, less costly and less time-consuming when compared to direct measures. The disadvantage of indirect measures is that they not always demonstrate what is really going on in daily practice. To improve quality, data about real practice behavior are also needed. Although most of the direct measures indeed observe physician's real practice behavior, these assessments usually take place while the physicians are aware of being observed. This will introduce a Hawthorne bias: physicians will do their upmost when they know they are being observed. So, even with direct measures real practice behavior is probably not always assessed. Assessments of real practice performance should therefore preferably take place in a direct but for the physician unobtrusive way. One way of doing that is by introducing incognito standardized patients into physician's offices to assess physician's authentic performance. A few studies have been published on this method. Rethans sent incognito standardized patients to 39 general practitioners (GPs), each GP receiving four different standardized patients. ${ }^{6}$ In a more recent study by Hutchinson, primary care physicians were visited by incognito standardized patients asking for preventive care advices. In this study, follow up visits occurred in a few cases. ${ }^{7}$ As far as we know, incognito standardized patients have never been introduced to specialists working in secondary care settings. Since the incognito SP-method gives insight into physician's daily practice in a direct way and is capable of assessing variation in performance when identical cases are presented to different physicians, we decided to use the incognito SP-method in our study for assessing clinical performance in a secondary care setting. When presenting different cases to physicians, content specificity is an important issue to be dealt with. 4.8 .9 Content specificity means that performance on one case does not correspond with performance on another (different) case. Therefore, when assessing physician's performance a sufficient number of cases have to be presented to obtain reliable results. 


\section{Variation in performance}

In actual daily practice considerable variation in performance exists in the delivery of health care. ${ }^{10.12}$ Variation can be found both among physicians (inter-doctor variation) and within physicians (intra-doctor variation). Daily practice is complex and depends on many aspects of care and hence variation in delivery of care is inevitable and in the process of translation from evidence to the individual patient even desirable. When incognito SPs register the content of the encounter with a physician, detailed information on physician's performance will be available. Because they all see the same patients, variation in the delivery of care by different physicians will become clear. The presence of variation should be a stimulus for physicians to learn about their daily practice and to understand the outcome of care they provide to patients. ${ }^{13}$ The SP-method is useful for comparing physician's performances among each other, since patients' presentations are standardized and all physicians see the same patients.

\section{The standardized patient-method}

SPs are non-physicians taught to portray patients in a standardized and consistent fashion. ${ }^{14}$ SPs can be asymptomatic, can have stable abnormal findings on physical examination, or can simulate physical findings. ${ }^{4}$ In the last years many studies have been published about use of SPS in undergraduate medicine ${ }^{15-20}$ and some reports have appeared on SPs in postgraduate medicine. ${ }^{7,21,22}$ SPS were first introduced in undergraduate medical education for teaching medical and communication skills, ${ }^{14.23}$ but later they were also used in OSCE's (Objective Structured Clinical Examinations) and SP-based tests to assess medical students. ${ }^{24.25}$ Nowadays SPs are sent to physicians to assess daily clinical performances, in a few studies incognito SPs are used. ${ }^{726.20}$ Most of these studies took place among residents and not among practicing specialists.

Ample evidence exists that the SP-method is a reliable, ${ }^{29.31}$ valid ${ }^{28,32}$ and acceptable method ${ }^{33,34}$ to assess performance of physicians. ${ }^{4,35}$ However, it is a logistically complicated task to arrange incognito SP-visits and it demands considerable efforts from researchers and SPs presenting the cases. ${ }^{36}$ During the first years of the use of incognito SPs visiting practices, ethical aspects were discussed regarding the fact that physicians were unaware that SPs visited them. Some researchers, therefore, started asking informed consent a long period before the SPS were actually introduced. ${ }^{6}$ By the time these incognito SPs entered practice, the physicians would have forgotten about these SPS. In this way, real practice can be assessed while asking for informed consent. SPs' reproducibility in playing and recording of a consultation has been investigated and encouraging results 
were obtained. ${ }^{29,35,37}$ As far as we know, reproducibility of the test results in an incognito SP-based assessment has never been investigated before. By providing exactly the same role different times, SPS are also able to compare participants' non-medical (attitudinal and communication) skills. These communication and attitudinal skills are important aspects of the consultation since it has been shown that physicians without malpractice claims have better communication skills than physicians with claims. ${ }^{39}$

\section{Comparison with other methods}

It is interesting to investigate in what way other and logistically less burdening methods than SPS can reliably predict performance in daily practice. If, for example, a written competence test would appropriately predict practice performance, quite some resources could be saved by applying this test instead of the SP method. Previous research has shown a statistically significant correlation between scores on a medical knowledge test and performance in practice by video observation of surgery hours with authentic patients. ${ }^{39}$ Another study did not find a sufficient correlation to predict practice performance with competency measures. ${ }^{6}$ Ramsey found moderately strong correlations between different performance measures and scores from written examinations. ${ }^{40}$ However, he only used indirect methods (chart reviews, peer assessment) to assess performance. The ability of a written competence test to predict actual practice performance, i.e. without physicians aware of being observed in daily practice, has never been investigated. When written cases resembling real life situations are used, this competence test might well be able to predict performance in daily practice in a global way. When this would be the case, this instrument could be used as a screening tool for groups of physicians. Those performing badly on a written competence test may then be visited by incognito SP-visits to obtain information from performance in real practice.

\section{Research questions}

In order to improve transparency in health care provided in a clinical specialized setting, a study was started using incognito SPs visiting a large number of Dutch rheumatologists in their outpatient clinics. We aimed to describe performance and eventually the variation in performance among the rheumatologists as a starting point for discussion about quality of care. The following research questions were set before the study started: 1) is it feasible to introduce incognito standardized patients in secondary care?,2) How reproducible is the incognito standardized patient method?, 3) How is 
the performance and variation in performance among a Dutch group of rheumatologists when confronted with the same eight incognito standardized patients?, 4) What is the ability of a written competence test to predict daily clinical performance as assessed by incognito SPS? and 5) How do incognito standardized patients appreciate the doctor-patient interaction?

\section{Guide to the reader}

Chapter 2 gives a review of the literature on the dlevelopment of checklists for standardized patient-based assessment in internal medicine. Assessing performance with incognito standardized patients implies the use of checklists for recording physicians' performance. These lists should reflect physician's performance and hence be developed in a valid way. The checklist should be specific for each case. Chapter 3 reports in detail on our experiences in preparing and implementing incognito SP visits during the first year of the study. Feasibility of the method is also discussed. In chapter 4, an elaborate description is given of the performances of the participants on eight different cases as presented by the SPs. Variations in medical history, physical examination, treatment as well as variation in costs generated by the rheumatologists are presented. Chapter 5 reports on the variation in the spectrum of actions performed as assessed on a checklist. Performance is then related to rheumatologists' background characteristics, such as age, working experience and type of practice. Chapter 6 is an elaborate description of the results of one of the cases as presented by the SPs: psoriatic arthritis. Detailed information is given on many aspects of the consultation, as well as on requested additional investigations. Chapter 7 investigates the reproducibility of the incognito SP based-method and chapter 8 investigates the value of a written competence test as a predictor of performance. SPs' reflections on the interaction between doctors and SPS are explored by means of a focus group interview and results of this study are presented in chapter 9 . Whereas in chapter 10 a general discussion and recommendations for further research are presented, chapter 11 and 12 give a separate English and Dutch summary of all chapters of this thesis. 


\section{References}

1. Lawrence M. Schoffield T. Medical audit in primary care. U.S.A.: Oxford University Press: 1993.

2. Rethans JJ, Westin S, Hays R. Methods for quality assessment in general practice. Fam Pract $1996 ; 13: 468-76$.

3. Riam $P$, van der Vleuten $C$, Rethans JJ, Grol R, Aretz K. Assessment of practicing family physicians: comparison of observation in a multiple-station examination using standardized patients with observation of consultations in daily practice. Acad Med $1999 ; 74: 62-9$.

4. van der Vleuten C. Swanson D. Assessment of clinical skills with standardized patients: state of the art. Teach Learn Med 1990;2:58-76.

5. Vu B. Use of standardized patients in clinical assessments: Recent developments and measurement findings. Educ Research 1994:23:23-30.

6. Rethans $J J$, Sturmans $F$, Drop $R$, van der Vleuten C. Hobus P. Doss competence of general practitioners predict their performance? Comparison between examination setting and actual practice. BMJ 1991;303:1377-80.

7. Hutchinson B, Woodward CA, Norman GR, Abelson J, Brown JA. Provision of preventive care to unannounced standardized patients. Can Med Assoc J 1998:27:185-93.

8. Vleuten van der CPM. The assessment of professional competence: developments. research and practical implications. Adv Health Sci Educ 1996;1:44-67.

9. Roberts J. Norman G. Reliability and learning from the objective structured clinical examination. Med Educ 1990;24:219-23.

10. Wennberg J, Gittelsohn A. Variations in medical care among small areas. Sci Am 1982; 246:100-11.

11. Westert GP. Nieboer AP, Groenewegen PP. Variation in duration of hospital stay berween hospitals and between doctors within hospitals. Soc Sci Med 1993;37: 833-9.

12. Bamji AN, Erhardt CC, Price TR, Williams PL. The painful shoulder: can consultants agree? Br J Rheumatol 1996;35:1172 4 .

13. Keller RB, Largay AM, Soule DN, Manchester ME, Katz JN, Boston MA. Maine carpal tunnel study: small area variations. J Hand Surg 1998;23A:692-6.

14. Barrows HS. An overview of the uses of standardized patients for teaching and evaluating clinical skills. AAMC. Acad Med 1993;68:443-51.

15. Stiliman PL, Regan MB, Swanson DB. A diagnostic fourth-year performance assessment. Arch Intern Med 1987;147:1981-5.

16. Colliver JA, Swartz MH. Assessing clinical performance with standardized patients. JAMA $1997 ; 278: 790-1$.

17. Gallagher TH, Pantilat $S Z$, Lo $B_{*}$ Papadakis MA. Teaching medical students to discuss advance directives: A standardized patient curriculum. Teach Learn Med 1999;11:142-7.

18. Hodges B. Regehr $G$, Hanson $\mathbb{M}$, McNaughton $N$. An objective structured clinical examination for evaluating psychiatric clinical clerks. Acad Med 1997;72:715-21.

19. Klamen DL, Williams RG. The effect of medical education on students" patient-satisfaction ratings. Acad Med 1997;72:57-61.

20. Rosebraugh CJ. Speer A.J. Ainsworth MA, Solomon DJ, Callaway MR, Holden MD. Developing a presentation and problem-solving station in a multistation standardizedpatient examination. Acad Med 1996;71:S1024 .

21. Boudreau D, Tambilyn R, Dufresne L. Evaluation of consultative skills in respiratory medicine using a structured medical consultation. Am I Respir Crit Care Med 1994; $150: 1298-304$. 
22. Day RPP. Hewson MG. Kindy P, Jr., Van Kirk J. Evaluation of resident performaince in an outpatient internal medicine clinic using standardized patients. J Gen Intern Med $1993 ; 8: 193-8$.

23. Wallace P. Following the threads of an innovation: the history of standardized patients in medical education. Caduceus 1997; 13:528.

24. Harden RM. Stevenson M, Downie WW, Wilson GM. Assessment of clinical competence using objective structured examination. BMJ 1975:1:447-51.

25. Wleuten van der $C$, Swanson DB. Assessment of clinical skills with standardized patients: state of art. Teach Learn Med 1990;2:58-76.

26. Brown JA, Abelson J, Woodward CA, Hutchison B, Norman G. Fielding standardized patients in primary care settings: lessons from a study using unannounced standardized patients to assess preventive care practices. Int J Qual Health Care 1998; 10:199-206.

27. Hoppe RB, Farquhar LJ, Henry $\mathbb{R}$, Stoffelmayr B. Residents attitudes towards and skills in counseling: Using undetected standardized patients. J Gen Intern Med 1990; 5:415-20.

28. Tamblyn $R$, Abrahamowicz $M$, Schnarch $B$, Colliver JA, et al. Can standardized patients predict real-patient satisfaction with the doctor-patient relationship? Teach Learn Med $1994: 6: 36-44$.

29. Tamblyn RM, Klass DJ, Schnabl GK, Kopelow ML. The accuracy of standardized patient presentation. Med Educ 1991:25:100-9.

30. Vu NV, Marcy MM, Colliver JA, Verhulst SJ, Travis TA, Barrows HS. Standardized (simulated) patients' accuracy in recording clinical performance check-list items. Med Educ 1992:26:99-104.

31. Vu MV. Steward DE, Marcy M. An assessment of the consistency and accuracy of standardized patients' simulations. I Med Educ 1987:62:1000-2.

32. Dollan NC MMDM. Using unidentified standardized patients to evaluate housestaff delivery of preventive services. Teach Learn Med 1997,9:60-5.

33. Hasle JL, Anderson DS. Szerlip HM. Analysis of the costs and benefits of using standardized patients to help teach physical diagnosis. Acad Med 1994:69:567-70.

34. Rethans $J \mathbb{J}$. Drop $\mathbb{R}$, Sturmans $F$, van der Vleuten $C$. A method for initroducing standardized (simulated) patients into general practice consultations. Br J Gen Pract $1991: 41: 94-6$.

35. Stillman P, Swanson D, Regan MB, Philbiin MM, Nelson V, Ebert T, et al. Assessment of clinical skills of residents utilizing standardized patients. A follow-up study and recommendations for application. Ann Intern Med 1991;1 14:393-401.

36. Tamblyn RM. Use of standardized patients in the assessment of medical practice. Can Med Assoc J 1998;158:205-7.

37. Colliver JA, Steward DE, Markwell SJ, Marcy ML. Effect of Repeated Simulations by Standardized Patients on Intercase Reliability. Teach Learn Med 1991;3:15-9.

38. Levinson W. Roter DL, Mullooly $\unlhd P$, Dull VT. Frankel RM. Physician-patient communication. The relationship with malpractice claims among primary care physicians and surgeons. JAMA 1997;277:553\%9.

39. Ram P. van der Veuten C. Rethans JJ, Schouten B. Hobma S, Grol R. Assessment in general practice: the predictive value of written-knowledge tests and a multiple-station examination for actual medical performance in daly practice. Med Educ 1999;33:197. 203.

40. Ramsey PG, Carline JD, Inui TS, Larson EB, LoGerfo JP, Wenrich MD. Predictive validity of certification by the American Board of Internal Medicine. Ann Intern Med $1989 ; 110: 719-26$. 


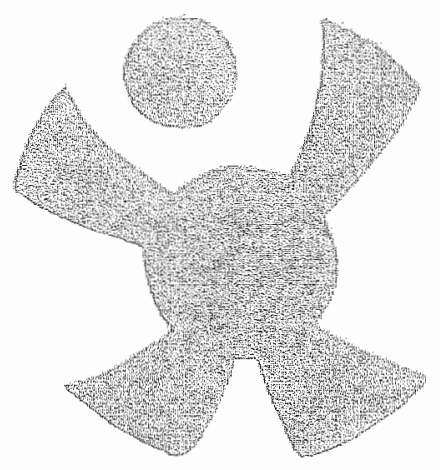

\section{Developing case-specific checklists for} standardized patient-based assessments in internal medicine: A review of the literature

Simone Gorter, Jan-Joost Rethans, Albert Scherpbier, Désirée van der Heijde, Harry Houben, Cees van der Vleuten, Sjef van der Linden

Academic Medicine 2000:75:77-84. 


\section{Abstract}

Purpose. To review the literature on the methodologies used in writing case-specific checklists for studies of internal medicine physicians. performance by standardized patients.

Method. The authors searched Medline, Embase, Psychlit, and ERIC for articles in English published between 1966 and February 1998. The following search string was used: "[(standardi * or simulat* or programm*) near (patient* or client* or consultati*)] and internal medicine. The authors then searched the reference lists of papers retrieved from the database searches, as well as those from seven proceedings of the International Ottawa Conference on Medical Education and Assessment.

Results. The procedure yielded 29 relevant articles: database searches vielded 14 published reports dealing with case-specific checklists, 11 articles were culled from the reference lists of these papers, and the Ottawa Conference on Medical Education and Assessment proceedings yielded four articles. Only 12 articles reported specifically on the development of checklists. In general, there were three procedures used for developing checklists: panels of experts, the investigators themselves, and the use of responses from expert physicians to written protocols. No article indicated that researchers had relied exclusively on data from the literature to compose their checklists. Only three articles indicated that literature sources informed their checklist development. All articles except one relied on explicit criteria for the inclusion of items on the checklists. In 21 of the 29 articles, the checklists were scored by SPS, but the scoring of specific items on the checklists varied according to the purpose of the SP-physician encounter. Only four of the articles made the checklist available or indicated that the checklist could be obtained from the authors.

conclusion. The development of case-specific checklists for SP examinations of physicians' performance has received little attention in the literature. To judge the validity of studies of physicians" performance that use SPs, the development processes for the checklists needs to be more fully described to enable readers to evaluate the validity and reliability of the studies. 


\section{Introduction}

New technologies, aging populations, and the growing demand and increasing costs for health care have all stimulated interest in the assessment of the care being provided to patients. Efforts to assess patients care have yielded direct and indirect approaches to measuring physicians" performances." The indirect assessment of physicians" performances involves the evaluation of physicians' referral or prescribing behaviors, the review of morbidity or complication rates, the review of medical records, and the assessment of patients' satisfaction rates. Methods for direct assessment of physicians" performance are the observation of practice, using video or audio equipment, and the use of standardized patients (SPS), introduced to medical education by Barrows. ${ }^{2,3}$ In this literature review, we focus on the direct assessment of physicians through the use of standardized patients. In particular, we sought literature describing the development of case-specific checklists for evaluating physicians' performance in an SP assessment encounter.

\section{Background}

Standardized patients portray patients in a standardized and consistent fashion either in a formal examination setting or when sent unannounced into clinical practice to assess physicians' performances. ${ }^{4.5}$ They can be asymptomatic, have stable, abnormal findings on physical examination, or they may be able to simulate physical findings. ${ }^{6}$ The SP method has proven to be a valid and reliable method to assess performance. ${ }^{6,7}$

After a physician encounter, SPS usually report the physician"s performance on a checklist, which can be either generic or case-specific. Generic lists are used to assess general skills (for example the Arizona rating scale ${ }^{8}$ ). whereas case-specific checklists provide detailed information about the physician's skills with medical history taking, physical examination, case management, and communication. Case-specific checklists are developed specially for each case and are tailored to the content of the consultation. Generic lists can be used for many different cases.

The information gathered from SP checklists can be used for educational purposes, as a needs assessment tool for developing appropriate continuing medical education programs, or as a tool for summative assessment. In either case, the development of the checklist should be appropriate to the intendled use of the data. For example, if checklists are to be used as an assessment tool where decisions about accreditation may be made, the scoring system needs to be appropriately developed for each checklist. The information on the checklists must be reliable and valid and carefully 
trained SPs must complete checklists in a consistent way. There is good evidence that the reliability of checklists is sufficient. ${ }^{9.10}$ Validity, in general, means that an instrument measures what it is supposed to measure, and for case-specific checklists validity means that the checklist reflects a physician's performance. Checklist construction is, therefore, crucial to the validity and reliability of an SP assessment of a physician's performance. In order for readers to effectively evaluate the validity of a checklist used in an SP encounter, it is important that they be told who developed the checklist, what procedures were followed, and the order and content of the checklist's items.

This paper presents a review of the literature on the methodologies used in writing case-specific checklists for studies of internal medicine physicians performance that were assessed using SPS. We focused primarily on validity aspects, such as who developed the checklist; which development procedure was used; whether or not the development process was based on data from the literature or on data resulting from consensus procedures; what scoring system was used; and, finally, whether or not the checklist was published. Many studies of SPS have taken place in undergraduate settings. Given the focus of our recent project to investigate the performance of rheumatologists in real practice using unannounced SP visits, we reviewed only studies with SPS in internal medicine postgraduate settings.

\section{Method}

We searched Medline, Embase, Psychlit, and ERIC for articles in English published between 1966 and February 1998 by using the following string of search terms: "[istandardi* or simulat* or programm*) near (patient" or client* or consultati " $\|$ and internal medicine." We then searched the reference lists of the retrieved papers and all seven proceedings from the International Ottawa Conference on Medical Education and Assessment. For this review we selected only articles that assessed physicians' performances through the use of case-specific checklists.

We structured the review using the following questions:

- Is the process of developing the checklist described?

If yes, which procedure was used?

- How many and what kind of people (experts, lay people, etc.) were involved in this process?

- Was the development of the checklist based on literature, consensus, or both?

- Was the checklist baised on explicit criteria?

- How were results reported and, if applicable, how was the scoring system developed? 
- Did standardized patients score the checklist?

- Is the full checklist published or otherwise available?

\section{Results}

The literature search yielded 14 papers dealing with case-specific checklists in studies with SPS assessing physicians' performances. In addition, we found 11 articles in the reference lists of these papers. The seven proceedings of the Ottawa Conference on Medical Education and Assessment provided four additional studies. The results for all 29 papers are summarized alphabetically by author in Table 2.1 . The results that follow are organized by research question.

\section{Descriptions of checklist development}

Of the 29 articles, only 12 reported the procedure of the checklist's development. Checklists were developed in three ways: by panels of experts, by the study investigators, and by the review of findings after the SP encounter protocol had been sent to a group of expert physicians.

In seven studies ${ }^{1118}$ a panel developed the case-specific checklists and indicated important items. For example, Boudreau et al. ${ }^{11}$ in their assessment of consultative skills in respiratory medicine, arranged four SP encounters for 22 physicians. For all cases, an expert panel consisting of four senior university respiratory specialists had identified specific criteria with respect to the quality of the consultation. The expert panel, working by consensus, also assessed each item on the checklist for its relative importance. Using a similar approach, Gordon ${ }^{14}$ published a study in which the performance of interns was assessed with the use of three unannounced SPs. An expert panel of two family physicians, two internists, and two housestaff was used to obtain criteria for these cases. First, the panel had to modify a checklist that was developed by the investigators. Then the members met to review the responses, made individual modifications, and met again to reach consensus on each case.

The second procedure that we encountered entailed investigators" developing the checklists themselves. The investigators then presented the checklists to other physicians or investigators for validation. ${ }^{19-21}$

The third procedure was reported by Norman. ${ }^{7}$ A written protocol for each case was sent to a group of expert physicians who were asked to make a differential diagnosis, propose investigations and management options, and list all essential findings. The checklist was then developed based on the expert physicians" responses to the protocol. 


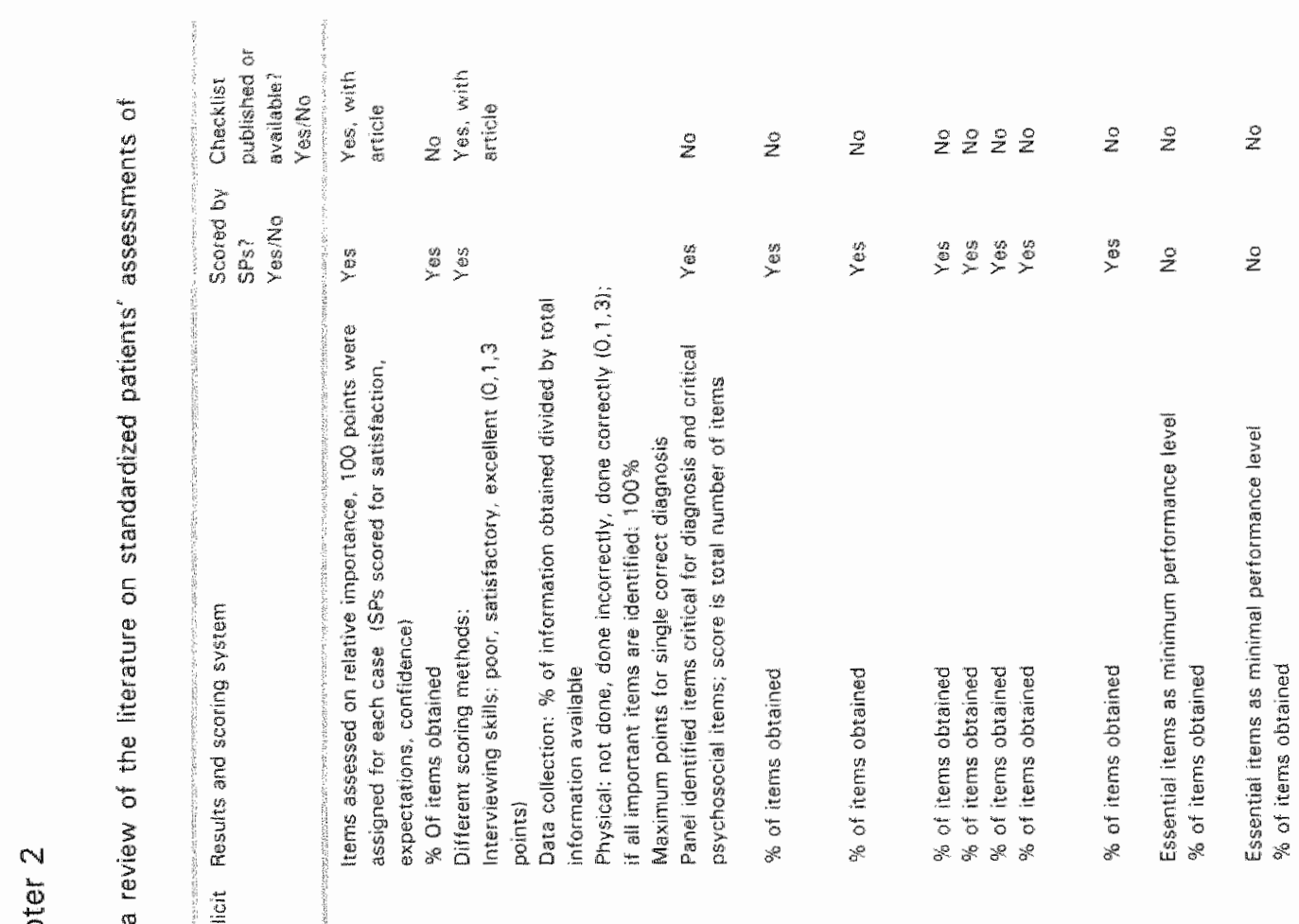

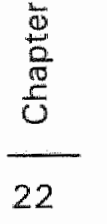

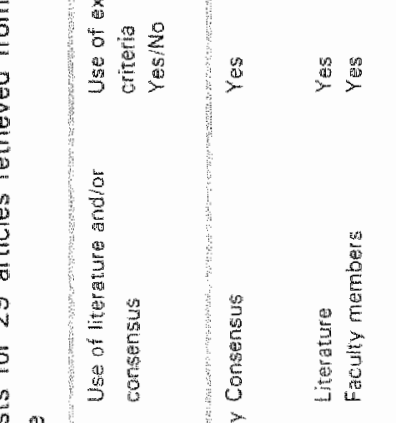

$\frac{\frac{5}{3}}{\frac{5}{5}}$

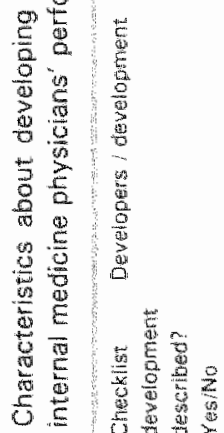

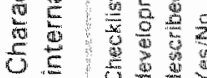

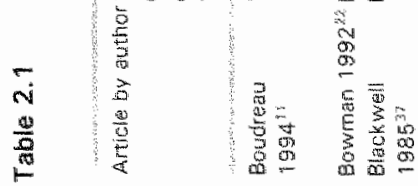

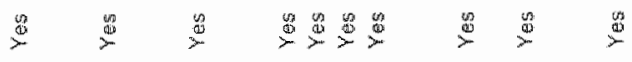

要要

焉

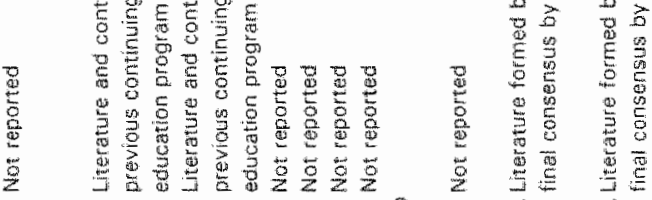

柴

量焉

$\frac{E}{\mathrm{x}}$

邆

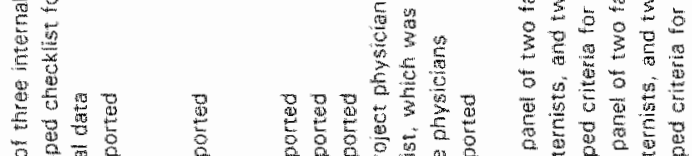

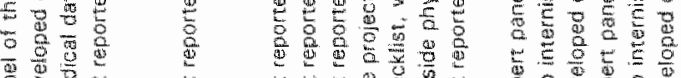

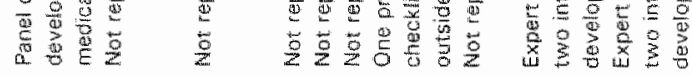

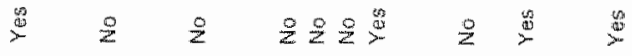

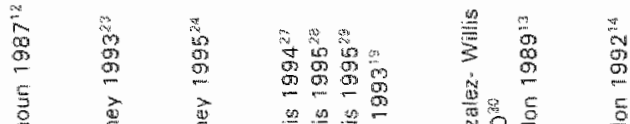




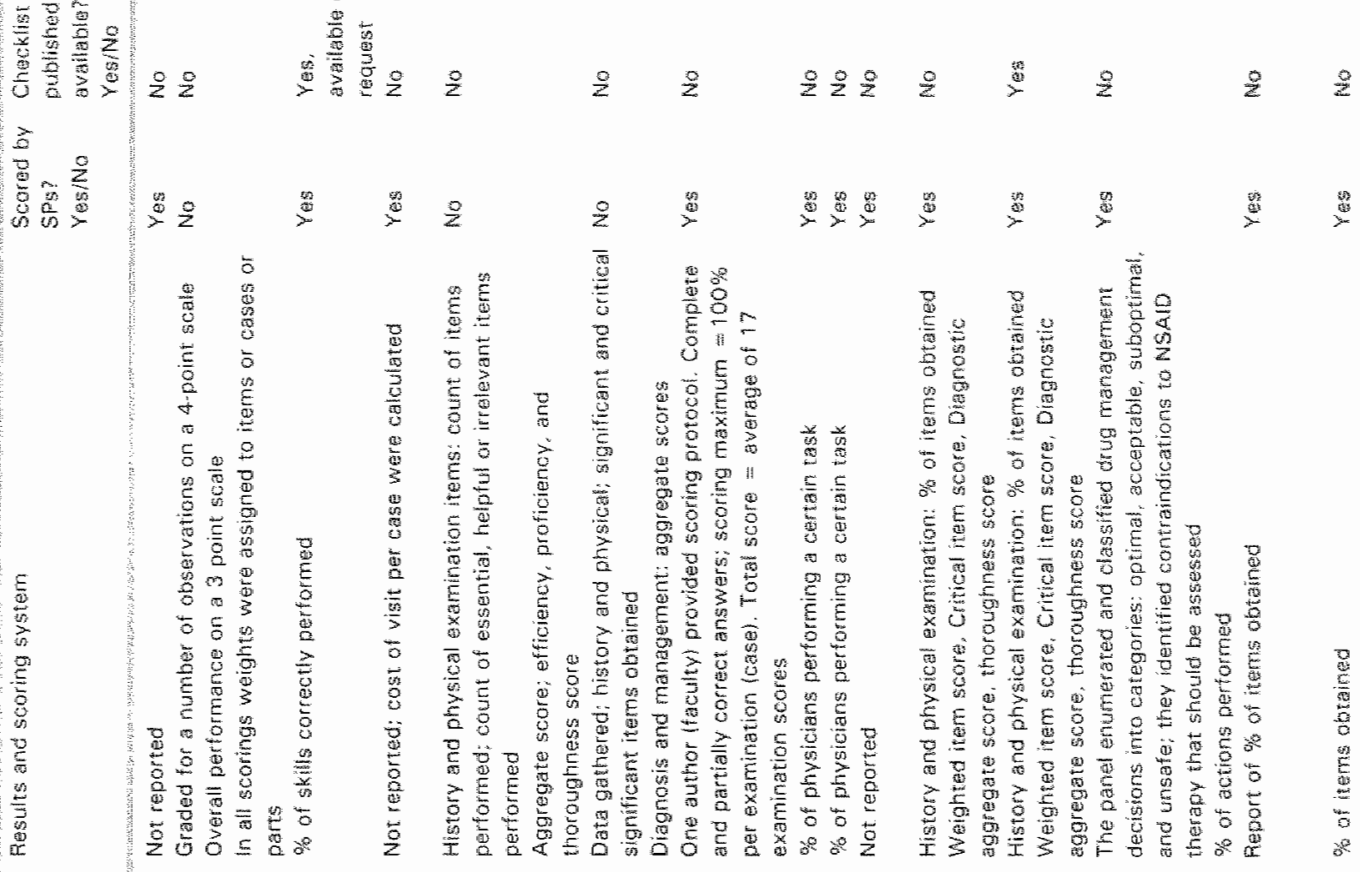

$\frac{5}{5}$

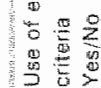

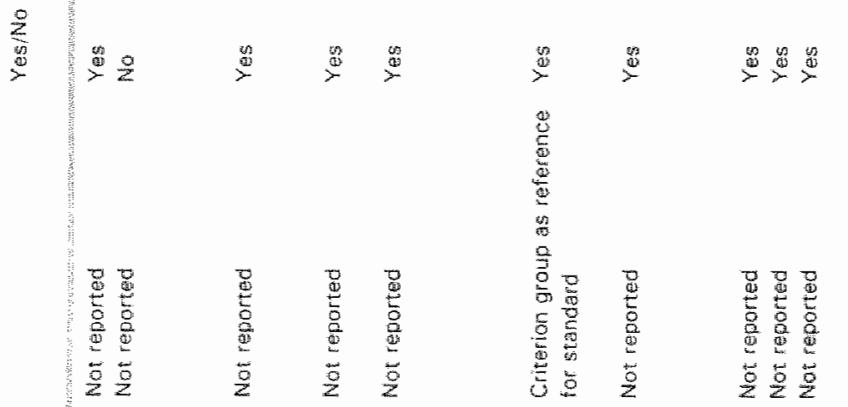

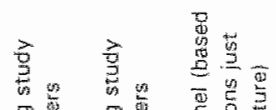

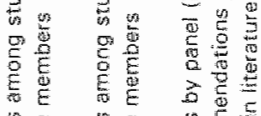

,

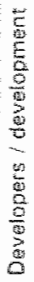

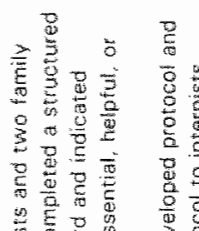

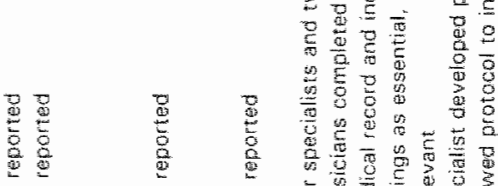

总宫

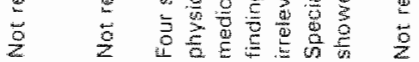

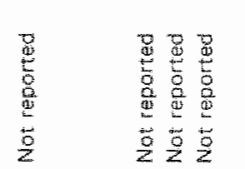

照:

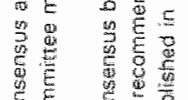

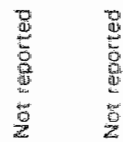

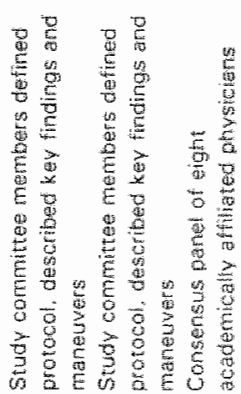

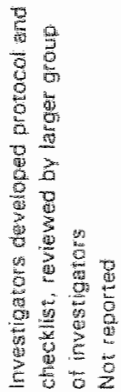

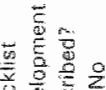

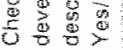

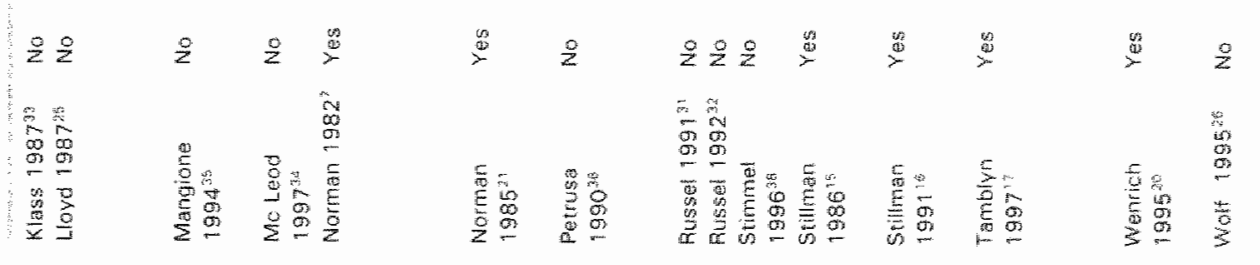


None of the studies reported that researchers relied exclusively on data from the literature to compose their checklists. A total of 16 articles did not describe the development process, but three of these ${ }^{22.24}$ did indicate that literature sources were used to develop the checklist. Carney ${ }^{23,24}$ used the content of a continuing medical education program in addition to information obtained from the literature as a source for the checklists.

\section{Use of explicit criteria for checklist development}

With one exception, ${ }^{25}$ all articles reported using explicit criteria for the inclusion of items on their checklists.

\section{Results and scoring systems}

All 29 articles reported in detail on the scoring or registration of the encounter between the standardized patient and physician, but the actual scoring or classification of results varied considerably. Most authors provided only an overview of the physicians' performances. They did not compare these performances to a standard, nor did they describe a scoring system. Fourteen studies ${ }^{18-20,22-24,26-33}$ reported the frequency of items or points obtained. Klass ${ }^{33}$ also reported results as percentages of items obtained from the maximum, and mentioned but did not elaborate on the application of a weighting system.

Most studies that assigned different weights to different aspects of the SP-physician encounter did so in one of three ways. First, some studies identified critical items, for example items deemed important to establish a diagnosis, and weighted them more highly. 12-15,18.21 Second, some studies used the classification of items in four categories lessential, important, indicated, or non-contributory) with corresponding numerical weights 13,2 , 1 and 0$)^{7.11,15 \cdot 17.34}$ Third, some studies distributed different scores to partially correct and completely correct answers..$^{25.35 .37}$ Two studies used their own methods to develop scores. Norman ${ }^{21}$ used the performances in a criterion group as a reference standard. Stillman ${ }^{15}$ performed a study of 336 internal medicine residents. For its scoring, the percentage of checklist items completed was calculated and an overall score was created by averaging scores from different cases while correcting for differences between cases. ${ }^{15}$ 


\section{Use of standardized patients to score the checklist}

In 21 of the 29 articles, the SPS scored the checklists. ${ }^{12,15-20,22-24,26-38}$ In the remaining eight articles, either observers scored the checklists or the authors did not provide sufficient information to determine who did the scoring.

\section{Publication of checklists}

Checklists were published or made available by the authors in only four articles. ${ }^{11,16,35,37}$

\section{Discussion}

In our review of the literature concerning the development of checklists in studies where SPS were used to assess physicians, we found 29 articles that met our selection criteria. Some articles appeared to report different aspects of the same study, but because we could not ascertain whether this was actually the case, we included all articles as separate studies. Based on our review of the literature, we found that only a limited number of articles, 12 of the $29(41 \%)$, reported the process of checklist development. Reports that did describe checklist development differed depending on the aims of the assessment. SP encounters can be used as an educational or needs assessment tool, or as a summative way to assess the performances of interns, residents, fellows, or specialists. When SP encounters are used as a summative instrument, with possible implications regarding accreditation for participating physicians our opinion is that, stricter rules should be applied to the development of the checklist than would be required if the instrument were to be used for formative assessment or needs assessment. The validity of case-specific checklists used for both educational and summative goals has been demonstrated in undergraduate medicine. With the use of SPS in the formal assessment of physiciansi performances, it is preferable to use evidence-based performance standards. However, since only a few evidence-based performance criteria are currently available, these performance criteria have to be defined in other ways, such as with consensus procedures. In the literature we reviewed, one study used a modified Delphi process to reach consensus $^{8}$ and three articles ${ }^{11.13 .14}$ reported a procedure that comes close to a nominal group procedure. ${ }^{39,40}$ Some reports indicated that case-specific checklists were developed by a team of experts, but the exact procedure was not reported. Our study suggests that too few researchers are describing the method they have used to reach consensus, even when a 
rather pragmatic approach is used, and as a result readers are unable to draw conclusions about the validity of the checklists.

Further, our review of the literature found that, while some studies based the content of their checklists on literature data, in most cases it was not clear what literature source was used. When checklists are based on data from the literature, it is preferable to use evidence-based data. However, these data are scarce, which, again, suggests that procedures are needed to reach consensus on the cases. These procedures must be explained to enable the reader to estimate the value of the assessment and its results. Unfortunately, few authors described this development process and too many of them did not mention it at all.

Scoring systems were described in the literature we reviewed. When the purpose of the assessment is to evaluate physicians' performances, reporting the "percentage found" may be a sufficient scoring system. In SP encounters with other purposes, however, some aspects of the encounter between physician and SP are more important than others and the checklist should take into account these differences in significance. We found several different scoring methods that weighted for significance through the classification of items, the identification of critical items, and the distribution of points for partially and completely correct answers. In general, these weights were assigned by means of the consensus. procedure.

Our review of the literature indicates that, although many people have struggled with the development of these lists, the use and development of case-specific checklists for SP encounters has so far received little attention in the published literature. We found only 29 papers on SPs in postgraduate internal medicine settings and only $40 \%$ of them described the development of the checklists in any way and with widely varying detail. To judge the validity of studies with SPs, we belleve that it is essential that the development process of these lists be described in the literature for both postgraduate and undergraduate settings. The publication of checklists should be encouraged. We hope that this review will stimulate careful consideration of the validity aspects of checklists as well as encourage researchers to describe the applied procedures in their papers on this topic. Such descriptions will help us further in developing reliable and valid instruments to measure physicians" clinical performance. 


\section{References}

1. Rethans JJ, Westin S. Hays RH. Methods for Quality Assessment in General Practice. Fam Pract 1996:13:468-76.

2. Barrows HS. Simulated patients in medical teaching. Can Med Assoc J 1968:98:674-6.

3. Barrows HS. An overwiew of the uses of standardized patients for teaching and evaluating clinical skills. Acad Med 1993;68:443-51.

4. Hoppe RB, Farquhar LJ, Henry R. Stoffelmayr B. Residents" attitudes towards and skills in counseling: using undetected standardized patients. J Gen Intern Med 1990;5:415-20.

5. Rethans $J\rfloor$, Saebu $L$. Do general practitioners act consistently in real practice when the meet the same patient twice? Examination of intradoctor variation using standardised (simulated) patients. BMI 1997;314:1170-3.

6. Van der Vleuten C. Swanson D. Assessment of clinical skills with standardized patients: state of the art. Teach Learn Med 1990:2:58-76.

7. Norman GR. Tugwell P. Feightner JW. A comparison of resident performance on real and simulated patients. J Med Educ 1982;57:708-15.

8. Stillman PL, Brown DR, Redfield DL, Sabers DL. Construct validation of the Arizona Chinical Interviewing Rating Scale. Educ Psychol Meas 1977;37:1031-8.

9. Tamblyn RM, Klass D., Schnabl GK, Kopelow ML. The accuracy of standardized patient presentation. Med Educ 1991:25:100-9.

10. VU NV: Marcy MM, Colliver JA, Verhulst SJ, Travis TA, Barrows HS. Standardized (simulated) patients' accuracy in recording clinical performance check-list ittems. Med Educ 1992;26:99-104.

11. Boudreau D, Tamblyn R, Dufresne L. Evaluation of consultative skills in respiratory medicine using a structured medical consultation. Am J Respir Cirit Care Med 1994:150:1298-304.

12. Calhoun JG, Waolliscroft JO, Ten Haken JD. Internal Medicine House Officers' Performance as Assessed by Experts and Standardized Patients. J Med Educ $1987 ; 62: 754-60$.

13. Gordon Jl, Saunders NA, Sanson-Fisher RW. Evaluating "interns' performance using simulated patients in a casualty department. Med J Aust 1989;151:18-21.

14. Gordon $\sqrt{ }$ J. Saunders NA, Hennrikus D, Sanson- Fisher RW. Interns peirformances with simulated patients at the beginning and the end of the intern year. J Gen intern Med $1992 ; 7: 57-62$.

15. Stillman PL, Swanson DB, Smee $S$, et al. Assessing clinical skills of residents with standardized patients. Ann Intern Med 1986;105:762-71.

16. Stillman $P$, Swanson D. Regan MB, et al. Assessment of clinical skills of residents utilizing standardized patients. A follow-up study and recommendations for application. Ann intern Med 1991:114:393-401.

17. Tamblyn R. Berkson L, Dauphinee WD, et al. Unnecessary prescribing of NSAIDs and the management of NSAID-related gastropathy in medical practice. Ann Intern Med $1997: 127: 429-38$.

18. Woolliscroft JO, Calhoun JG, Billiu GA, Stross JK, MacDonald M, Templeton B. House officer interviewing techniques: impack on data elicitation and patient perceptions. J Gen Intern Med 1989:4:108-14.

19. Day RP, Hewson MG, Kindy P, Jr, Van Kirk d. Evaluation of resident performance in an outpatient internal medicine clinic using standardized patients. I Gen Intern Med $1993: 8: 193-8$.

20. Wenrich MD, Paauw DS, Carline JD, Curtis JR, Ransey PG. Do primary care physicians screen patients about alcohol intake using the CAGE quastions? J Gen intern Med $1995: 10: 63 \cdot 1-4$ 
21. Norman GR, Tugwell P. Feightner JW, Muzzin LJ, Jacoby LL. Knowledge and clinical problem-solving. Med Educ 1985;19:344-56.

22. Bowman MA, Russell NK. Boekeloo BO, Rafi IZ. Rabin DL. The effect of educational preparation on physician performance with a sexually transmitted disease-simulated patient. Arch Intern Med 1992;152:1823-8.

23. Carney PA, Dietrich AJ, Freeman DH, Jr., Mott LA. The periodic thealth examination provided to asymptomatic older women: an assessment using standardized patients. Ann Intern Med 1993; 19:129-35.

24. Carney PA, Dietrich Ad, Freeman DH, Jr., Mott LA. A standardized-patient assessment of a continuing medical education program to improve physicians' cancer-control clinical skills. Acad Med 1995; 70:52-8.

25. Lloyd JS, Sener SF, Duncan ED, Bundra SJ and Niedenthal AE. Examining in the clinical competence of residents in two specialties. In Hart UR, Harden RM (eds). Further developments in assessing clinical competence. Quebec, Canada, Can-Heal Publications 1987:609-21.

26. Wolf FM, Sisson JC, Zweifler AJ. A standardized patient program to evaluate summarization skills in patient interviews. Acad Med 1995:70:443.

27. Curtis JR, Paauw DS, Wenrich MD, Carline JD, Ramsey PG. Internal medicine residents: skills at identification of HIV-risk behavior and HIV-related disease. Acad Med 199.4; 69:\$45-7.

28. Curtis JR, Paaum DS, Wenrich MD, Carline JD, Ramsey PG. Ability of primary care physicians to diagnose and manage Pneumocystis carinii pneumonia. J Gen Intern Med 1995; 10:395-9.

29. Curtis JR. Paauw DS, Wenrich MD, Carline JD, Ramsey PG. Physicians" ability to provide initial primary care to an HIV-infected patient. Arch Intern Med 1995;155:1613-8.

30. Gonzalez Willis A, Rafi I. Boekeloo B, et al. Using simulated patients to train physicians in sexual risk assessment and risk reduction. Acad Med 1990;65:S7-8

31. Russell NK, Baekeloo BO, Rafi 1Z, Rabin DL. Using unannounced simulated patients to evaluate sexual risk assessment and risk reduction skills of practicing physicians. Acad Med 1991:66:\$37-9.

32. Russell NK, Boekeloo BO, Rafi IZ, Riabin DL. Unannounced simullated patients" observations of physician STD/HIV prevention practices. Am ل Prev Med 1992;8:235-40.

33. Klass D CC. Hassard T, Kopelow $M$ and Schnabl $G$. Influence of level of training on performance in a standardized test of clinical abilities. In: Bender W. Hiemstra $R J$ Scherpbier AJJAA. Zwierstra RP leds). Teaching and assessing clinical competence. Groningen Boekwerk Publications 1990:327-32.

34. McLeod PJ, Tamblyn RM, Gayton D, et al. Use of standardized patients to assess between-physician variations in resource utilization. JAMA 1997:278:1164-8.

35. Mangione S, Peitziman SJ, Gracely E. Nieman LZ. Creation and assessment of a structured review course in physical diagnosis for medical residents. J Gen Intern Med 1994;9:
213-8.

36. Petrusa ER, Blackweil TA, Ainsworth MA. Reliability and vallidity of an objective structured clinical examination for assessing the clinical performance of residents. Arch
Intern Med $1990 ; 150: 573-7$.

37. Blackwell TA, Petrusa ER, Saydjari CL. Performance in general internal medicine: comparative study using a objectively scored evaluation system. In: Hart UR, Harden RM Watton HJ (eds). Newer developments in assessing clinical competence. Quebec, Canada Can-Heal Publications 1986:229-37.

38. Stimmel B, Colliver JA, Cohen DS, Smith L, Swartz MH. Using standardized patients for teaching and assessing clinical skills for encounters with patients with problems of substance abuse, pain control, and AIDS. In: Scherpbier AJJIA, van der Vleuten CPM. Rethans JJ, van der Steeg AFM (eds). Advances in medical education. Kluwer academic
Publishers 1998:722-4. 
39. Jones J. Hunter D. Consensus methods for medical and health services research. BMJ $1995 ; 311: 376-80$.

40. Fink $A_{a}$ Kosecoff J, Chassin M. Brook RH. Consensus methods: characteristics and guidelines for use. Am J Public Health 1984;74:979;83. 


\section{Chanderis}

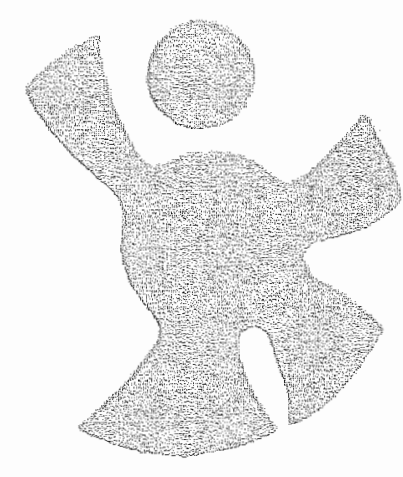

How to introduce incognito standardized patients into outpatient clinics of specialists in rheumatology

Simone Gorter, Jan-Joost Rethans, Albert Scherpbier, Sjef van der Linden, Marijke van Santen-Hoeufft, Désirée van der Heijde, Harry Houben, Cees van der Vleuten

Medical Teacher 2001;23:138-44. 


\section{Abstract}

To know what is going on in physicians' surgery hours, assessment of practice performance is important with regard to quality assessment activities. The incognito standardized patient (SP) method is a powerful method to assess this. However, until now no reports have been published about specialists' performance using this method. In this study, 27 rheumatologists in 16 hospitals were each visited by eight incognito SPs to study the feasibility of sending incognito SPs to specialists working in different hospitals, of follow-up consultations and of simulating additional investigations. SPs recorded performance on case-specific checklists. The different steps needed for these visits are described in detail. A total of 136 first and 32 follow-up visits took place. SPs remained undetected in $98 \%$ of the visits. It is concluded that this SP method is a feasible one, however, only to be used for very specific purposes. Use of incognito SPS for larger scale projects is not recommended.

$m$

$\frac{1}{0}$ 


\section{Introduction}

Over the last decade incognito visits by standardized patients have been used in several studies to assess physicians" clinical performance. Standardized patients are non-physicians taught to portray patients in a standardized and consistent fashion. "SPS can be asymptomatic, can thave stable abnormal findings on physical examination theart murmurs. pulmonary crackles, joint abnormalities, etc.h, of can simulate plhysical findings labnormal reflexes, diminished breath sounds, elevated blood pressure." After giving consent, physicians can expect one or more incognito office visits by SPS assessing different aspects of medical performance, usually by completing a checklist. Since the physicians do not know which patients are the mock patients, their clinical performance will be entirely authentic. There is clear consensus that this is a very powerful method for assessing actual clinical performance. ${ }^{23}$ However, the method has also been criticized for being umethical (an argument refuted nowadays since participants give written consent) and for involving massive logistic problems. The validity, reliability and feasibillity of performance assessment by SPS have been confurmed in several studies. ${ }^{2.4-8}$ Other studies have reported on the procedure of incognito SP visits in primary care settings..$^{9.15}$ To our knowledge, however, no studies have been published on the use of SPs in secondary care. Introducing SPs into the hospital setting requires arrangements that are quite different from those in primary care settings. Indeed, the implementation of incognito visits by SPS to outpatient clinics in hospitals requires arduous work. Since patients in the Netherlands can only see a specialist after referral by a general practitioner (GP), we needed GP's cooperation in writing referral letters. As part of a study evaluating theumatologists" clinical performance, we have studied the feasibility of 1) sending incognito patients to specialists working in different hospitals, 2$)$ follow-up appointments and 3) simulating ordered laboratory and radiology investigations. For the study a total of 216 first visits to 27 rheumatologists in 16 different Dutch hospitals have been scheduled. This paper reports in detail on the experiences with preparations for and implementation of the SP visits during the first year of the study. Conclusions concerning the feasibility (consent, detection of SPs) of this method of collecting data are presented.

\section{Method}

Twenty-seven rheumatologists in sixteen hospitals were each visited by eight incognito SPs. At the end of the consultation, the SP recorded the 
rheumatologist's performance on checklists regarding medical history. physical examination, diagnostic investigations, and treatment plan and communication skills.

The preparations for and the implementation of the SP visits will be described by various categories and subcategories. We have distinguished six categories of preparations for the SP visits: preliminary preparations, general preparations, case-specific preparations, visit-specific preparations, preparations for the second visit and arrangements after the visits. If applicable, we have subdivided the six categories into preparations concerning the SPS, preparations within the hospital le.g., laboratory investigations) and preparations outside the hospital (e.g., referring general practitioners) (Table 3.1). Activities that fall under more than one category are presented under different headings.

\section{Preliminary preparations}

\section{Standardized patients}

Simulated cases had to meet at least one of the following criteria: 1) carrying challenging diagnostic features, 2) highly prevalent in outpatient clinical practice and 3 ) relevant to discussions on quality of care. Cases were derived from real patients presenting in outpatient rheumatology clinics. Initially, we developed more than eight cases, to enable selection of the most realistic and feasible cases best suited to the recruited SPS. The eight cases finally selected were: ankylosing spondylitis, fibromyalgia, hemochromatosis arthropathy, lateral epicondylitis, osteoporatic vertebral fracture, polymyalgia rheumatica, psoriatic arthritis and rheumatoid arthritis with possible cervical cord compression.

To record the content of the encounter with the rheumatologist, SPS completed checklists comprising aspects of medical history, physical examination and management plan immediately after each visit. Part of a checklist is shown in Table 3.2. A consensus procedure was used to develop a checklist for each case in a structured way. ${ }^{16}$ First, one of the researchers (S.G.) composed a list of items for each case, covering all the relevant aspects of the consultation. Eleven rheumatologists evaluated the list indicating whether they thought any items were missing and whether items were relevant, optional or superfluous.

\section{Within the hospital}

In January 1997, all rheumatologists in the Netherlands except those involved in the project $(n=116)$ were informed on the objectives of the 
study and asked to participate. Participants gave written consent. They were informed that SPS would visit their outpatient clinic at some time during the next three years and that they would be kept blind to the identity of the SP, to the time of the visit and to the exact number of visits. It was agreed that the participating rheumatologists would receive individual anonymous feedback at the end of the study period. Consent was obtained from 57 rheumatologists $(49 \%)$, working in 23 different hospitals. They received an "SP Detection card" which they were asked to send to the investigators if they suspected a patient of being a SP. The participating rheumatologists also signed an undertaking that they would not receive payments for the SP consultations. The researchers visited the Boards of Directors of the selected hospitals to discuss what participation in the project would entail for the hospital.

\section{General preparations}

\section{Standardized patients}

Real patients with rheumatic disorders as well as healthy persons were recruited as SPs. The real patients were selected by three rheumatologists participating in the checklist development. The healthy persons were trained SPs used in medical undergraduate training in four Dutch medical schools. It was decided that each rheumatologist would be presented with eight cases, because this has been found to be a sufficiently reliable sample to assess an individual physician's performance. ${ }^{17}$ SPs had to meet the following criteria: stable health, ability to play the role and to fill out the checklist, no confounding physical symptoms (such as tophi when gout is not to be presented/ and sufficient time available for the visits. Since many people from the region of Maastricht University have a regional accent that makes them easily identifiable as coming from this region and the participating rheumatologists knew that the study was initiated in Maastricht, we recruited SPs who did not have this accent. As each of the eight cases was to be portrayed by two SPS, 16 SPs 110 healthy persons and six real patients) were selected for training. One SP was replaced during the process of training due to previously unknown confounding symptoms, another SP had to be replaced because of chronic backpain that prevented her from playing the role authentically and one SP had to be replaced after seven visits, because of a hip fracture (at home). A sixmonthly newsletter was sent to all SPS to keep them up to date on the progress of the study and to share mutual tips and tricks for the incognito visits. 


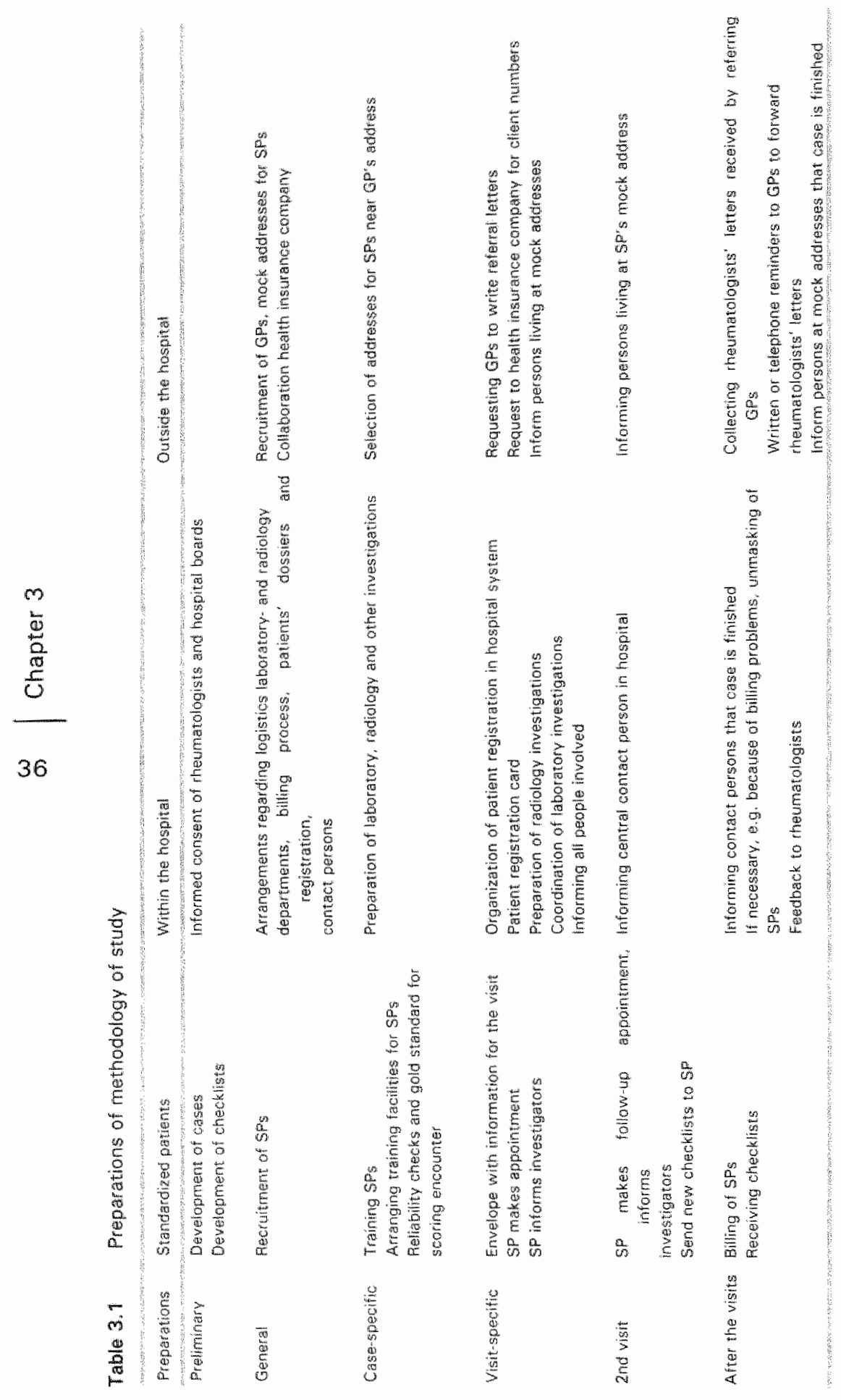


Table 3.2 Part of the checklist for case on osteoporotic vertebral fracture

Three of 26 items on the medical history

During the consultation attention was patd to:

$\begin{array}{lccc}\text { The localization of complaints } & \text { Yes know } & \text { No } & \text { Don't } \\ \text { Radiation of pain } & \text { Yes know } & \text { No } & \text { Don't } \\ \text { Onset of the complaints } & \text { Yes know } & \text { No } & \text { Don't }\end{array}$

Three of 15 items on the physical examination

During the physical examination:

The physician palpated the wertebrae

The physician measured my height

The physician asked me to extend my arms and compared the length of both arms with my height

$\begin{array}{lll}\text { Yes know } & \text { Don't } \\ \text { Yes know } & \text { No } & \text { Don't } \\ \text { Yes know } & \text { Don't }\end{array}$

Three of 25 items on management

During the consultation the physician:

Told me his or her findings

Proposed treatment with bisphosphonates

Gave written information

if Y'es: which brochure was given?

$\begin{array}{lll}\text { Yes know } & \text { No } & \text { Don't } \\ \text { Yes know } & \text { No } & \text { Don't } \\ \text { Yes know } & \text { No } & \text { Don't }\end{array}$

\section{Within the hospital}

After the Boards of Directors of the hospitals had given informed consent, separate meetings were organized with representatives from the department of radiology, the department of pathology, the laboratory, and the medical and financial administration offices, respectively. The purpose and procedures of the study were explained and arrangements were made to simulate the results of these investigations, such as coordination of laboratory, radiologic and other investigations and the interruption of the billing process. Since the SPs were not to undergo any real investigations, such as venepunctures or $X$-rays, arrangements were made to simulate the results of these investigations. For instance, if the rheumatologist ordered laboratory investigations, the SP would hand over the application form to the contact person in the laboratory immediately after the encounter with the rheumatologist. The simulated results of the tests ordered (as prepared by the investigators) were then entered into the local hospital computer. If radiographs were ordered, copies of radiographs of a similar case and reports of the results were sent to the hospital. Arrangements were made 
to give the copies of the radiographs as similar in appearance as possible to radiographs taken in the hospital concerned and to present the results in the customary way for that hospital.

\section{Outside the hospital}

For each hospital GPs who generally referred their patients to the hospital's rheumatology outpatient clinic were confidentially approached to act as the $\mathrm{SP}^{\prime}$ s referring GP. Informed consent was obtained from the GPS who agreed to participate and the GPS were contacted when their participation was actually required. Researchers' friends, relatives, and colleagues living in the area of the participating hospitals, were asked for permission to use their addresses and telephone numbers as the SPs' addresses and telephone numbers. Arrangements were made with a national health insurance company to provide insurance numbers for the SPS.

\section{Case-specific preparations}

\section{Standardized patients}

Two SPS were trained together to present the same role. For practical reasons, two SPS were trained every two months, in two 6-hour training sessions in two days. During the training sessions final adjustments to the cases were made, in order to make the presentations as realistic as possible and to minimize the risk of detection. Depending on the availability of rheumatologists to attend the training session, two to four pillot consultations took place, which were videotaped. The rheumatologists assessed the SP's portrayal on face validity and accuracy. At the end of the encounter the SP playing the role completed checklists as did the other $\mathrm{SP}$. who had been observing, and the trainer. Any differences in scoring between SP and trainer were compared and discussed. Feedback and additional training was given until $85 \%$ agreement between SP and trainer was reached. Only then was the SP allowed to start the actual visits. To estimate reliability of the SP'S scoring, the tapes were also viewed by three observers. First, the observers completed the checklist, then their individual scores were compared and items on which they disagreed were discussed until agreement was reached. The SPs received a copy of their taped consultations and were encouraged to watch these as an aid to improving their role play. Intra-rater reliability was evaluated when an SP had completed half of the visits to the rheumatologists. The SP viewed one of the videotaped pillot consultations and completed the checklist afterwards. 


\section{Within the hospital}

The eleven rheumatologists participating in the development of the checklist were asked which additional investigations they would order for each case. For those investigations simulated results were prepared before the SPs visited the rheumatologist at the hospital. For the SPS with rheumatologic disorders, the patient's own available radiographs were used with printed dates adapted as needed. For the other SPs, real patient's radiographs from the outpatient clinic of Maastricht University hospital were used. Appropriate results for laboratory investigations were proposed by rheumatologists familiar with the original cases. For each hospital the values were adapted to the local reference values and distributed by the SP to the local contact person in the laboratory.

\section{Outside the hospital}

When a GP had been selected, an address for the SP in the GP's neighborhood was selected from the pool of available mock SP addresses.

\section{Visit-specific preparations}

\section{Standardized patients}

Before each visit, SPs received an envelope containing a map of the town to be visited with important locations clearly marked, such as the hospital and the SP's address in town, a floor plan of the hospital, and a form instructing them where to go in the hospital when any additional investigations were ordered. They were also provided with information about the referring GP, the checklists, a patient registration card, the GP's referral letter and the prepared laboratory test results. If anything should go wrong, the SP could hand over a "calamity letter" containing information about the project and names and telephone numbers of the researchers and the contact person at the hospital. Only after receiving all this information, did the SP telephone the hospital to make an appointment to see the rheumatologist. As soon as the appointment was made the research team was informed of the exact date and time of the appointment.

\section{Inside the hospital}

At least two weeks prior to the actual appointment, all hospital contact persons were informed of the upcoming event by telephone, letter, fax or e-mail. To check whether all contact persons were indeed available at the 
day of appointment, they were again informed by the research team one day before the sheduled SP visit. Demographic data and addresses of SPS were entered into the local hospital computer system and registration cards were produced in the usual manner.

If rheumatologists ordered radiological investigations for the same day. SPS were instructed to pretend they had to go home urgently and that they were unable to undergo the investigation that day. Subsequently, the radiographs ordered were copied using the radiology identification cards of the hospital concerned, and the copies together with the "results" were mailed to the contact person in the radiology department. In every hospital a radiology file was made for every SP. Results were processed in such a way that theumatologists received the radiographs and the corresponding results in the usual manner. Also reports of the radiographs were signed by a local (informed) radiologist.

The SPs informed the contact persons in the hospital's laboratory of the ordered laboratory investigations. The results were entered into the hospital's computer system to make sure that the rheumatologist would receive the laboratory results in the usual way. If the rheumatologist ordered any unforeseen tests (i.e. for which test results had not been prepared in advance by the investigators), the local contact person immediately called the researchers who could then prepare the required mock test results.

\section{Outside the hospital}

GPs were asked to write a referral letter in their own personal style and send it to the investigators. They were informed about the letter's key content, about the $\mathrm{SP}^{\prime}$ s simulated rheumatic disorder and personal and social characteristics, and about the reason for the referral to the rheumatologist. The health insurance company generated insurance numbers for each SP-rheumatologist encounter as soon as the SP's address was known.

The persons whose addresses were used as SP addresses were informed of the SP's name, gender and date of appointment and were asked to notify the researchers when they received any messages intended for the SP (such as change in the appointment or a bill). 
Preparations for the second visit

\section{Standardized patients}

Follow-up appointments were always included in some roles and always canceled in other roles. In a few roles follow-up appointments took place depending on the content of the first visit, with the SP calling the researchers after the visit to discuss whether a follow-up appointment was necessary. Reasons for canceling were the type and amount of information already obtained during the first visit and the probability of detection at follow-up. If a follow up visit was considered necessary by the researchers, the content of the first visit was rehearsed a few days before the follow-up appointment. The SP also received a new checklist and was instructed to complete only the part of the checklist about management, i.e. excluding details of the medical history and physical examination already recorded on the first visit.

\section{Within the hospital}

Contact persons in the administration offices were informed of the followup appointments, in case bills for these appointments had to be intercepted.

\section{Outside the hospital}

People, whose addresses were used as addresses for SPS, were informed of follow-up appointments. Any bills or letters received for the SPs were sent to the investigators.

\section{Arrangements after the visits}

\section{Standardized patients}

SPs completed the checklists after the encounter, usually in the train on their way home. The completed checklists together with any prescriptions, dates of follow-up appointments and other comments by the SPs were sent to the research team. 


\section{Inside the hospital}

When all the visits were completed and patient letters of the rheumatologists to the GP were received, the contact persons at the hospitals were informed. They could then erase the simulated data from the computer system. Only when all the SP visits were completed would the rheumatologists receive individual feedback about their performance compared with that of the anonymous group of rheumatologists, in order to prevent unmasking of SPs before the end of the project. In some hospitals bills from rheumatologists' fees could not be intercepted and were received at the $S P^{\prime} s$ mock addresses. To prevent any inconvenience to the volunteers living at these addresses, the SPS were either ummasked, or arrangements were made with the rheumatologists ${ }^{*}$ administration offices.

\section{Outside the hospital}

After the visits, patient letters from the rheumatologist to the referring GP were collected. GPs regularly received a newsletter and also the dates of the SPS' appointments to remind them to send the rheumatologist's letter to the investigators.

\section{Results}

Out of 57 consenting rheumatologists, 30 rheumatologists in 18 hospitals were selected for SP-visits in order to restrict the logistic problems of the project (convenience sampling). Next, the Boards of Directors of the hospitals of the participating rheumatologists were approached. One (university) hospital board refused to cooperate, because of the presumed heavy burden to their organization; one hospital did not respond and the remaining 16 hospitals, including two university hospitals, gave informed consent. Finally, 27 rheumatologists were available for incoginito SP visits. During the first vear of the study one rheumatologist dropped out, because of a four-month waiting list for new patients and because the rheumatologist canceled two appointments made by the SP.

In January 1997 written informed consent was obtained from the participating theumatologists and the incognito visits started in June 1998. In the first year of the study 168 encounters took place, i.e. 136 first visits (63\% of the planned first visits) and 32 follow-up appointments. In the first three months of 1997 , before the visits had even started, three detection forms were received from rheumatologists reporting suspected SPS. In June " 99 all 16 SPS (8 roles) had been trained, three roles were finished, eight SPs playing four roles were still visiting the rheumatologists, and the two 
SPs from the last role had just made their first appointments. One SP was unmasked more than 3 months after the encounter had taken place due to an unpaid bill of the rheumatologist. This was caused by miscommunication between the billing office and the hospital financial administration office. Two SPs were unmasked after their first visit, because the rheumatologists discovered that the radiographs deviated from the usual house style of that hospital. One SP presenting the polymyalgia rheumatica case unmasked himself at the end of the encounter, because the rheumatologist insisted on injecting corticosteroids into both shoulder joints during the visit.

Of the 208 GPs, asked to refer SPs, $91(44 \%)$ consented and wrote referral letters for one or two cases each. Agreement between scoring by the SPS and the gold standard obtained from a panel scoring videotaped pilat visits varied between $85 \%$ and $97 \%$ (kappa: $0.71-0.93$ ). The SPS reported no major problems in completing the checklists. The space provided for individual comments was frequently used to criticize communication skills, attitude, and organizational aspects relating to the outpatient office. The expectations regarding ordered laboratory and radiology tests turned out to be correct most of the time. Only in four visits did the rheumatologist order unexpected radiographs.

Each SP visited 13 rheumatologists in 13 different hospitals. Time spent for one consultation including traveling time, varied among between 1 hour 15 minutes and 12 hours 30 minutes, with a mean of 6 hours 55 minutes. SPS were paid 11.30 Euro $(\$ 12.50)$ per hour, including traveling time. The time interval between the call to make an appointment and the visit varied between 1 and 22 weeks, with a mean of 7 weeks.

In order to check the content of the referral letters, the referring GPs were asked to send their letters to the researchers. Copies were made and the original letters were sent to the SPs, who carried these with them to the appointment. Some GPs wrote these letters immediately, others after a few weeks and some forgot to do so. A reminder was sent to this last group and in some cases several calls had to be made before the GP mailed the letter. During the study period only few calamities occurred. One SP playing the polymyalgia rheumatica role was sent to the surgeon for a temporal artery biopsy, one SP was replaced due to a fractured hip and one SP had to use the calamity letter to prevent radiographs from actually being taken.

\section{Discussion}

Our experiences have demonstrated that using incognito SPs in the assessment of rheumatologists" clinical performance in the secondary care setting is possible. Cooperation of people working in laboratories, radiology departments and administration offices was indispensable and of great 
value. Real patients as well as healthy persons were taught to portray patients with rheumatic diseases and they remained undetected in $98 \%$ of the visits. It proved possible to simulate results of additional investigations, such as radiographs and laboratory tests. However, the logistics of this study were demanding. Substantial efforts were needed to coordinate the incognito visits and to simulate the results of requested additional investigations. With regard to detection of SPS, simulating the radiographs proved particularly problematic and resulted in two of the four unmasked SPs. Copies of radiographs were used, so that all rheumatologists received the same radiograph for the SP. The use of copies meant that the simulated radiographs were potentially detectable by the rheumatologist. Also different hospitals use different formats for the same radiograph, and we were seldom able to make copies on other formats than the original one. With increasing use of digitized radiographs in the future, these problems may be resolved.

One might ask whether our results are worth all the efforts and whether there are not easier, less burdensome methods by which the same results could be obtained. There are, indeed, other methods for assessing physicians' performance. Indirect measures, such as medical chart review. patient satisfaction surveys or morbidity rates, can be very useful in assessing certain aspects of performance. However, they do not provide information about what actually happens in clinical practice, and this was what we were after. Direct measures such as video-taping and observation of office visits by peers, ${ }^{10}$ have the disadvantage of not being unobtrusive. and thus possibly interfering with the physician's authentic behavior. Because of the demanding efforts in performing our study, we think that the incognito SP-method should be applied only in studies aimed at obtaining very specific detailed information on physicians' authentic clinical performance, for example for individual feedback purposes. When this appropriate and practical feedback is provided to the individual rheumatologist, targeted tailored training can be offered if necessary. This is particularly important, since there is evidence that changing physician performance is most effective when data on real practice behavior are used. Therefore we think that the results of our study can effectively contribute to efforts in changing behavior. ${ }^{19}$ In addition to this, our study provides data that are eminently suitable for discussions among small groups of professionals by illustrating the gap between clinicall practice and existing guidelines. ${ }^{20}$

In summary, introducing incognito SPs into the hospital setting with followup appointments has been possible, with almost all SPs remaining incognito for the duration of the study period. However, the demanding efforts needed to obtain the detailed information about specialists performance in secondary care do not make this method feasible for more general use. We 
think this method could be used as a kind of "service on demand" when physicians ask for medical audit. The information obtained could then be used to organize targeted continuing medical education activities. 


\section{References}

1. Earrows H.S. An overview of the uses of standardized patients for teaching and evaluating clinical skills. AAMC. Acad Med 1993;68:443*51.

2. Van der Veuten C. B Swanson D. Assessment of clinical skills with standardized patients: state of the art. Teach Learn Med 1990;2:58 76 .

3. Vu B. Use of standardized patients in clinical assessments: Recent dievelopments and measurement findings. Educ Research 1994:23:23-30.

4. Tamblyn RM, Klass DJ, Schnabl GK et al. The accuracy of standardized patient presentation. Med Educ 1991;25:100-9.

5. Vu NV. Marcy MM, Colliver JA, et al. Standardized (simulated) patients'accuracy in recording clinical performance check-list items. Med Educ 1992;26:99-104.

6. Vu NV, Steward DE, Marcy M. An assessment of the concsistency and accuracy of standardized patients' simulations. J Med Educ 1987:62:1000-2.

7. Stillman PL, Swanson DB, Smee $S$, et al. Assessing clirnical skills of residents with stamdardized patients. Ann Intern Med 1986; 105:762-71.

8. Petrusa ER, Blackwell TA, Rogers LP, et al. An objective measure of clinical performance. Am J Med 1987:83:34-42.

9. Dolan NC. Using unidentified standardized patients to evaluate housestaff delivery of preventive services. Teach Learn Med 1997;9:60-5.

10. Pussel NK, Boekeloo BO, Rafi $1 Z$, et al. Using unannounced simulated patients to evaluate sexual risk assessment and risk reduction skills of practicing physicians. Acad Med $1991 ; 66: 537-9$

11. Rethans J-J. Drop $R$, Sturmans $F$, et al. A method for introducing standardized (simulated) patients into general practice consultations. Br J Gen Pract 1991;41:94-6.

12. Woodward CA, McCOnvey GA, Neufeld $V$, et al. Measurement of physician performance by standardized patients. Refining techniques for undetected entry in physicians' offices. Med Care 1985;23:1019-27.

13. OHagan JJ, Botting $\mathrm{CH}$, Davies LJ. The use of a simulated patient to assess clinical practice in the management of a high risk asthmatic. $N Z$ Med J 1989;102:252-4.

14. Hutchinson B, Woodward CA. Norman GR, et al. Provision of preventive care to unannounced standardized patients. Can Med Assoc J 1998;158:185-93.

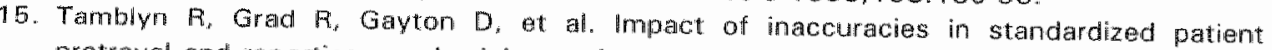
protrayal and reporting on physician performance duping blinded clinic visits. Teach Learn Med 1997:9:25-38.

16. Gorter S, Rethans J-J, Scherpbier A, et al. Developing case-specific checklists for standardized patient based assessments in internal medicine: a review of the literature. Aced Med 2000; 75:77-84.

17. Ramsey PG. Curtis JF. Paauw DS, et al. History-taking and prewentive medicine skills among primary care physicians: An assessment using standardized patients. Am J Med $1998 ; 104: 152-8$.

18. RamP, van der Vleuten $C$. Rethans $J-J$, er al. Assessment of practicing family physicians: comparison of observation in a multiple station examination using standardized patients with observation of consultations in daily practice. Acad Med 1999;74:62-9.

19. Davis DA, Thomson MA, Oxman AD, et al. Changing physician performance. A systematic review of the effect of continuing medical education strategies. J Am Med
Assoc $1997 ; 274: 700-5$.

20. Neufeld VR. An introduction to measurement properties, in: Neufell V.R. \& Norman G.R. (Eds) Assessing Clinical Competence, 1985:39-50 (New York: Springer Publishing 


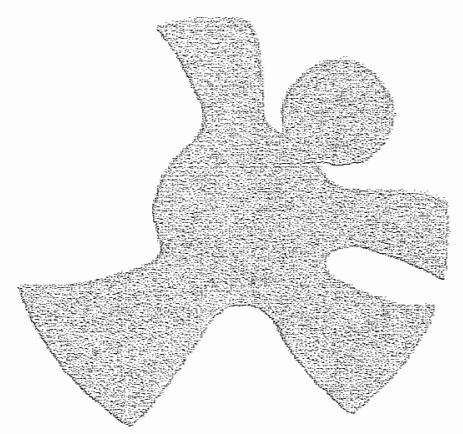

\section{Rheumatologists' performance in daily practice}

Simone Gorter, Sjef van der Linden, Jolanda Brauer, Désirée van der Heijde, Harry Houben, Jan-Joost Rethans, Albert Scherpbier, Cees van der Vleuten, Annelies Boonen, Huib Dinant, Henk Goei Thè, Ed Griep, Irene van der HorstBruinsma, Annelies Linssen, Marijke van Santen-Hoeufft, Hille van der Tempel, Toon Westgeest

Arthritis Care and Research 2001;45:16-27. 


\section{Abstract}

Objective. To assess rheumatologists' performance for 8 rheumatological conditions and to explore possible explanatory factors.

Methods. After written informed consent was obtained, 27 rheumatologists $121 \%$ of all Dutch theumatologists) practicing in 16 outpatient departments were each visited by 8 incognito "standardized patients" (SPs). The diagnoses of these 8 cases account for about $23 \%$ of all new referred patients in the Netherlands. Results for ordered lab tests as well as real radiographs with corresponding results of a radiologist were simulated. Information from the visits was obtained from the SPS, who completed predefined case-specific checklists, and by collecting data on resource utilization Feedback was provided.

Results. Altogether 254 encounters took place, of which 201 were first visits and 53 were follow-up visits. SPs were unmasked twice during a visit. There was considerable variation in resource utilization llab tests and imaging between cases and between rheumatologists. Mean costs per rheumatologist ranged from US $\$ 4.67$ to $\$ 65.36$ per visit for lab tests and from $\$ 33.15$ to $\$ 226.84$ per visit for imaging tests. No significant correlations were seen between resource utilization costs and number of years of clinical experience or performance on checklist scores. Rheumatologists with longer experience had lower total item checklist scores $(r=-0.47 ; p<0.05)$.

Conclusion. A considerable variation in resource utilization was found among 27 Dutch theumatologists. The information obtained is an excellent source for discussions on the appropriateness of care. 


\section{Introduction}

One of the aims of clinical practice is to improve patient outcome. Practice variation in delivering care is a well-known phenomenon. Promoting good clinical practice means also reducing undesired variation. Obtaining insight into physicians' every day performance and linking such data to case mix and patient outcome will facilitate defining standards for good clinical practice and developing guidelines to improve the efficacy and efficiency of clinical care. 'Data on physician's real performance can be obtained in different ways. Direct methods such as video observation in practice, ${ }^{2}$ assess what is really going on, in contrast to indirect measures. ${ }^{3}$ However, when physicians know that they are being observed, they might increase their efforts. "Assessment of true practice behavior is possible by introducing incognito standardized patients into physicians" offices. ${ }^{5,6}$ Standardized patients (SPs) are real patients or healthy persons who are trained to play a particular role in a consistent and accurate way." They present identical cases to different physicians. Information obtained by SPs can also be used to provide feedback and as a needs assessment tool for targeted education. ${ }^{8}$ The purposes of this study were to assess rheumatologist's variation in daily practice performance on 8 different rheumatological conditions, to provide feedback on their performance and to explore a number of factors that might contribute to practice variation.

\section{Patients and Methods}

\section{Participants}

In January 1997, $116(91 \%)$ of all 127 Dutch rheumatologists not involved in the development of the study were asked to participate and to give written informed consent. Individual feedback on their own performance and on that of all anonymous participating peers was to be given after completion of the study. Fifty-seven rheumatologists $(49 \%)$ from all parts over the country agreed to participate. Based on logistic considerations we selected 27 rheumatologists working in 16 different hospitals (including two university hospitals) in the central and southern part of the country for the study. Table 4.1 shows some characteristics of the participants. One and a half year after informed consent was obtained, the visits actually started. We created this delay on purpose in order to lower the risk of the SP being detected. A detailed description of the procedures that we followed is published elsewhere. ${ }^{9}$ 
Table 4.1 Characteristics of participating rheumatologists

$\begin{array}{lcc}\text { Sex } & \text { malie } & \\ \text { female } & 22 \\ \text { Age* } & & 5 \\ \text { Years of working experience as a rheumatologist } & 46 \pm 6.4 \\ \text { Number of outpatients seen each week } & 12 \pm 5.7 \\ \text { Hospital setting teaching hospital } & 109 \pm 56 \\ \text { Mean } \pm S D & \text { non-teaching hospital } & 6 \\ \end{array}$

\section{Cases}

Eight cases were selected that, in the opinion of the research team, fulfilled at least 1 of the following 4 criteria: There was a high prevalence of the condition, the case presented challenging diagnostic features, the cases was suitable for a discussion of efficiency considerations, or the case presented important features for patient education. The feasibility of introducing these cases into clinical practice was also considered. We presumed that by using 8 cases, covering a broad spectrum of rheumatic conditions, it would be possible to get generalizable results. ${ }^{10}$ in addition, the cases had to be feasible for the SPs.

The 8 cases were based on real patient histories. Case-specific aims were identified by a group of 11 rheumatologists (who were not visited by SPs). Two of the 8 cases were represented by 4 real patients presenting their own signs and symptoms. The other SPs were healthy people simulating a rheumatic disorder. Table 4.2 shows the aims and features of the 8 rheumatic conditions presented by 16 SPs.

\section{Checklists and scores}

After each visit the SP had to complete a role-specific and predefined checklist to be used as indicators of the diagnostic and management process. These lists had been developed by the same panel of 11 rheumatologists who identified the case-specific aims. The number of items for these 8 cases varied between 50 and 75, with 3 subdivisions: medical history, physical examination and case management. Every checklist was developed to cover the whole consultation. An example is shown in Table 4.3. For each case, key items were also identified by the panel (items defined as key items by at least $75 \%$ of panel members). Scores were calculated. The total score is the percentage of the maximum possible score obtained, each item counting as 1 . The key score is the percentage of the maximum possible number of key-items obtained. Subsequently, the score for each visit was split into separate scores for medical history, 
physical examination and case management patient education, treatment plans).

\section{Training and reliability}

Between July 1998 and February 2000, 16 SPs were trained to present 8 different rheumatic diseases. For each disease, two SPs were trained together to play their role in a reliable way and to score the checklist consistently. During the training sessions close attention was paid to a realistic presentation. The SPS presentations were judged to have sufficient face validity by 4 rheumatologists who participated in the training sessions. Checklists to register physcians' performance when exposed to an SP were completed by SP and trainer after every consultation with a theumatologist from the panel. Any discrepancies in scoring were discussed. Toward completion of the training, a panel of 3 physicians scored a physician's performance according to a videotaped registration of the SP training session. Differences in checklist rating scores between the members of the panel were discussed and the taped consultation was reviewed whenever needed. Percentage of agreement between SP and the panel ranged from $85 \%$ to $97 \%$ (mean $91.4 \%$ ) with kappa values between 0.44 and 0.93 (mean 0.78 ) for all cases. All SPs again assessed the videotaped consultation after they had completed about $50 \%$ of the visits. Then they scored the checklists again and these scores were again compared with the panel scores (inter SP reliability). Agreement at this stage ranged from $88 \%$ to $96 \%$ (mean $90.6 \%$ ) with kappa values between 0.63 and 0.92 (mean 0.78 ).

\section{Practice visits}

All SPs were referred to the hospital by letter from a local general practitioner (GP). In the Netherlands, this is the usual way to see a specialist. For each case a referral letter was prepared by us. The GPS used this letter to write a referral letter in their own style and handwriting. Immediately after a visit, the SP completed the case-specific checklist." All ordered studies such as lab tests and reports of radiological exams as well as the radiographs themselves were simulated and then were transmitted to the rheumatologist in the usual way. A follow-up appointiment took place only if gainful information was expected to be obtained from that visit. This was the case if the physician wanted to see results from lab tests or radiological exams before he or she would propose further action or would discuss the diagnosis; for example with hemochromatosis. Written reports on the patients from the rheumatologists on the patients were forwarded to us by the referring GP. 


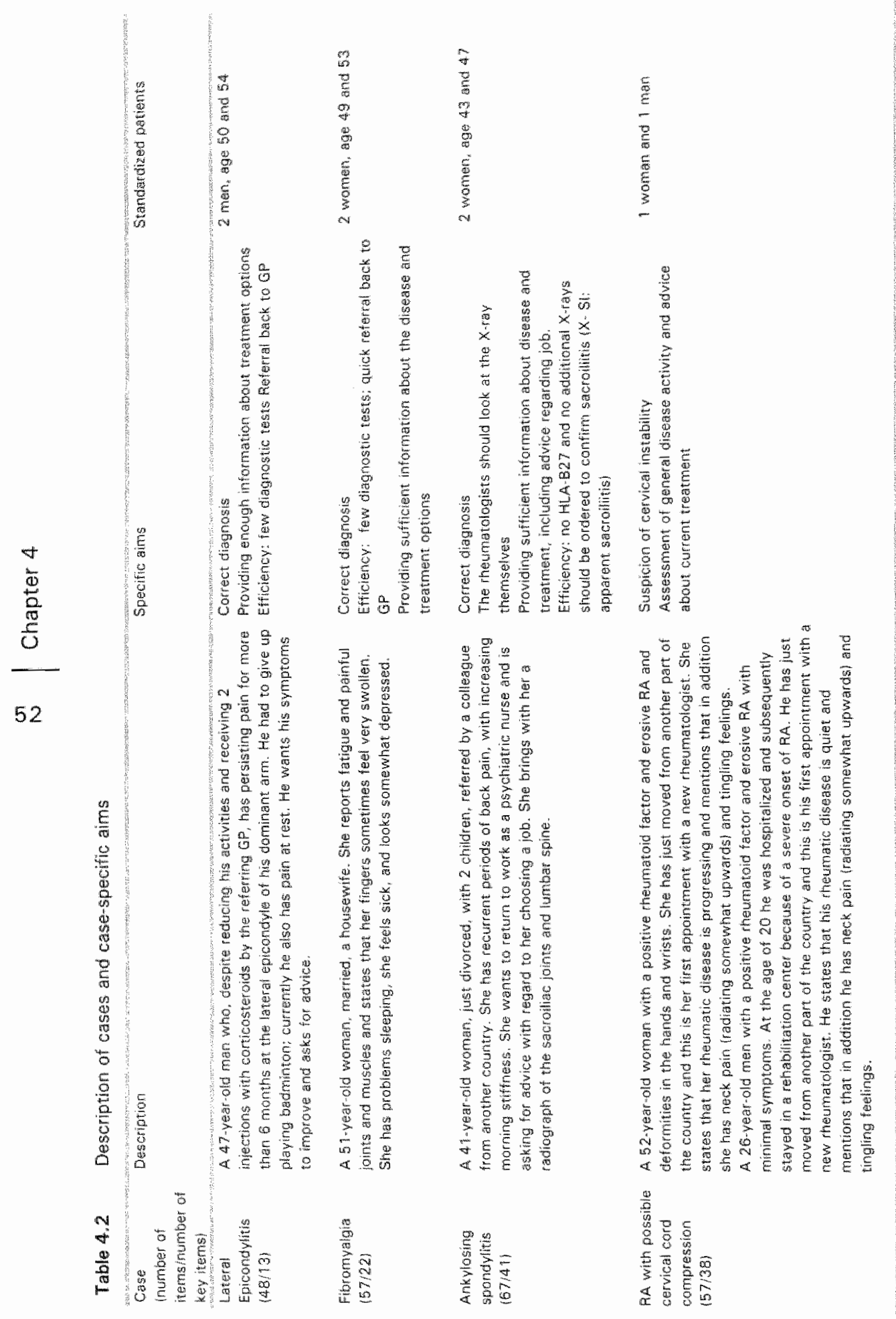


Performance in dally practice

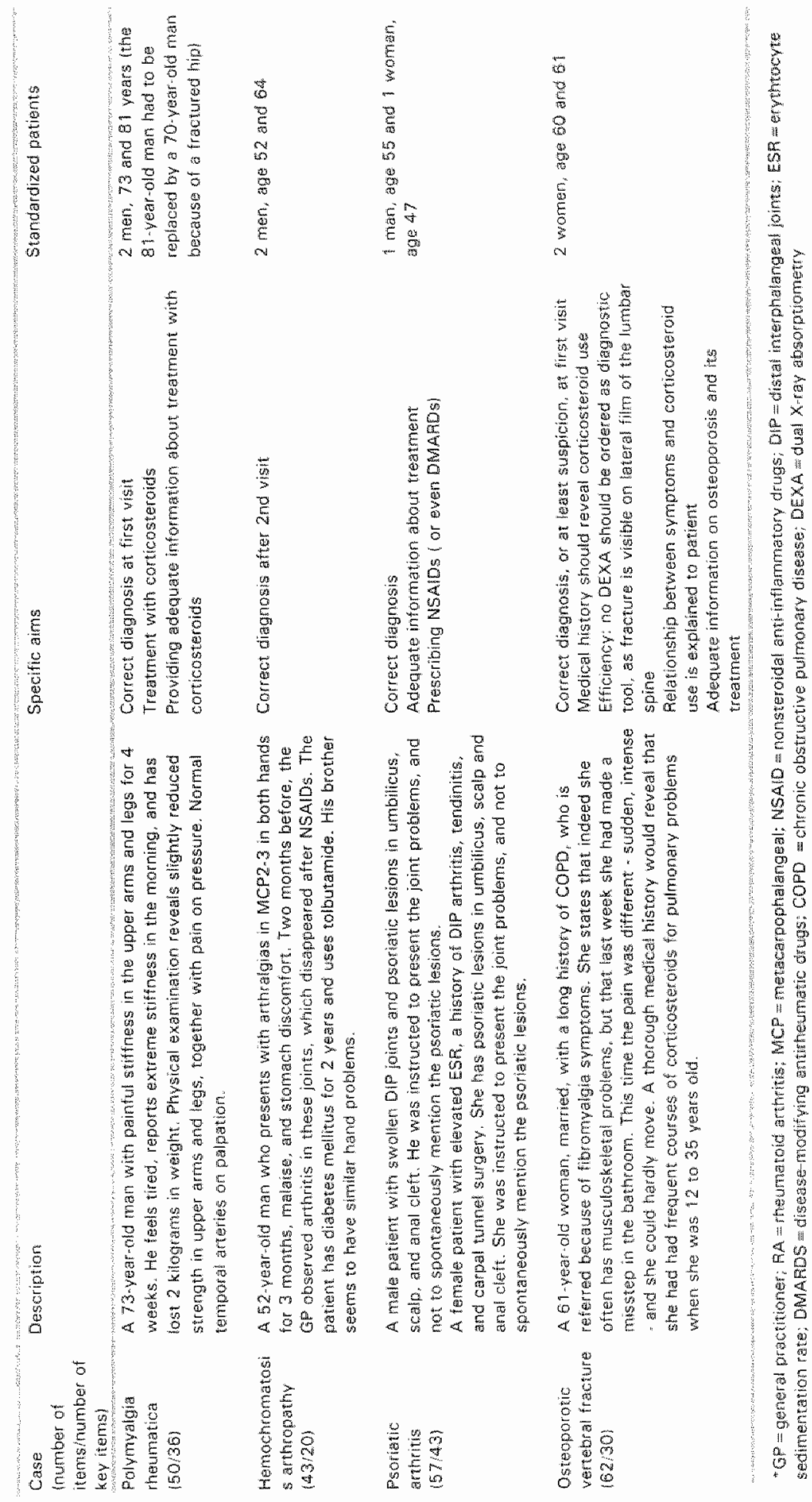




\section{Representativeness}

The 8 cases are required to mirror, to some degree, rheumatologists" every day performance. According to a register of rheumatological diagnoses in one large participating center (Spectrum Medical Center, Enschede) accounting for $5 \%$ of all rheumatological referrals in the Netherlands, ${ }^{12}$ the cases presented have the following incidence figures lexpressed as percentage of all new patients): lateral epicondylitis $1.3 \%$, fibromyalgia $4.8 \%$, ankylosing spondylitis $2.0 \%$, polymyalgia rheumatica $3 \%$, rheumatoid arthritis $7.5 \%$, hemochromatosis arthropathy $0.2 \%$, psoriatic arthritis $2.0 \%$, and osteoporosis due to steroid use $0.5 \%$. The cases presented by SPS are therefore to some degree proportional to the admixture of actual new referrals in the Netheriands. Note that in this country low back pain is mostly referred to other specialists, but not to rheumatologists.

Table 4.3 Part of the checklist for case on osteoporotic vertebral fracture

Three of 26 items on the medical history

During the corsultation attention was paid to:

The localization of complaints

Radiation of pain

Yes No

Don't

54

Yes know No Don't

Onset of the complaints

res know Don't

Three of 15 ittems on the physical examination

During the phrsical examination:

The physician palpated the vartebrae

$\begin{array}{lll}\text { Yes know } & \text { No } & \text { Don't } \\ \text { Yes know } & \text { No } & \text { Don't } \\ \text { Yes know } & \text { No } & \text { Don't }\end{array}$

The physician measured my height

The physician asked me to extend my arms and compared

the length of both arms with my height

Three of 25 items on management

During the consultation the physician:

Told me his or her firdings

Proposed treatment with bisphosphonates

Gave written information

if Yes: which brochure was given?

$\begin{array}{lll}\text { Yes know } & \text { No } & \text { Don't } \\ \text { Yes know } & \text { No } & \text { Don't } \\ \text { Yes know } & \text { No } & \text { Don't }\end{array}$




\section{Statistics}

Results were processed anonymously. Total checklist scores and key checklist scores were calculated. Reliability analysis was done to assess the reproducibility of the results. Each case score was considered as independent measurement. The reproducibility of the measurement as a whole was estimated by considering different case scores as repeated measurements. This is a common strategy in the assessment of authentic professional competence. ${ }^{13}$ Using classical test theory. Cronbach's alpha was calculated as an index for the estimation of the reproducibility. This index may be interpreted as the estimated correlation (reproducibility) with a hypothetical other measurement using 8 other cases from the same content domain. Pearson correlation coefficients between different scores and the number of years of working experience as a rheumatologist and number of outpatients seen each week were calculated to explain the variation in performance. Because of the small number of female rheumatologists and rheumatologists working in teaching hospitals, Mann Whitney $U$ tests were used to calculate differences in sex and type of practice. Statistical tests were performed using SPSS 10.0 (SPSS, Chicago, IL).

\section{Results}

\section{Number of visits}

Between July 1998 and February 2000, 254 encounters took place, including 201 first visits and 53 follow-up visits. One of 27 rheumatologists had to be left out because he had a very long waiting list for new patients and because he had canceled 2 appointments. Two rheumatologists temporarily stopped seeing new patients. Two other rheumatologists did not see an SP for other reasons. Ultimately, 22 rheumatologists were visited by all 8 SPs.

\section{Reliability}

Analysis resulted in a reliability coefficient alpha of 0.85 . This means that the results of a similar test with any other 8 cases derived from all possible cases will correlate at 0.85 with the current test. 


\section{Validity}

We assumed validity as long as the SP was not "detected" by the rheumatologist and thus stayed incognito. All rheumatologists received detection forms after they had given consent to the study. They had to complete these forms whenever suspecting a patient of being an SP. We did not actively collect these forms but lat the initiative for the rheumatologists. Eleven detection forms were received. Eight dealt with SPS and 3 concerned patients who were not involved in our study. Most detection forms were received at the end of the study period. We had to unmask 8 SPS after the visits because otherwise they would have undergone invasive procedures, such as a liver biopsy or a temporal artery biopsy. These unmaskings took place after all the information we needed was obtained (usually after the follow-up visit had taken placel, and hence these visits were included in the analysis. Two detection forms were received before we had even entered the first SP. It should be noted that in only 2 cases had the (same) rheumatologist "unmasked" the SP during a visit because of administrative shortcomings. Therefore, a total of 252 first visits results were available for analysis $(199$ first visits and 53 follow-up visits).

\section{Results of the eight cases}

The cases are presented in Table 4.2.

\section{Lateral epicondylitis}

Twenty-six first visits and no follow-up visits took place.

Case-specific aims

The diagnosis of tennis elbow was confirmed by $24(92 \%)$ of 26 rheumatologists. Fourteen $(54 \%)$ recommended a brace, $3(12 \%)$ recommended splinting the elbow, whereas $9(35 \%)$ strongly recommended a local infiltration with steroids, although the referring GPs had stated that they had already given 2 such injections without amelioration of symptoms. Eleven rheumatologists $(42 \%)$ prescribed physiotherapy.

Regarding resource utilization, 3 rheumatologists $(12 \%)$ ordered a radiograph of the elbow and $1(4 \%)$ ordered lab tests. Four rheumatologists $(15 \%)$ explicitly referred the SP back to the GP immediately after the first visit, whereas $14(54 \%)$ rheumatologists arranged a follow-up appointment. Eight $(31 \%)$ told the patient to come back if symptoms did not improve. 


\section{Other results}

One rheumatologist did a full neurological examination, and 12 (46\%) examined other joints as well. Costs for lab and radiologic tests ranged from US $\$ 0.00$ to $\$ 79.48$ (median $\$ 0.00$ ).

\section{Additional remarks}

The therapeutic role of braces, splints, local infiltration with steroids, and physiotherapy is unclear. Evidence based on systematic reviews exists for corticosteroid injections, ${ }^{14}$. which shows moderate relief of symptoms during the first 6-12 weeks after intervention, but mo sustained effects. A common opinion on whether or not to follow-up these patients seems to be lacking. Few lab tests and radiological exams were ordered in this case.

\section{Fibromyalgia}

Altogether 26 first visits and $78(69 \%)$ follow-up visits took place.

Case-specific aims

$24(92 \%)$ rheumatologists stressed that the SP did not have an inflammatory rheumatic disease, and $19(73 \%)$ mentioned fibromyalgia explicitly. Thirteen $(50 \%)$ requested radiographs. These 13 rheumatologists together ordered 7 cervical spine and 3 lumbar spine exams, 2 shoulder and 2 knee studies, 1 study of the hands, 1 pelvic study, 1 detailed film of the sacroiliac joint and 7 chest radiographs. A bone densitometry was ordered once. Twenty-five rheumatologists $(96 \%)$ requested lab tests. SPs with a follow-up appointment were referred back to their GP on $12(67 \%)$ of 18 occastions. In the opinion of the SP sufficient information on the prognosis of the condition was provided by $19(73 \%)$ rheumatologists. The following treatment options were discussed: maintaining or improving physical condition (17 times), spreading physical activities over the day (12 times). the lingering effects of heat applications (17 times); 12 (46\%) theumatologists advised taking analgesics.

\section{Other results}

On 22 occasions (85\%) a full physical examination including auscultation of heart and lungs was performed. Costs for lab and radiologic tests ranged from US $\$ 4.65$ to $\$ 335.41$ (median $\$ 63.14$ ).

\section{Additional remarks}

A high degree of attempted reassurance, a large number of follow-up visits, and considerable, but varying, resource utilization for this syndrome of generalized pain is striking. Costmeffectiveness might be an issue for discussion. 


\section{Ankylosing spondylitis(AS)}

Twenty-five first visits and - in accordance with the study protocol - no follow up visits took place. Notice that the patient brought a pelvic film with her (Table 4.2). The presence of bilateral sacroiliitis on this film has been independently confirmed before by the 11 panel members and at a national group meeting of 50 rheumatologists. Radiological sacroiliitis is considered as a 'conditio sine qua non' for the diagnosis of ankylosing spondylitis (AS).

Case-specific aims

$14(54 \%)$ rheurnatologists told the SP that she has AS, including $10(40 \%)$ who also provided education about the disease, and $8(32 \%)$ included specific information on the prognosis. On $22(88 \%)$ accasions the rheumatologist spontaneously asked to see the radiographs and in 3 cases $(12 \%)$ the SP had to push the rheumatologist to look at the radiograph she had brought with her.

Regarding resource utilization, after they had seen the pelvic radiograph, 15 of the 25 rheumatologists $(60 \%)$ ordered HLA-B27 testing. Thirteen rheumatologists $(52 \%)$ proposed new radiographic studies of the sacroiliac joints: 4 times a detailed conventional $S I$ joint exam and 9 times a computer tomography. Two rheumatologists ordered lumbar spine radiographs.

58 Other results

Sixteen of 25 rheumatologists $(64 \%)$ performed an extensive physical examination including heart, lungs and abdomen. To assess spinal mobility $22(80 \%)$ performed Schober's test, $24(96 \%)$ the finger-to-floor test, and $23(92 \%)$ assessed latero-flexion of the lumbar spine. On no occasion at the first visit was advice given to see an ophthalmologist in case the patient would suddenly develop anterior uveitis. Costs for lab and radiologic tests ranged from US $\$ 0.00$ to $\$ 367.03$ (median $\$ 214.00$ ).

Additional remarks

More than half of the rheumatologists ordered HLA-B27 testing and additional imaging of the sacroiliac joints. Diagnostic tests were redundant, because knowledge on HLA- B27 carriership does not contribute to the diagnosis or management of AS and conclusive X-rays of the SI-joints were available. Inappropriate use of resources leading to increasing costs of health care might be due to perceived uncertainty about the presence of a key item for diagnosis (in this case radiographic sacroiliitis). Training to improve skills to correctly and confidently diagnose such items will increase quality of care and reduce costs. 


\section{Rheumatoid arthritis (RA) with possible cervical cord compression}

Two different cases were presented (Table 4.2). Twenty-six first visits and 12 follow-up visits took place.

Case-specific aims

One rheumatologist told the SP during the first visit to suspect cervical spine instability. Other rheumatologists did not overtly express any suspicion at that time; however, they specifically asked for urine or fecal incontinence (respectively, 10 times [38\%] and 7 times [27\%]). At physical examination sensibility qualities were assessed by 10 rheumatologists $(38 \%)$ and Babinski"s sign was tested by $7(27 \%)$. A plain radiograph of the cervical spine was ordered by 14 rheumatologists $(54 \%)$. Assessment of the disease by history and a clinical exam was performed by all rheumatologists. All rheumatologists asked the SP to make follow-up appointments.

\section{Other results}

Costs for lab and radiologic tests ranged from US $\$ 5.81$ to $\$ 367.77$ (median \$ 129.64).

\section{Additional remarks}

Experiencing tingling sensations in the neck and a feeling like felt in the fingers, suggesting the possibility of cord compression, prompted a neurological examination in about $30 \%$ and radiographic studies of the cervical spine in just over $50 \%$ of all first visits of patients with positive rheumatoid factor and erosive RA. Although the male patient had only minor symptoms of active disease, we think that there is room for discussion to raise these figures.

\section{Polymyalgia rheumatica (PMR)}

Twenty-five first visits were completed according to the study protocol. No follow-up visits took place.

\section{Case-specific aims}

All of the rheumatologists told the SPS at the first visit that the diagnosis was probably PMR. All of the rheumatologists ordered a sedimentation rate, and in addition 16 ordered a C-reactive protein. Twenty-one (84\%) promptly prescribed steroids; $19(76 \%)$ explained that these drugs reduce inflammation and 16 discussed possible adverse effects. Eight rheumatologists prescribed the corticosteroids 2 or 3 times daily (dosage ranged between 10 and $15 \mathrm{mg}$ daily) and 13 prescribed it once a day (same dose range). 


\section{Other results}

An extensive physical examination was performed by 22 rheumatologists $(88 \%) ; 24(92 \%)$ did a full joint exam. The temporal artery was palpated for signs of arteriitis by $20(77 \%)$. Altogether $6(24 \%)$ of the rheumatologists combined corticosteroids with drugs to prevent osteoporosis (4 times calcium supplements, twice calcium and vitamin D supplements). Four $(16 \%)$ combined steroids with ulcer prophylaxis. One rheumatologist proposed a temporal artery biopsy. Chest radiographs were requested by $23(92 \%)$ of the 25 rheumatologists. Uitrasonography of the abdomen was requested twice. Costs for lab and radiologic tests ranged from US $\$ 46.50$ to $\$ 355.71$ (median $\$ 115.25$ ).

\section{Additional remarks}

There was considerable consensus on the diagnosis and on treatment with corticosteroids. There was slight variation in the dose prescribed, but considerable variation in the frequency of administration (1 to 3 times daily). Preventing gastrointestinal ulceration and steroid-induced osteoporosis for these patients seems controversial. Osteoporosis prevention is advised by the Dutch Multidisciplinary Workforce on Osteoporosis ${ }^{15}$ whenever $T$ score is lower than -1 for dual-energy $X$-ray absorptiometry measurement or spinal fractures are present on lumbar radiograph and oral steroids are expected to be prescribed for at least half a year at a daily dose of $7.5 \mathrm{mg}$ or higher.

\section{Hemochromatosis arthropathy}

Altogether 25 first visits and 18 follow-up visits took place for this rather infrequently seen rheumatic condition characterized by increased transferrin saturation index and typical radiographic features of the metacarpophalangeal joints of the hands.

Case-specific aims

At the first or second visit 15 rheumatologists $(60 \%)$ explicitly stated that they suspected arthropathy due to hemochromatosis. Twenty-four (96\%) ordered radiographs of the hands. Ferritine, a key item in the diagnosis of hemochromatosis, was requested by $18(79 \%)$ of the rheumatologists; 8 times during the first visit, 4 times at follow-up, and 6 times at both visits. Serum iron was ordered by 17 , and total iron binding capacity was determined 9 times. Five rheumatologists did not order any markers for iron content. Eight $(55 \%)$ of the 15 rheumatologists who tentatively diagnosed hemochromatosis arthropathy told the SP that relatives should be screened for the disorder. With regard to treatment, $7(28 \%)$ proposed phlebotomy, $13(42 \%)$ prescribed nonsteroidal anti-inflammatory drugs (NSAIDs), and 7 $(28 \%)$ advised the SP to take acetominophen for the joint problems. 


\section{Other results}

Costs for lab and radiologic tests ranged from US $\$ 0.00$ to $\$ 349.38$ (median \$ 138.53).

\section{Additional remarks}

In a considerable proportion (nearly $80 \%$ ) of the first or second visits, arthropathy due to hemochromatosis was confirmed or strongly considered. Screening of family members is mandated if the diagnosis is confirmed. Phlebotomy does not provide relief of joint symptoms, but it may prevent further organ damage.

\section{Psoriatic arthritis}

Psoriatic skin lesions may be scarce and difficult to find unless a meticulous clinical exam is performed. The differential diagnosis of psoriatic arthritis may include degenerative osteoarthritis of the distal interphalangeal joints of the hand. Two different cases were presented (Table 4.2). Altogether 23 first visits and 2 follow-up visits took place.

Case-specific aims

An extensive physical exam was done by $13(57 \%)$ of 23 rheumatologists. Based on the SPs' observation $16(70 \%)$ thoroughly inspected the patient's skin for psoriatic lesions. Five $(22 \%)$ of the 23 rheumatologists diagnosed osteoarthritis (male patient), and $2(9 \%)$ diagnosed both osteoarthritis and psoriasis (once for the female patient). Fourteen rheumatologists $(61 \%)$ correctly diagnosed psoriatic arthritis. Eleven (48\%) educated the patient about the disease at the first visit, and $4(17 \%)$ provided the SP with a leaflet on psoriatic arthritis. Six $(26 \%)$ prescribed medications: 4 times NSAIDs, once acetaminophen and once glucosamine. The latter prescription was changed after the rheumatologist had seen the radiograph and the preliminary diagnosis of osteoarthritis was changed to psoriatic arthritis.

Other results

Costs for lab and radiologic tests ranged from US $\$ 0.00$ to $\$ 485.38$ (median \$ 94.79).

\section{Additional remarks}

Most of the time a correct diagnosis was made at the first visit. In the male patient the differential diagnosis osteoarthritis caused some difficulty.

\section{Osteoporotic vertebral fracture}

Twenty-four first visits and - in accordance with the study design - no follow-up visits took place. 


\section{Case-specific aims}

Twelve $(50 \%)$ rheumatologists stated explicitly that they suspected a vertebral spine fracture. Four rheumatologists $(17 \%)$ spontaneously asked about the use of corticosteroids in the past. It should be noted that the GPS had not mentioned the use of steroids in the past in their referral letters. Eleven $(46 \%)$ of the theumatologists inquired about a possible family history of osteoporosis, and $8(33 \%)$ assessed age at menopause. At physical examination, 21 (88\%) performed axial compression and firm pressure on single vertebrae. Twenty-one rheumatologists $(88 \%)$ ordered lumbar spine radiographs, 6 thoracic spine radiographs, 5 ordered a pelvic radiograph, and 1 rheumatologist requested a rib detail. DEXA was ordered twice, on both occasions combined with lumbar spine radiographs.

One $(4 \%)$ rheumatologist told the patient that the vertebral fracture could be due to the frequent courses of steroids that she had taken in the past for her pulmonary obstructive disease. At the first visit long-term therapy for asteoporosis was prescribed by 4 rheumatologists $(17 \%): 2$ times calcium tablets and 2 times bisphosphonates. Five $(21 \%)$ advised the SP to assure a sufficient dietary intake of calcium.

\section{Other results}

Physical examination, including heart and lungs, was performed by 13 $(54 \%)$ of the rheumatologists. Costs for lab and radiologic tests ranged from US $\$ 105.97$ to $\$ 402.12$ (median $\$ 211.96$ ).

\section{Additional remarks}

There was a high index of suspicion of a vertebral fracture. There is clearly some ambiguity on when to start what kind of anti-osteoporotic therapy. The Dutch Multidisciplinary Workforce on Osteoporosis ${ }^{15}$ advises treatment with bisphosphonates or hormone replacement therapy for these women (more than 5 years post menopausal) with a vertebral fracture on lumbar radiograph.

\section{Aggregated results}

\section{Laboratory tests}

In 150 first visits lab tests were ordered. A large variety of requests for lab tests was noted among the 8 cases and among all rheumatologists (Table 4.4 and Figure 4.1). Mean costs per rheumatologist for lab tests (calculated by adding the national fares as set by the government [COTG tarieven]) varied between US $\$ 4.67$ and $\$ 65.36$ (SD 14.6). The most expensive case was hemochromatosis arthropathy: the least expensive was lateral epicondylitis. 


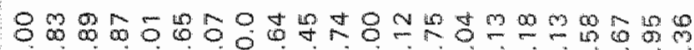

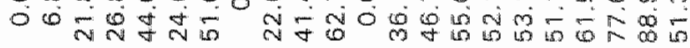

$\infty \times \infty$

(1)

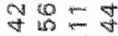

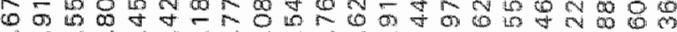

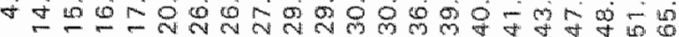

is

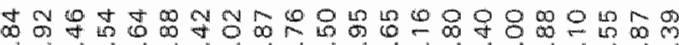

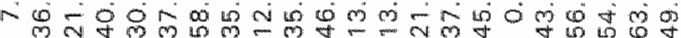

$18 \times 8$

in

0
0
0
0
0
0
0
0
0
0

$\infty$

i

$\stackrel{48}{4} 8$

0

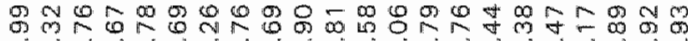

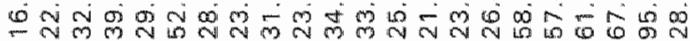

is 8

* mi

$m_{3}$

幽

i is

of

$\frac{\cos }{a t a}$

(n)

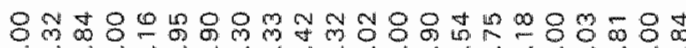

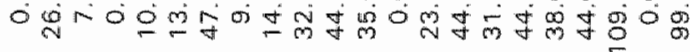

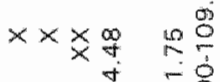

的

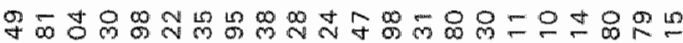

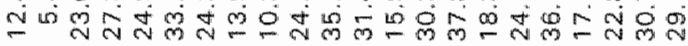

$\sin 0.8$

ம்

फो

8下

-

$8 \times 98=8$

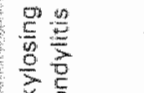

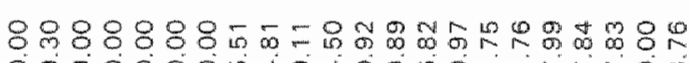
0000000

$x \times \log _{0} x$

ले

$=\infty$

5

$+5$

08

$-$

\section{$\circ$}


W का

过8 8 漹

4800\%

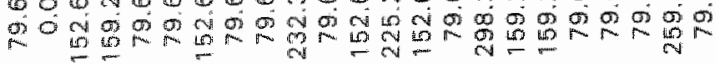

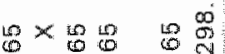

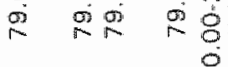

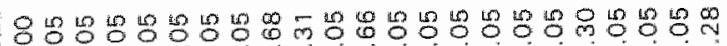

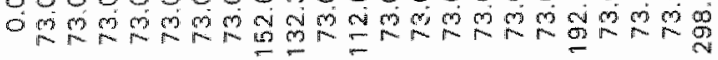

$8 x \times$

ले m

ल 8

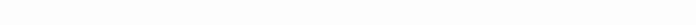

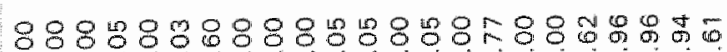

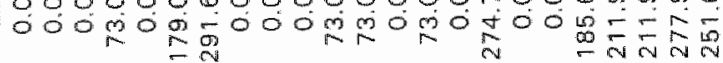

क人

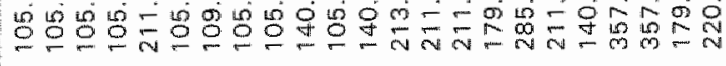

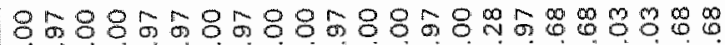

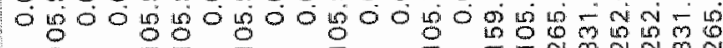
-20 은

$8 \log _{0} \stackrel{0}{10}$ 两范

8 m 88 可 0000 0. 娄 00

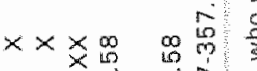
品 守点 言

8 ?<smiles>[Y][X]</smiles>

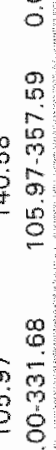
$\infty$ $m-7$

$8988888 \% 88898888888$ - 89 ○ी

$8 \times 8$
$8 \times 18$
0

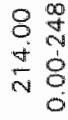

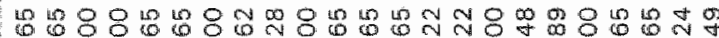

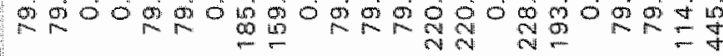

$x \times \underset{\infty}{\infty} \times$

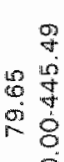

i

$88888898888889 \% 8888888$ 4

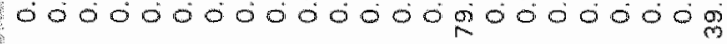

马ㄴ용 0.00 
Imaging tests

In 134 of the 201 first visits radiologic investigations were ordered. A large variety was seen between as well as within cases (Table 4.5 and Figure 4.1). Mean costs per rheumatologist per case ranged between US $\$ 33.15$ and $\$ 226.84$ (SD 47.2 ). The most expensive case was osteoporotic vertebral fracture; the least expensive cases were lateral epicondylitis and fibromyalgia..

\section{Scoring}

To illustrate the variance in checklist item scoring among the rheumatologists, box plots are presented in Figure 4.2. They show the scores for the key items as percentage of the maximum possible score and the score for the total items. Every box provides the results for one case. Considerable variance within and between cases is noted for these process indicattors.

\section{Explanatory factors}

We studied whether number of vears of working experience as a rheumatologist, and number of outpatients seen per week, were correlated with key checklist scores and total checklist scores as process measures. Only years of working experience as a rheumatologist showed a significant negative correlation with the total checklist score (Pearson correlation coefficient $r=-0.47, P<0.05$ ) and with the score on the key items (Pearson correlation coefficient $r=-0.46, P<0.05)$. None of the background variables, nor key checklist nor total checklist score correlated statistically significant with costs for additional studies. Mann-Whitney $U$ test showed no significant differences between background variables (sex, hospital setting) for the total checklist scores, key checklist scores or costs. 


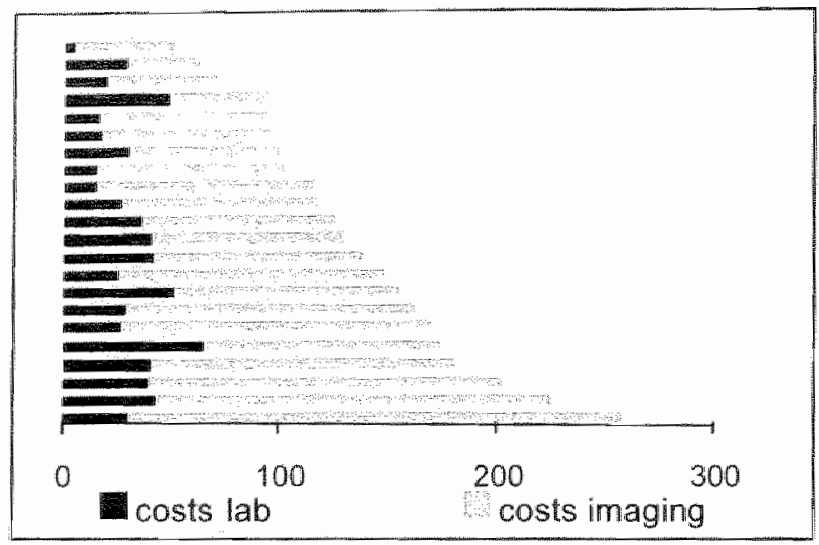

Every horizontal bar presents one rheumatologist

Figure 4.1 Mean costs per rheumatologist for 8 cases for laboratory and imaging tests, in US dollars.

+
$\frac{1}{0}$
$\frac{a}{0}$
$\frac{5}{0}$
0

66
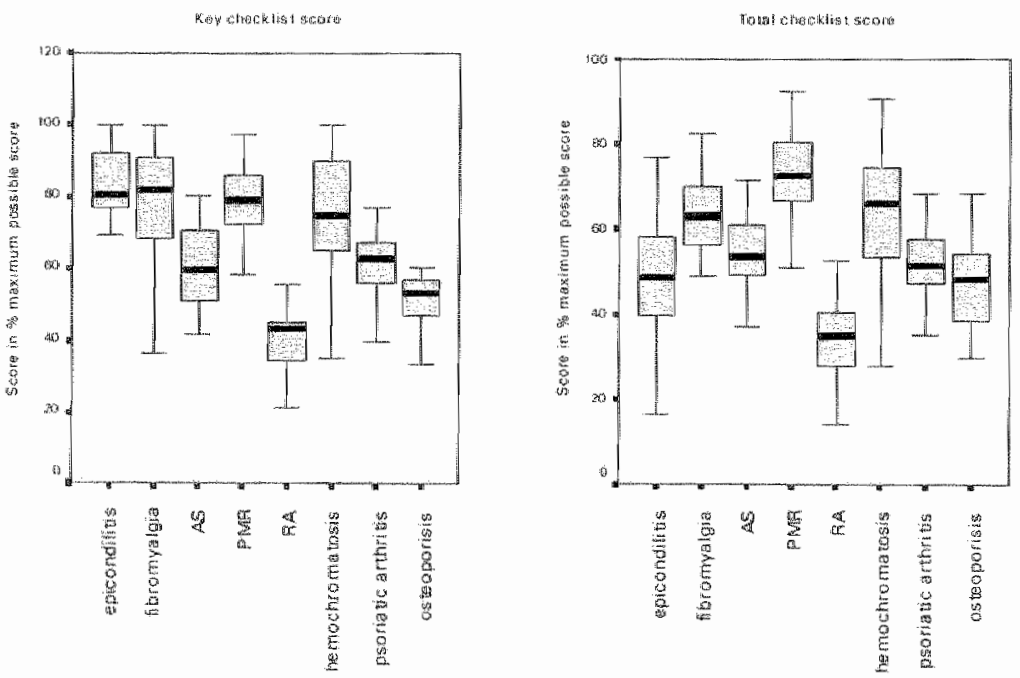

Figure 4.2 Every box represents $50 \%$ of rheumatologists' scores. The whiskers (vertical lines) are 1.5 times the box width and the horizontal line is the median score for that case.

$R A=$ theumatoid arthritis; $A S=$ ankylosing spondylitis;

$P M R=$ polynnyalgia rheumatica. 


\section{Discussion}

This is the first study describing actual daily clinical performance among rheumatologists. The study is reliable and provides valid results on daily practice behavior. This study was encouraged by the Dutch Society of Rheumatology and involved many theumatologists who took up the challenge to stand a test of their performance. It is important that professional organizations take responsibility to assess and reduce inappropriate variation. If the profession does not accept the challenge, others will, and this may lead to solutions that are not aiways in the best interest of the patients. ${ }^{16}$

Our study focused on describing, rather than explaining, practice variation. We did not intend to evaluate the rheumatologists' performance, but only registered their practice behavior. The checklist is process oriented and was used in a nonnormative way. The variation in scores among rheumatologists reflects a difference in number of items performed during the consultation. Higher checklist scores do not per se mean higher quality rheumatologists. Detailed case-specific information is available on request. Overall the results are encouraging, although there is room for improvement and discussion focusing on efficiency and adherence to guidelines. Practice variation is poorly understood. ${ }^{17}$ Uncertainty about key items, lack of agreement about optimum treatment, legal implications promoting defensive medicine, economic constraints, reimbursement policies, conservative or elaborate style of practicing, peer pressure, and knowledge regarding the outcomes of interventions are among the factors that might contribute to the observed variation. ${ }^{16.17} \mathrm{~A}$ number of factors included in this study did not contribute to explaining the observed variation. Only the number of years of working experience as a rheumatologist partly explained the number of items performed.

Although it is likely that costs or practice behavior observed in this study differ from those of other countries with different health care systems, we stronglly suspect that comparable degrees of variation would have been found. The detailed results of performance might be different across countries and settings, but we do not expect the amount of variation to be smaller. Therefore, the results will be generalizable and useful in discussions on quality assurance and appropriateness of care by rheumatologists. However, one should keep in mind that quality improvement activities are most effective when used with local data. ${ }^{18}$ Moreover, results dealing with practice variation should, whenever possible, be linked to case-mix and patient outcomes.

As far as we know a study on this scale has never been performed before among hospital-based specialists. However, the study is logistically 
demanding and is not easy to implement as a routine quality-of-care assessment instrument.

The results obtained show good reliability. Actual practice behavior was measured in all but 2 consultations where one rheumatologist unmasked SPS as fake patients. Therefore, $99 \%$ of the data are valid and representative of what really happens in practice. However, some limitations exist for this type of studies. It is not always feasible to arrange follow-up visits, e.g., when surgical interwentions or biopsies are proposed. Therefore, the results obtained cannot always be regarded as complete. For most cases we decided only to assess the first visit. This may implicate underestimation, for example if a rheumatologist uses the follow-up visit to provide the patient with more detailed information.' ${ }^{\prime 9}$ This also applies to physicians waiting to see lab test results before deciding to order additional tests. Not every problem has to be finished completely within the first visit. Clearly, it is also possible that results of ordered tests lead physicians to the correct diagnosis in one of the follow-up visits.

Another limitation is that we could only assess those aspects of performance that were observable by patients or indicated by data obtainable from laboratory and radiology departments. For example, in the case with RA and possible cord compression, a number of rheumatologists may indeed have considered cervical cord instability, but withhold this suspicion at the first visit while awaiting the results of confirming investigations.

In summary, assessment of hospital-based specialists' performance by introducing incognito standardized patients in practice provides detailed, valid and reliable information on daily clinical performance. Considerable variation exists in practice performance as well as in costs for laboratory and imaging investigations. The resulting information can be used as a needs assessment tool for continuous medical education and might be a valuable source for discussions on the appropriateness af care and the development of guidelines. 


\section{References}

1. Davis DA, Thomson MA, Oxman AD, Hayes RB, Changing physician performance. $A$ systematic review of the effect of continuing medical education strategies. JAMA 1995:274:700-5.

2. Ram $P$, van der Vleuten $C$, Rethans JJ. Grol $R$, Aretz K. Assessment of practicing family physicians: comparison of observation in a multiple-station examination using standardized patients with observation of consultations in daily practice. Acad Med $1999 ; 74(1): 62-9$.

3. Rethans JJ. Westin S. Hays R. Methods for quality assessment in general practice. Fam Pract 1996:13(5):468-76.

4. Rethans $J J$, Sturmans $F$. Drop R, wan der Vleuten $C_{*}$ Hobus P. Does competence of general practitioners predict their performance? Comparison between examination setting and actual practice. BM.J 1991:303:1377-80.

5. Dolan NC MMDM. Using unidentified standardized patients to evaluate housestaff delivery of preventive services. Teach Learn Med 1997;9:60-5.

6. Rethans $J J$, Sturmans $F$, Drop $\mathbb{R}$, van der Vleuten $C$. Assessment of the performance of general practitioners by the use of standardized (simulated) patients. Br J Gen Pract $1991: 41(344): 97-9$.

7. Barrows HS. An overview of the uses of standardized patients for teaching and evaluating clinical skills. AAMC. Acad Med 1993;68(6):443-51.

8. Rethans J.J. Needs assessment in continuing medical education through standardized patients. J Continuing Educ Health Professions 1998;18:172-8.

9. Gorter SL, Rethans J-J, Scherpbier AJJA, van der Linden S, Van Santen-Hoeufft MHM, Vain der Heijde DMFM, et al. How to introduce incognito standardized patients into outpatient clinics of specialists in rheumatology. Med Teach 2001:23:138-44.

10. Ramsey PG, Curtis JR, Paauw DS, Carline JD, Wenrich MD. History-taking and preverntive medicine skills among primary care physicians: An assessment using standardized patients. Am J Med 1998;104(2):152-8.

11. Gorter $S_{x}$ Rethans Ju-J, Scherpbier A, wan der Heijde D, Houben H, Vleuten van der C, et al. A review of methodologies in writing case specific checklists for standardized patientbased assessment in internal medicine. Acad Med 2000;75:77-84.

12. Miedema HS, wan der Linden SM. Rasker JJ, Valkenburg HA. National database of patients visiting rheumatologists in The Netherlands: the standard diagnosis register of theumatic diseases. A report and preliminary analysis. Br $₫$ Rheum 1998;37(5):555-61.

13. Swanson DB. A measurement ramework for performance-based tests. In: Hart 1, Harden $R$, editors. Further developments in assessing clinical competence. Montreal CanmHeal Publications 1987:13-45.

14. Assendelft WJ. Hay EM, Adshead R, Bouter LM. Corticosteroid injections for lateral epicondylitis". a systemic overwiew. Br J Gen Pract 1996;46:209-16.

15. Interdisciplinary Workforce on Osteoporosis. Osteoporose in de praktijk: diagnostiek, preventie en behandeling. 2nd ed; 1997.

16. Keller RB, Soule DN, Wenmberg JE, Hanley DF. Dealing with geographical variations in the use of hospitals. J Bone Joint Surg 1990;72-A:1286-93.

17. Westert GP, Groenewegen PP. Medical practice wariations: changing the theoratical approach. Scand J Public Health 1999;27:173-80.

18. Gundersen, L. The effect of clinical practice guidelines on wariations in care. Ann Intern Med 2000:133:3177.8

19. Tamblyn RM, Abrahamowicz M, Berkson L, Dauphinee MD, Gayton DC, Grad RM, et al. First-visit bias in the measurement of clinical competence with standardized patients. Acad Med 1992;67:S22 4. 


\section{chapter}

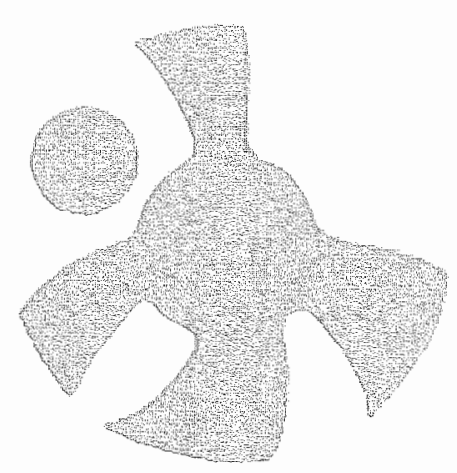

Rheumatologists' variation in actual daily practice: Expertise partly predicts practice performance

Simone Gorter, Jan-Joost Rethans, Désirée van der Heijde, Albert Scherpbier, Harry Houben, Sjef van der Linden, Cees van der Vleuten 


\section{Abstract}

Background. In actual daily practice considerable inter-doctor variation exists in the delivery of care, but explanation of variation of care is still a matter of debate. One of the problems in studies about variation is that it is difficuit to compare physicians since each physician faces different patients. In this paper, variation in actual daily practice performance is described for a group of 27 Dutch rheumatologists using an innovative method: each rheumatologist was visited by eight incognito standardized patients. In this way it was possible to better compare physicians with regard to their performance and their background characteristics.

Methods. Twenty-seven rheumatologists working in 16 hospitals spread across the country were each visited by eight incognito standardized patients, presenting eight different rheumatological conditions. Detailed information on the content of the visit was obtained by case-specific checklists, which were completed by the standardized patients after each visit. Validity was assumed as long as the standardized patients stayed undercover. Background characteristics of the physicians were correlated with actual performance.

Results. Between July 1998 and February 2000, 254 visits took place of which 201 first visits and 53 follow-up visits. A true detection rate of $1 \%$ was obtained. A considerable amount of variation in items performed during consultations existed between cases (mean score ranged between $34-73 \%$ ) as well as between rheumatologists (mean score ranged between: $14-92 \%$ ). Another striking result was that rheumatologists with more experience performed less items than those with less experience.

Interpretation. These results are a valuable source for discussions among groups of rheumatologists about good clinical practice and might be useful to assure and improve quality in the delivery of care. 


\section{Introduction}

In actual daily practice considerable variation in performance exists in the delivery of health care. ${ }^{4-4}$ The presence of variation should be a stimulus for physicians to learn more about their practice patterns and a better understanding of the outcome of care they provide to patients. ${ }^{3}$

Variation can be found both among physicians (inter-doctor variation and within physicians (intra-doctor variation). Intramdoctor variation occurs when a doctor performs differently when facing exactly the same problem. This was substantial among general practitioners visited by incognito (standardized) patients. ${ }^{5}$ Another form of intra-doctor variation exists when different cases are presented to one physician. Performance on one case poorly predicts performance on another case, which is known as the content-specificity problem of clinical competence. Inter-doctor variation can be found both when the same case is presented to different physicians. Consliderable inter-doctor variation was observed when three rheumatolagists consecutively saw the same 26 patients and in only $46 \%$ completely agreed on diagnosis."

The explanation of variation among physicians is still a matter of debate. Some variation in practice is inevitable, since patients are different in context, symptoms, and responses. However, these differences in practice performance do not sollely rely on differences in these patient characteristics. " The physicians" personal characteristics may be a source of variation as well. An example is the role of uncertainty: uncertain physicilans order more tests or, with regard to treatment options, "do as their direct colleagues do". Also, in the absence of clinical standards variation in practice performance is probably higher, compared to clinical situations with well-defined criteria in consensus guidelines. Some physicians" background characteristics have been found to be of importance in the explanation of variation of medical performance. Increasing age and numbers of years elapsed since certification predicted lower scores on tests for medical knowledge $e^{9,10}$ as it did for performance in daily practice. "It has also been suggested that a busy practice, the type of practice, or physician's sex might influence actual practice behavior. ${ }^{12-14}$

A drawback in most previous studies is that either the practice or patient characteristics are too variable to really be able to compare the performance of individuall doctors, leaving much room for discussion. Most of the studies assessing variation also did not take place in real practice. Those that did, however, mostly used indirect measurements of performance, such as drug prescription, instead of information on what really happened in day-to-day practice. Yet, obtaining valid information on how physicians vary in performance seems critical. This information can be 
discussed among professionals to identify "best" practice performance and to develop guidelines to improve quality of care and patient outcome. In addition, exploring reasons for variation could enhance efficiency, equity and effectiveness of care for patients. "So far quality assurance activities, such as consensus conferences and discussions on good clinical practice organized to develop guidelines have only had marginal impact on changes of physicians' practice behavior. ${ }^{15}$ Guidelines, tailored to real daily practice performance will probably be more effective. ${ }^{16}$

Ideally, when real practice assessment is to be measured, a large number of physicians should see the same patients in a standardized way. In real practice, however, this would be an impossible situation. One way to solve this problem is to introduce standardized patients (SPS). SPs are real patients or healthy persons who are trained to play a role in a consistent and accurate way, ${ }^{17,18}$ and thus represent identical stimulus for physicians. The detailed information that will be obtained in a standardized way, enables to compare the true performances of different physicians.

We were interested if earlier reported associations in background variables would still stand if assessed in real practice. The following variables were investigated: age, number of years of working experience as rheumatologist, number of outpatients seen each week, rheumatologists' sex and type of practice.

\section{Methods}

\section{Subjects}

A study was conducted where 16 incognito SPs presenting eight different roles regarding eight different rheumatic disorders were sent to a convenience sample of rheumatologists in the Netherlands. One and a halfyear before the first SP entered practice, 116 of all (127) Dutch rheumatologists were asked to participate the remaining rheumatologists were involved in the development process of the study). Fifty-seven (49\%) gave written consent and for logistical reasons 27 spread across the whole country, were selected for the incognito visits. Hospital boards of directors had consented. All rheumatologists were each visited by eight different SPs. It was estimated that eight cases should give a reliable presentation of rheumatologist's individual performance. ${ }^{19}$

\section{Cases}

The cases were based on real presentations of patients to rheumatologists. The following rheumatological disorders were presented: ankylosing 
spondylitis, fibromyalgia, hemochromatosis arthropathy, lateral epicondylitis, asteoporotic vertebral fracture, polymyalgia rhoumatica, psoriatic arthritis and rheumatoid arthritis with possible cervical cord compression. The psoriatic arthritis and heumatoid arthritis cases were presented by real patients, the other cases were presented by healthy subjects.

\section{Training}

For each case, two SPs were trained together to play the role and score a checklist on physician's performance consistently. The SP's presentations were judged to have sufficient face validity by four rheumatologists who participated in the training sessions and who were not otherwise involved. During the training sessions close attention was paid to a realistic presentation. Checklists were completed by SP and trainer after each pilot consultation. Any discrepancies were discussed. For each SP, at completion of the training, three observer-physicians scored a videotaped registration of the training session. Differences in scores between the three observers were discussed and whenever needed the registered consultation was reviewed. The final observer score was compared with the SP's score of the same consultation. To check consistency over time, the SPs scored that consultation again after they had seen about half the rheumatologists in real practice.

\section{Checklists}

Information on the content of the encounter was obtained by predefined case-specific checklists completed by each SP after the consultation had taken place. ${ }^{20}$ The checklists were based on written cases, developed by a panel of 11 rheumatologists (not involved in the practice visits) and were judged for its face validity. The number of items for these cases varied between 50 and 75, with three subdivisions: medical history, physical examination and management. For each case a panel of four rheumatologists identified items that were essential to do. When any item was indicated as such by at least three of four panel members, this item became a key-item. An example of a part of a checklist is shown in Table 5.1. The SPs marked whether the action indicated by the item had taken place or not. Results of the follow-up visit conly management section was completed then) were supplementary to the first visit. SPs had declared to keep all information obtained during the visits confidential. An extensive description of the variation on the eight different cases is published elsewhere. 21 
Table 5.1 Part of the checklist for case on osteoporotic vertebral fracture

Three of 26 items on the medical history

During the consultation attention was paid to:

The localization of complaints

Riadiation of pain

Onset of the complaints

$\begin{array}{lll}\text { Yes know } & \text { No } & \text { Don't } \\ \text { Yes know } & \text { No } & \text { Don't } \\ \text { Yes know } & \text { No } & \text { Don't }\end{array}$

Three of 15 items on the physical examination

During the physical examination:

The physician palpated the vertebrae

The physician measured my height

$\begin{array}{lll}\text { Yes know } & \text { No } & \text { Don't } \\ \text { Yes know } & \text { No } & \text { Don't } \\ \text { Yen know } & \text { No } & \text { Don't }\end{array}$

Three of 25 items on management

During the consultation the physician:

Told me his or her findings

$\begin{array}{lll}\text { Yes know } & \text { No } & \text { Don't } \\ \text { Yes know } & \text { No } & \text { Don't } \\ \text { Yes know } & \text { No } & \text { Don't }\end{array}$

Proposed treatment with bisphosphonates

Gave written information

if Yes: which brochure was given?

The physician asked me to extend my arms and Yes know 
key item score is the total number of key-items per case. All scores are presented as percentages from the maximum possible score. Separate scores were calculated for the medical history, physical examination and management part of the checklist. Kappa statistics was applied to report agreement beyond chance-agreement in scoring of the checklists between SP and observer-panel.

To explore the variation in performance among pheumatologists for each rheumatological condition, means, standard deviations and ranges on all scores were calculated. To explain the variation in performance. Pearson correlation coefficients were calculated between the different scores and the following continuous variables: age, number of years of working experience and number of outpatients seen each week. Because of the small number of female rheumatologists and rheumatologists working in teaching hospitals, differences in gender and type of practice were calculated using a Mann Whitney $U$ tests. All statistical tests were performed with SPSS $10.0 .{ }^{23}$

\section{Results}

One rheumatologist of the group of 27 had to be left out at the beginning of the study, because of a very long waiting list. Two were left out after a few visits because they ceased accepting new patients and one rheumatologist did not see the last SP, because the referral letter lacked. At the end of the study, 254 incognito visits had taken place, of which 201 first visits and 53 follow-up visits. During the training a mean kappa of 0.78 was obtained between SP-score and a consensus-score of three observers. The re-scoring by the SPs resulted in a mean kappa of 0.78 as well. Eleven detection forms were received, of which eight dealt with our SPs. Six of these SPS were suspected only after the encounter had taken place, for example when a rheumatologist tried to call the patient at home. Therefore, two visits could not be included in the analysis, and a true detection rate of $1 \%$ was obtained.

Table 5.2 shows that the cases with the lowest total case score and case score on the key-items, are rheumatoid arthritis and osteoporotic vertebral fracture. The highest case score on the key-items are obtained for the epicondylitis and fibromyalgia cases. Polymyalgia rheumatica receives the highest total case score. The lowest variation in case score on the key items is seen for the psoriatic arthritis case (range $40 \%-77 \%$ ). whereas the lateral epicondylitis shows the largest variation (range 36\%-100\%). For the total case score psoriatic arthritis has the lowest variation (range $35 \%-68 \%$ ) and both hemochromatosis arthropathy and fibromyalgia have the largest variation (range $28 \%-91 \%$ ). There are no substantial differences between the mean scores for the different phases!medical history, physical 


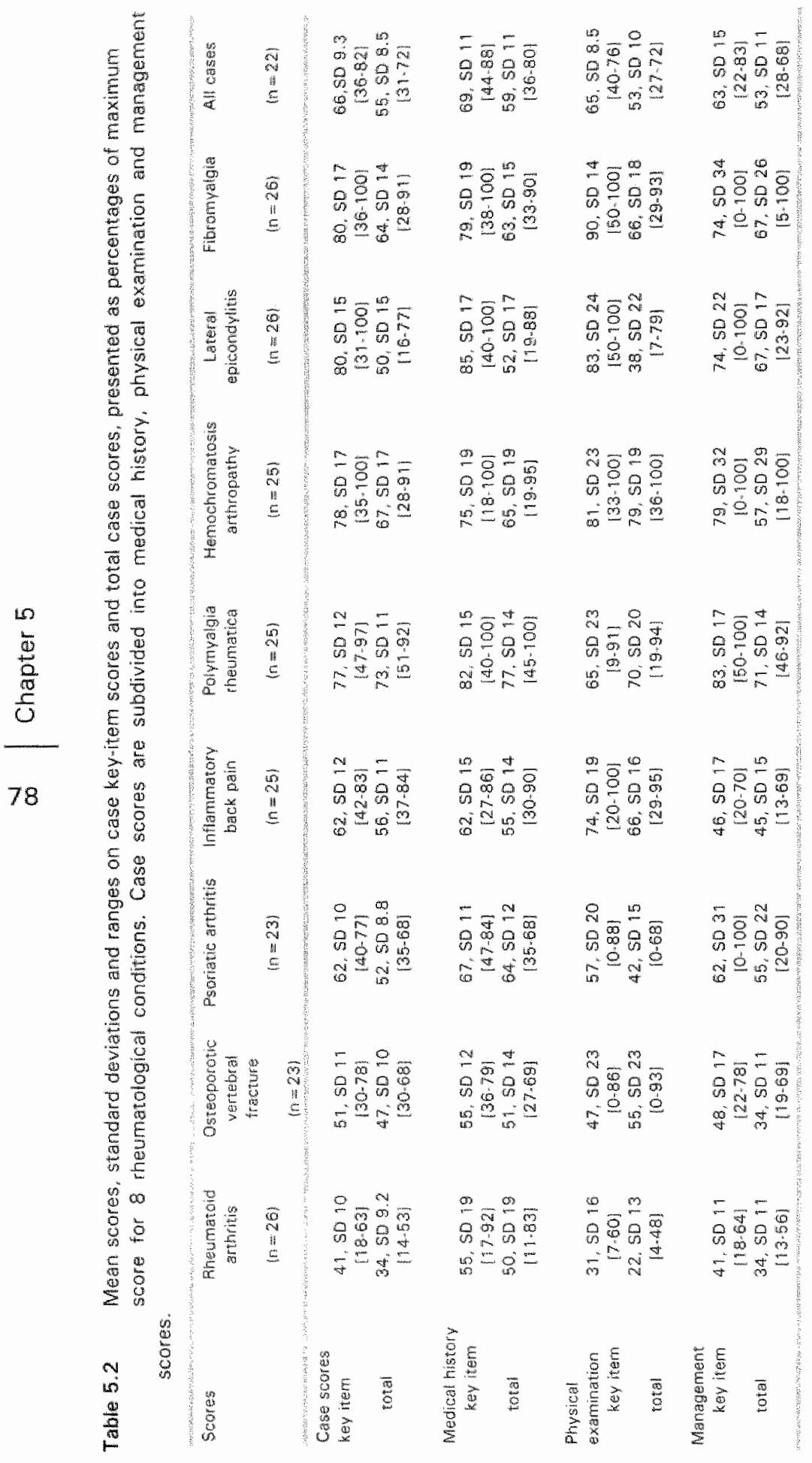


examination and management) of the consultations. The largest variation is seen for the total score and score on the key-items for the management part of the consultations.

Table 5.3 shows that the number of vears of working experience as a rheumatologist significantly negatively correlates with the mean of the total case score, the mean of the case score on the key items, the mean of all medical history total scores and with the mean of all medical history scores on the key-items. Years of working experience also significantly negatively correlates with the mean of all management total scores. Since age and years of working experience are, as expected, strongly correlated. significant correlations between age and different scores are also found. No statistically significant correlations are found between number of outpatients seen each week and the different scores. No differences in scoring were found by Mann Whitney $U$ tests between female and male rheumatollogists, nor between rheumatologists working in teaching hospitals and non teaching hospitals. This is due to a lack of power because of the small number of female rheumatologists and rheumatologists working in teaching hospitals. Table 5.4 shows the differences in mean scores for these groups.

Table 5.3 Pearson correlation coefficients between working experience, age and number of outpatients and mean case scores across all 8 cases and subscores for medical history, physical examination and management.

$\begin{array}{cccc}\text { Score } & \begin{array}{c}\text { Years of working } \\ \text { experience as } \\ \text { rheumatologist }\end{array} & \text { Age } & \begin{array}{c}\text { Number of outpach } \\ \text { seen each }\end{array} \\ \text { Case score on key items } & -0.46^{*} & -0.43^{*} & -0.20 \\ \text { Medicall history } & -0.50^{*} & -0.48^{*} & -0.23 \\ \text { Physical examination } & -0.16 & 0.10 & -0.25 \\ \text { Management } & -0.36 & -0.35 & -0.04 \\ \text { Total case score } & -0.47^{*} & -0.40 & -0.18 \\ \text { Medical history } & -0.47^{*} & -0.43^{*} & -0.24 \\ \text { Physical examination } & -0.26 & -0.15 & -0.22 \\ \text { Management } & -0.42^{*} & -0.39 & -0.12\end{array}$

$* 0<0.05$

We were also interested whether rheumatologists working experience interacted with the relevance of actions taken, as indicated by the key items and hence, were potentially more efficient in their practice performance. If this is the case, the ratio between scores on the key-items and scores on the total checklist should increase with more working experience. Figure 5.1 illustrates this ratio between scores on the key-items and total case scores, compared to the number of years of working 
experience as a rheumatologist. As can be seen, the slope is rather flat, meaning that with increasing working experience the ratio between score on the key-items and total case score remains about the same. Therefore, rheumatologists with more working experience do not perform better on the score on the key items.

Table 5.4 Mean scores for key items and total score (percentages) across all 8 cases for male and female rheumatologists and rheumatologists working in teaching or non-teaching hospitals

\begin{tabular}{|c|c|c|c|c|}
\hline \multirow[b]{2}{*}{ Different scores } & \multicolumn{2}{|c|}{ Gender } & \multicolumn{2}{|c|}{ Type of practice } \\
\hline & $\begin{array}{c}\text { Male } \\
(n=17)\end{array}$ & $\begin{array}{l}\text { Femaile } \\
(n=5)\end{array}$ & $\begin{array}{c}\text { Teaching } \\
\text { hospital } \\
(n=4)\end{array}$ & $\begin{array}{l}\text { Non teaching } \\
\text { hospital } \\
(n=18)\end{array}$ \\
\hline Case score an key items & 65 & 69 & 69 & 65 \\
\hline Medical history & 68 & 74 & 73 & 69 \\
\hline Physical examination & 66 & 62 & 71 & 64 \\
\hline Management & 62 & 67 & 62 & 63 \\
\hline Case total score & 54 & 57 & 58 & 54 \\
\hline Medical history & 58 & 62 & 64 & 57 \\
\hline Physical examination & 53 & 54 & 61 & 52 \\
\hline Management & 52 & 56 & 49 & 54 \\
\hline
\end{tabular}

$n=$ number of rheumatologists

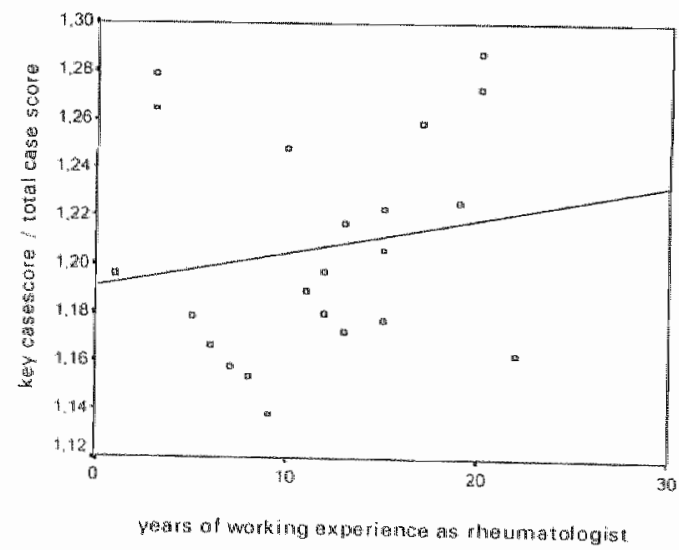

Figure 5.1 Ratio between score on the key-items and case total score, related to the number of years of working experience as a rheumatologist 


\section{Discussion}

Detailed information on real daily clinical performance of theumatologists was obtained by sending 16 incognito SPs presenting eight different rheumatological cases to 27 rheumatologists. The validity and reliability of this study was adequate. Compared to other studies with incognito SPS, a very low detection rate of $1 \%$ and high reliability of results was obtained. ${ }^{24}$ ${ }^{25}$ Although all checklists were developed to cover the whole consultation, enormous differences exist in mean scores of the cases presented as percentage of the maximum possible score. The difference between the case with the lowest mean score and the case with the highest mean score is $39 \%$.

A striking finding of our study was that rheumatologists with more working experience have significantly lower scores. They do or ask less with increasing experience. If these lower scores would implicate a more efficient way of consulting, one would expect that the ratio between case score on the key-items and total case score would increase. However, this was clearly not the case: the ratio between both scores remained about the same. More experience does not seem to lead to more efficient performing practice.

The phenomenon that physicians do less with increasing experience is, maybe ironically to some, called expertise. Schmidt and colleagues explain the phenomenon of experienced physicians doing less by saying that "experts rapidly and routinely recognize the nature of a problem, because it is similar to previous cases". ${ }^{27}$ Literature on assessment of medical competence shows similar results where novices performing better on written competence tests than experienced physicians. ${ }^{9.10}$ Our finding that experienced physicians perform fewer items in daily practice is very interesting, since it is has now been shown that this also holds for actual practice behavior.

It is difficult to explain why more experienced physicians do not perform relatively more on the key-items. Physicians might develop expertise in their own way, depending on their training and individual experience in an idiosyncratic way. Therefore, it unfortunately is difficult to predict how they will perform on a certain case. ${ }^{27}$

This study also resulted in detailed information on rheumatologists' real daily practice behavior in outpatient clinics. The results on real clinical practice behavior of the different cases are a valuable source for discussions among small groups of rheumatologists. The process of discussing data on real practice behavior will stimulate participants more to change practice behavior (if needed) when it concerns information on one's own performance. ${ }^{28}$ Changing physician performance by traditional and 
widely used continuing medical education activities such as conferences have proven to have little impact on improving professional practice. ${ }^{29}$ We also know that guidelines based on scientific evidence not always are successful in changing actual performance. ${ }^{15}$ We therefore propose that the results of this method of assessing real practice performance with incognito SPs should be discussed in small groups of professionals. This information could then be used for discussions on good clinical practice and be useful to assure and improve quality in the delivery of care. 


\section{References}

1. Wennberg J, Gittelsohn A. Variations in medical care among snell areas. Scl Am 1982;246: 100-1.

2. Westert GP, Nieboer AP, Groenewegen PP, Variation in dutrton of hogptat stay batwean hospitals and between doctors within hospitals. Soc Sci Med $1993 \cdot 37: 933-9$.

3. Keller RBB, Largay AM, Soule DN. Manchester ME, KatZ JN, Boston MA. Matria Earpat tunnel study: small area variations. J Hand Surg 1998;23A:692-6.

4. Bamji AN, Dieppe PA, Haslock DI, Shipley ME. What do theumatologists do 7 A pitot audit study. Br J Rheumatal 1990;29:295-8.

5. Rethans $J J$, Saebu L. Do general practitioners act consistenth in real practice when they meet the same patient twice? Examination of intradoctor variation using standardised (sinulated) patients. BMJ 1997;314:1170-3.

6. Roberts J, Norman G. Reliability and learning from the objective structured chinicat examination. Med Educ 1990;24:219-23.

7. Westert GP, Groenewegen PP. Medical practice variations: changing the theoretical approach. Scand J Public Health 1999;27:173-80.

8. Eddy DM. Variations in physician practice: the role of uncertainty. Health affairs. 1984:74-89.

9. Norcini JJ, Lipner RS, Benson JA, Webster GD. An analysis of the knowledge base of practicing internists as measured by the 1980 recertification examination. Ann Inten Med $1985 ; 102: 385-9$

10. Ramsey $P G$, Carline JD, Inui $T S$, et al. Changes over time in the knowledge base of practicing internists. JAMA 1991;266:1103-7.

11. Ram P, Groll R, van den Hombergh P, Rethans JJ, van der Vleuten $C$, Aretz K. Structure and process: the relationship between practice management and actual clinical performance in general practice. Fam Pract 1998;15:354-62.

12. DeSalvo KB. Bowdish BE, Alper AS, Grossman DM. Merrill WD. Physician practice variation in assignment of return interval. Arch Intern Med 2000; 160:205-8.

13. Keller RB, Soule DN, Wennberg JE, Hanley DF. Dealing with geographical variations in the use of hospitals. J Bone Joint Surg 1990;72-A:1286-93.

14. Langley GR, Salomon Minkin. Till JE. Regional variation in nonmedical factors affecting farmily physicians' decisions about referral for consultation. Can Med Assoc J $1997: 157: 265-72$.

15. Lomas J. Anderson GM, Domnick-Pierre K, Vayda E, Enkin MW, Hamnah WJ. Do practice guidelines guide practice? N Engl J Med 1989:321:1306 11.

16. Davis DA. Thomson MA, Oxman AD, Haynes RB. Changing physician performance. A systematic review of the effect of continuing medical education strategies. JAMA $1995: 274: 700-5$.

17. Barrows HS. An overview of the uses of standardized patients for teaching and evaluating clinical skills. A.AMC. Acad Med 1993;68:443-51.

18. wan der Vieuten C. Swanson D. Assessment of clinical sikills with standiardized patients: state of the art. Teach Learn Med 1990:2:58-76.

19. Ramsey PG. Curtis JR, Paauw DS, Carline JD. Wenrich MD. History-taking and preventiwe medicine skills among primary care physicians: An assessment using standardizad patients. Am J Med 1998: 104:152-8.

20. Gorter S, Rethans J.J. Scherpbier A, et all. A review of methodologies in writing case specific checklists for standardized patient-based assessment in internal medicine. Acad Med 2000:75: 1130-7.

21. Gorter $S$, van der Linden $S$. Brauer J, et al. Rheumatologists' performance in daily practice. Arthritis Care Res 2001;45:16-27. 
22. Gorter SL, Rethans J.J, Scherpbier AJJA, et al. How to introduce incognito standardized patients into outpatient clinics of specialists in rheumatology. Med Teach 2001:23:138. 44.

23. SPSS 10.0 fprograml. SPSS 10.0 version. Chicago: SPSS incorporated, 2000.

24. Tamblyn $R$, Berkson L, Dauphinee WD et al. Unnecessary prescribing of NSAIDs and the management of NSAID-related gastropathy in medical practice. Ann Intern Med $1997 ; 127: 429-38$.

25. Day AP. Hewson MG, Kindy P, Jr., Van Kirk J. Evaluation of resident performance in an outpatient internal medicine clinic using standardized patients. I Gen Intern Med 1993:8:193-8.

26. Dolan NC MMDM. Using unidentified standardized patients to evaluate housestaff delivery af preventive services. Teach Learn Med 1997:9:60-5.

27. Schmidt HG, Norman GR, Boshuizen HPA. A cognitive perspective on medical expertise: theory and implications. Aced Med 1990;65:611-21.

28. Rethans J-J. Meeds assessment in continuing medical education through standardized patients. J Cont Educ Health Profess 1998;18:172-8.

29. Davis $D$, Thomson O'Brien MA, Freemantle $N$, Wolf FM, Mazmanian P, Tayior-Vaisey A. Impact of formal continuing education. Do conferences, workshops, rounds and other traditional continuing education activities change physician behavioi or health care outcomes? JAMA 1999;282:867-74. 


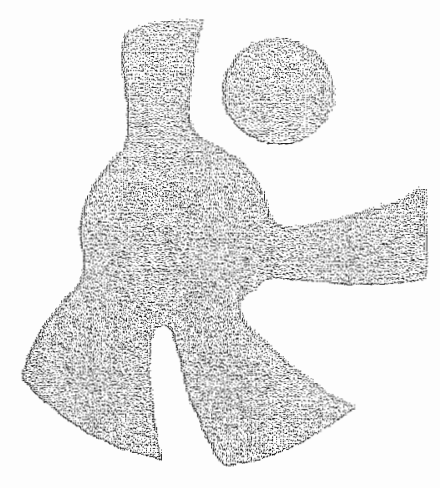

Psoriatic arthritis: Performance of rheumatologists in daily practice. A study with incognito standardized patients

Simone Gorter, Désirée van der Heijde, Sjef van der Linden, Harry Houben, Jan-Joost Rethans, Albert Scherpbier, Cees van der Vleuten

Annals of the Rheumatic Diseases 2002;61:219-24 


\section{Abstract}

Objectives.To assess, using standardized patients ISPs). how rheumatologists diagnose psoriatic arthritis, whether the diagnostic efficiency is influenced by specific characteristics of the rheumatologists, and to study the relationship with costs.

Methods. Twenty three rheumatologists were each visited by one of two SPs (one male, one female) presenting as a patient with psoriatic arthritis. SPS remained incognito for all meetings for the duration of the study. Immediately after the encounter. SPs completed case-specific checklists on the medical content of the encounter. Information on ordered laboratory and imaging tests was obtained from each hospital.

Results. Fourteen rheumatologists diagnosed psoriatic arthritis correctly. They inspected the skin for psoriatic lesions more often than those rheumatologists who established other diagnoses. Rheumatologists diagnosing psoriatic arthritis spent more costs on additional laboratory and imaging investigations. These were carried out after the diagnosis to confirm it and to record the extent and severity of the disease. No differences in type of practice, number of outpatients seen each week, working experience, or sex were found between rheumatologists who made the correct diagnosis and those who made other diagnoses. The correct diagnosis was more often missed by rheumatologists who saw the male SP, who presented with clear distal interphalangeal DIP joint arthritis only, causing confusion with osteoarthritis of the DIP joints.

Conclusion. There is a considerable amount of variation in the delivery of care among rheumatologists who see an SP with psoriatic arthritis. Rheumatologists focusing too much on the most prominent features IDIP joint arthritis) sometimes seem to forget "the hidden (skin) symptoms". 


\section{Introduction}

Psoriatic arthritis can be a diagnostic challenge to theumatologists because it may resemble rheumatoid arthritis and osteoarthritis in its presentation. For a correct diagnosis demonstration of psoriatic skin lesions, which may be found nat only at evident sites such as elbows or knees but may also be hidden at the scalp, the anal cleft or the umbilicus is important. Litule is known about the diagnostic and management skills of theumatologists in daily practice for patients presenting with psoriatic arthritis. Health authorities, the medical community, and society increasingly emphasize the need to obtain insight into the way doctors diagnose and treat medical conditions. The rheumatological community could use the information on daily practice behavior to increase their diagnostic and therapeutic elficiency and possibly, also, to save resources. The information could additionally be used to develop guidelines to improve quality in the dellivery of care and patient outcome. Consensus conferences and discussions on good clinical practice organized to develop guidelines have so far not resulted in changes of doctors' practice behaviour. 'Guidelines, tailored to real daily practice performance will probably be more effective. ${ }^{2}$

Medical conditions such as psoriatic arthritis may give rise to a substantial variation in clinical practice and use of diagnostic tests, and hence in costs. It is difficult to determine how doctors really perform in their meetings with patients because they may increase their efforts once they know they are being observed. The use of standardized patients (SPs) - real patients or healthy people who play the part of a patient in a consistent way in meetings with various doctors who are unaware of the simulation - has been advocated so that actual practice behavior can be assessed unobtrusively. ${ }^{3,4}$

This paper is part of a langer study that aims at assessing variation in rheumatologists" performance in daily practice for eight different rheumatological disorders. ${ }^{5}$ The paper on all eight disorders will give only an aggregated overview. In contrast, the purpose of this report is to assess, using SPS, how rheumatologists diagnose psoriatic arthritis, whether the diagnostic efficiency is influenced by specific characteristics of the rheumatologists, and the relationship with costs. By selecting one case, data can be presented in detail giving individual theumatologists the opportunity to compare their own policy for psoriatic arthritis with that of the other theumatologists participating in the study. 


\section{Methods}

\section{Subjects}

In the larger study, 16 incognito SPs presenting eight different roles resembling a rheumatic disease visited Dutch rheumatologists. One and a half-year before the first SP entered the practice, 116 of all 127 Dutch rheumatologists were asked to participate. The remaining 11 rheumatologists participated in this study by developing the checklists that were used to register the visits of the SPS or in the preparative training sessions with the SPs. In addition, some of them searched among their own patients for people who were suitable and willing to be an SP in our project. Fifty-seven (49\%) of all invited rheumatologists, gave written consent. For logistical reasons only 27 were selected for the incognito visits. Hospital boards of directors consented. Twenty-three rheumatologists were visited by one of the two SPs presenting with a case of psoriatic arthritis. The study protocol for this case did not allow followup visits.

\section{Case}

The case was based on a real presentation on the outpatient ward of our hospital and was somewhat adjusted to the two real patients recruited to play the part. These patients were treated by two Dutch rheumatologists for psoriatic arthritis. They comprised a 55 year old male patient who had had swollen distal interphalangeal (DIP) joints for two years and psoriatic lesions at umbilicus, scalp and anal cleft, and a 47 year old female patient with raised erythrocyte sedimentation rate (ESR), a history of DIP arthritis six months before, tendinitis and carpal tunnel surgery. She had psoriatic lesions at umbilicus, scalp and anal cleft as well. Family history for psoriasis was positive, but negative for early onset osteaarthritis for both patients. Patients were told to present the joint problems, and not to mention the psoriatic lesions spontaneously. Whenever a rheumatologist ordered hand films, the radiograph for the female patient was completely normal, whereas the radiograph for the male patient showed abnormalities (Figure 6.1). Although the two patients were not completely comparable, the main goal of the case- that is, finding the psoriatic lesions by a thorough physical examination and hence diagnosing psoriasis, was the same. 


\section{Training}

The two SPs were trained together to play the part and score a checklist on the doctor's performance consistently. The SPs' presentations were judged to have sufficient face validity by four rheumatologists who participated in the training sessions. During the training sessions close attention was paid to a realistic presentation, and reliability in scoring the checklist was assessed. ${ }^{\sigma}$

\section{Checklists}

Information on the content of the meeting with the theumatologist was abtained by the predefined case-specific checklist completed by each SP after the consultation had taken place. ${ }^{6}$

A panel of 11 rheumatologists developed the checklist covering the whole consultation. It comprised 61 items, of which 22 related to medical history. 25 to physical examination, and 14 to management (Table 6.1). Immediately after the consultation the SPs indicated whether the item had taken place or not. SPS had consented to keep all information obtained during the visits confidential.

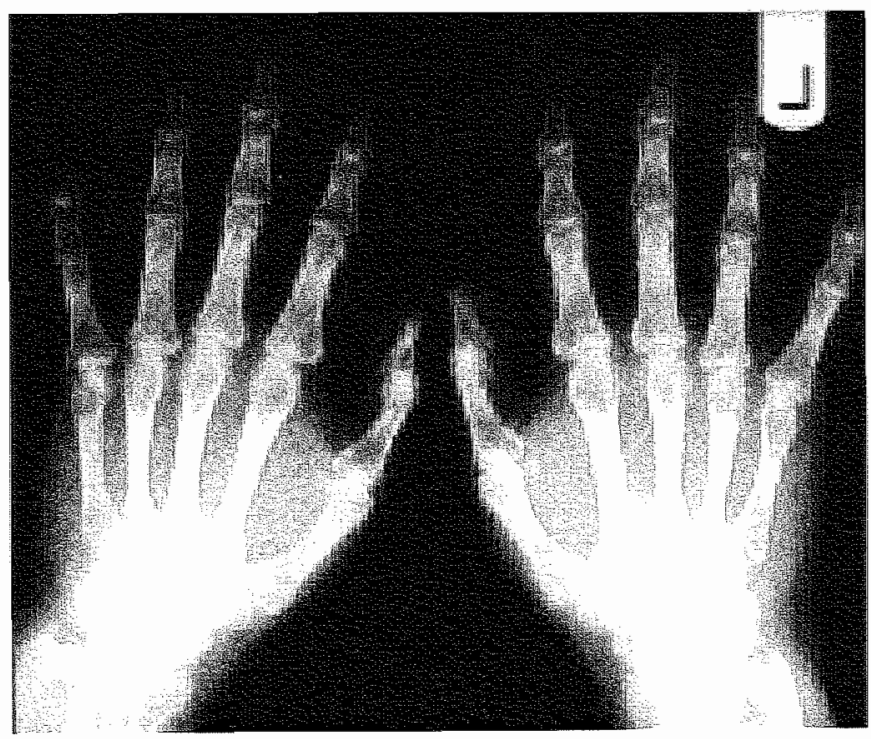

Figure 6.1 Radiograph of the hands of the male patient 


\section{Costs for laboratory and imaging investigations}

Information on ordered laboratory and imaging tests was obtained from each hospital. Costs for these tests were calculated for each visit by adding the Dutch national fares for the ordered investigations. Costs are presented in Euro.

\section{Practice visits}

Arrangements were made with the participating hospitals to keep the SPs incognito. Ordered studies such as laboratory tests and reports of radiological examinations as well as real radiographs were simulated and received by the rheumatologist in the usual way for that hospital. We assumed validity as long as the SPs stayed under cover. Rheumatologists were asked to complete a detection form when suspecting a patient of being an SP. A detailed description on the methods followed has been published elsewhere.?

\section{Statistics}

Different scores were calculated for each meeting. The total case score is the total number of items performed on the whole checklist. Separate 90 scores were calculated for the medical history, physical examination and management sections of the checklist. All scores are presented as percentages of the maximum score possible. All data are presented as descriptive statistics. Because of the relatively small numbers of encounters, the study has not sufficient power to yield statistically significant differences. Owing to the enormous logistics involved, it was not feasible to increase the number of meetings.

\section{Results}

Table 6.2 presents rheumatologists' background characteristics. No encounters were unmasked by the rheumatologists. Two follow-up visits took place, because the SP was asked to reattend to discuss the diagnosis, and this was critical for evaluation of the results. The information about this secand visit was supplementary to the first visit, so a final score was calculated for both visits together.

Fourteen theumatologists diagnosed psoriatic arthritis, five diagnosed osteoarthritis as the only disorder, one a combination of osteoarthritis and psoriasis and three rheumatologists did not mention any diagnosis. Table 6.3 shows the most important differences in performance for those who 
Table 6.1 Checklist items

\begin{tabular}{|c|c|c|}
\hline Medicall history & Physical examination & Management \\
\hline Onset of disease & $\begin{array}{l}\text { Physical examination of } \\
\text { internal organs }\end{array}$ & $\begin{array}{l}\text { Told the patient helshe } \\
\text { probably has psoriasis }\end{array}$ \\
\hline $\begin{array}{l}\text { Course of symptoms during } \\
\text { the day }\end{array}$ & linspection of hands & $\begin{array}{l}\text { Told the patient he/she } \\
\text { probably has psoratic arahritis }\end{array}$ \\
\hline $\begin{array}{l}\text { Course of symptoms since } \\
\text { onset }\end{array}$ & Inspection of feet & $\begin{array}{l}\text { Told the pationt he/she has } \\
\text { osteoarthritis }\end{array}$ \\
\hline Red or swollen joints & $\begin{array}{l}\text { Palpation of hands, } \\
\text { wrists }\end{array}$ & $\begin{array}{l}\text { Explained the disorder psoriatic } \\
\text { arthritis }\end{array}$ \\
\hline Complaints in other joints & Pallpation of ankles & Explained the disorder psoriasis \\
\hline Squamous scalp skin & Palpation of feet & $\begin{array}{l}\text { Prescribedi drugs } \\
\text { If Yes, what kind of drugs? }\end{array}$ \\
\hline Presence of psoriasis & Palpation of finger joints & Referral to dermatologist \\
\hline $\begin{array}{l}\text { Presence of psoriasis in } \\
\text { relatives }\end{array}$ & $\begin{array}{l}\text { Tangential pressure on } \\
\text { hands and asking for } \\
\text { pain }\end{array}$ & Ordered laboratory tests \\
\hline $\begin{array}{l}\text { Discoloration of hands and } \\
\text { feet when using cold water }\end{array}$ & Active flexion of wrists & Ordered imaging tests \\
\hline Morning stiffness & $\begin{array}{l}\text { Active extension of } \\
\text { wrists }\end{array}$ & $\begin{array}{l}\text { Requested SP attended for } \\
\text { follow-up }\end{array}$ \\
\hline Presence of nail pits & $\begin{array}{l}\text { Active abduction of fore } \\
\text { arm }\end{array}$ & $\begin{array}{l}\text { Gave written information about } \\
\text { the disease }\end{array}$ \\
\hline Low backpain & $\begin{array}{l}\text { Active adduction of fore } \\
\text { arm }\end{array}$ & $\begin{array}{l}\text { Sufficiently discussed the } \\
\text { prognosis of the disease }\end{array}$ \\
\hline Eye inflammation & Active flexion of fingers & $\begin{array}{l}\text { Drew attention to the society } \\
\text { of patients with rheumatic } \\
\text { diseases and mutual support } \\
\text { groups }\end{array}$ \\
\hline Intestinal complaints & $\begin{array}{l}\text { Active extension of } \\
\text { fingers }\end{array}$ & \\
\hline Oral ulceration & Spreading of fingers & \\
\hline Current drug use & Active fist making & \\
\hline Dintary habits & $\begin{array}{l}\text { Passive examination of } \\
\text { hands and wrists }\end{array}$ & \\
\hline Alcoholic consumption & $\begin{array}{l}\text { Muscle resistance tests } \\
\text { of hands and wrists }\end{array}$ & \\
\hline Aggravating factors & Squeeze doctor's finglers & \\
\hline Ameliorating factors & $\begin{array}{l}\text { Opposing thumb to } \\
\text { fingers }\end{array}$ & \\
\hline $\begin{array}{l}\text { Influence of complaints on } \\
\text { daily activities }\end{array}$ & $\begin{array}{l}\text { Examination of other } \\
\text { joints }\end{array}$ & \\
\hline Family history & $\begin{array}{l}\text { Inspection for skin } \\
\text { abnormalities } \\
\text { Inspection for tofi } \\
\text { Inspection for psoriasis } \\
\text { on specific locations } \\
\text { Scalp } \\
\text { Elbows } \\
\text { Umbilicus } \\
\text { Anal cleft } \\
\text { Knee } \\
\text { Inspection for noduli }\end{array}$ & \\
\hline
\end{tabular}


Table 6.2 Rheumatologists' background characteristics $(n=23$ )

Dutch rheurna

Age wearsh, mean

Working experience (years).

median

Fonale

Male

Traching hospital

Non teaching hospital

Median number of outpatients

each week (range)
40

(SD 6.5, range 34,611

12

(range $1-22$ )

5

18

4

19

111

(12-300)
46

(50 7.0. range 34-62)

*

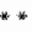

*information not available, * in 2001: females: 54 , males: 116

made the correct diagnosis (psoriatic arthritis) and those who made another diagnosis. The cut off point for inclusion in the table was a difference in occurrence of at least $15 \%$. In the following section the performance of the theumatologists is described in more detail.

\section{Description of rheumatologists' performances}

The total case score for all rheumatologists ranged from $35 \%$ to $68 \%$ (Table 6.4). The mean total case score for rheumatologists who diagnosed psoriatic arthritis was $56 \%$, compared with $47 \%$ for those rheumatologists who made a different diagnosis. This difference was mainly caused by the difference in the management score.

All rheumatologists asked about the cause of the symptoms and all except one about arthritis in other joints, whereas $17 / 23$ asked about the presence of psoriasis. Rheumatologists with the incorrect diagnosis less commonly asked about psoriatic lesions, but they asked more often about inflammation of the eyes and any influence of complaints on daily activities.

A physical examination of the internal organs. including auscultation of heart and lungs and an abdominal examination, was done by $13 / 23$. In the opinion of the SPs $16 / 23$ thoroughly inspected patient's skin for psoriatic lesions. Twenty one of the 23 rheumatologists examined other joints as well. Rheumatologists who made the diagnosis psoriatic arthritis inspected the skin more often, especially at places specific for psoriasis.

Eleven of 23 rheumatologists informed the patient at the first visit about the nature of the disease and four of them provided the SP with written educational materials on psoriatic arthritis. Six rheumatologists prescribed medications ffour prescribed non-steroidal anti-inflammatory drugs (NSAIDs), one acetaminophen and one glucosaminel. The last prescription 
was changed after the rheumatologist had seen the radiograph and the preliminary diagnosis of osteoarthritis was changed to psoriatic arthritis. Three of 14 meumatologists who made the correct diagnosis prescribed NSAIDs, compared with $1 / 9$ rheumatologists who made a diagnosis other than psoriatic arthritis.

Table 6.3 Items showing most remarkable differences between 23 rheumatologists with diagnosis psoriatic arthritis and the other diagnosis

\begin{tabular}{|c|c|c|c|}
\hline & All rheumatologists & $\begin{array}{c}\text { Rheumatologists } \\
\text { with correct } \\
\text { diagnosis } \\
n=14(\%)\end{array}$ & $\begin{array}{l}\text { Pheumatologists } \\
\text { with other } \\
\text { diagnosis } \\
n=9(\%)\end{array}$ \\
\hline \multicolumn{4}{|l|}{ Medical history } \\
\hline Squamous scalp sikin & $14\{611$ & $11(73)$ & $3(33)$ \\
\hline $\begin{array}{l}\text { Presence of psoriasis in } \\
\text { relatives }\end{array}$ & $13(57)$ & $9(64)$ & $4(44)$ \\
\hline Eye inflammation & $8(35)$ & $4(29)$ & $4\{44\}$ \\
\hline Alcoholic consumption & $15[65\}$ & $8(57)$ & $7(77)$ \\
\hline $\begin{array}{l}\text { Influence of complaints on } \\
\text { daily activities }\end{array}$ & $15\{65\}$ & $7(50)$ & $8(88)$ \\
\hline \multicolumn{4}{|l|}{ Physical examination } \\
\hline $\begin{array}{l}\text { Inspection for skin } \\
\text { abnormalities }\end{array}$ & $17174 \mathrm{H}$ & $12(86)$ & $5(55)$ \\
\hline $\begin{array}{l}\text { Inspection for psoriasis on } \\
\text { specific locations }\end{array}$ & $16(70)$ & $12 \mid 86 \|$ & $4(44)$ \\
\hline Knees/elbows & $9(39)$ & $8(57)$ & $1(11)$ \\
\hline Scalp & $13(57)$ & $10(71)$ & $3(33)$ \\
\hline Umbilicus & $13(57)$ & $11(73)$ & $2(22)$ \\
\hline Anal cleft & $7(30)$ & $5(36)$ & $2(22)$ \\
\hline Knee & - & $\sim$ & - \\
\hline \multicolumn{4}{|l|}{ Management } \\
\hline Ordered laboratory tests & 18178 & $12(86)$ & $6(66)$ \\
\hline Ordered radiology tests & $17(74)$ & $12(86)$ & $5(55)$ \\
\hline Requested SP for follow-up & $18(78)$ & $13(93)$ & $5(55)$ \\
\hline
\end{tabular}

Table 6.4 Mean (SD) scores on checklist as percentage of maximum score possible

Different checklist scores

Different chacklist scores
All rheumatologists Rheumatologists

(SD) drange with correct diagnosis. (SO) (rangel $n=14$
Riheumatologists with other diagnosis (SD) lrangell

$$
n=9
$$

Total case scare

Medicall history

Physical examination

Management
$52(8.8) \llbracket 35-68 \|$

$64(12)|35-68|$

$41(15)(0-68)$

55 (22) [20.90]
$56(6.8)[46-68)$

$64(13)$ [41-86]

$44(10)$ [24-68]

69 (13) [50-90!
$47(8.7)(35-60)$

$64(9.9)|55-86|$

$37(20)(0-68)$

$33(13)|20.50|$ 
Six of 14 rheumatologists who made the correct diagnosis referred the SP to a dermatologist for confirmation of psoriasis, compared with none of the rheumatologists who made a different diagnosis. They also more often requested the SPs to attend for follow-up.

The number of rheumatologists who ordered radiographs differed, but most strikingly in the number and type of radiographs ordered. Rheumatologists who made an alternative diagnosis restricted the request to hand films only, except for one who also ordered a pelvic $x$ ray examination. In contrast the rheumatologists who diagnosed psoriatic arthritis asked for a wide range of films (Table 6.5).

Table 6.5 Resource utilization: imaging tests and costs

No imaging tests

$X$ Rhay examination of:

hainds

thands + feet

hands + lumbar spine

hands + pelvis

hands + feet + Sl joints

hands + lumbar spine + Si joints

hands + lumbar spine + pelvis

hands + feet + lumbar spine th

Sl joints

hands + feet + llumbar spine +

Sl joints + shoulders +

knees

Total costs in euros

Marat

Median

Renge

All rheumatolo
\[ (n=23) \]

6

8

2

1

4

1

1

1

1

1

120
86
0.479

164

171

$0-479$
52

86

0.123

Laboratory tests were ordered by $12 / 14$ rheumatologists who made the diagnosis psoriatic arthritis compared with 6/9 rheumatologists who made a different diagnosis. Table 6.6 presents the laboratory tests ordered by both groups. Large differences were seen, especially for the ESR, red blood count, and liver function tests. Rheumatologists with the correct diagnosis ordered more of these tests.

The median costs for imaging tests in euros for the "psoriatic arthritis" group was 171 compared with the median costs of the remaining rheumatologists of 86 . Difference in costs also existed for laboratory investigations ordered during the first visit. The median costs for these tests for rheumatologists with the correct diagnosis were 21, and for the 
Table 6.6 Use of resources: laboratory tests ordered by at least 3 rheumatologists and costs

\begin{tabular}{|c|c|c|c|}
\hline Laboratory test & All rheumatologists & $\begin{array}{c}\text { Rheumatologists } \\
\text { with correct } \\
\text { diagnosis } \\
(n=14)\end{array}$ & $\begin{array}{l}\text { Phoumatologists } \\
\text { with other } \\
\text { diagnosis } \\
(n=9)\end{array}$ \\
\hline ESR & 16 & 12 & 4 \\
\hline Creatinine & 15 & 10 & 5 \\
\hline Haemoglobin & 14 & 11 & 3 \\
\hline Leucocytes & 13 & 11 & 2 \\
\hline ALT & 10 & 9 & 1 \\
\hline AP & 10 & 8 & 2 \\
\hline CRP & 9 & 6 & 3 \\
\hline Thrombacytes & 9 & 7 & 2 \\
\hline Erythrocytes & 8 & 7 & 1 \\
\hline Mean cell volume & 8 & 7 & 1 \\
\hline Differentiation & 8 & 6 & 2 \\
\hline Fheumatoid factor & 8 & 6 & 2 \\
\hline ANA/ANF & 8 & 5 & 2 \\
\hline AST & 7 & 6 & 1 \\
\hline TSH & 7 & 5 & 2 \\
\hline Calcium & 7 & 5 & 2 \\
\hline Gamma GT & 6 & 4 & 2 \\
\hline Glucose & 5 & 3 & 2 \\
\hline LD & 3 & 3 & - \\
\hline Phosphate & 3 & 2 & 1 \\
\hline Free-T4 & 3 & 3 & - \\
\hline ck & 3 & 2 & 1 \\
\hline Uric acid & 3 & 2 & 1 \\
\hline Ferritin & 3 & 1 & 2 \\
\hline HLA B27 & 3 & 2 & 1 \\
\hline \multicolumn{4}{|l|}{ Total costs in euros } \\
\hline Mean & 33 & 46 & 13 \\
\hline Median & 12 & 21 & 9 \\
\hline Range & $0-163$ & 0.163 & 0.51 \\
\hline
\end{tabular}

ESR, Erythrocyte sedimentation rate; $A L T$, alanine arminotransterase; $A P$, alkaline phosphatase: CRP, C reactive protein; ANA/ANF, antinuclear antibody/ antinuclear factor; AST, aspartate aminotransferase: TSH, thyroid stimulating hormone; gamma GT, gammaglutemyl transterase: LDH, lactate dehydrogenase; TA, thyroxine: $C k$, creatine kinase.

remaining rheumatologists 9 . Figure 6.2 presents the costs for the additional investigations for each rheumatologist.

No difference in mean score of the whole checklist was seen for rheumatologists whether visited by the male or the female patient (mean for both female and male SP: $53 \%$ ). However, those rheumatologists who were visited by the female patient had a higher mean score for the medical history section (68\% versus $59 \%$ ), but somewhat lower scores for physical examination $(39 \%$ versus $44 \%)$ and management $(53 \%$ versus $58 \%)$. Rheumatologists visited by the male patient less frequently asked about psoriasis among relatives, and less often inspected the umbilicus and anal 
cleft. More of them inspected the scalp. Six of 12 rheumatologists visited by the male patient diagnosed psoriatic arthritis compared with $8 / 11$ of those visited by the female patient.

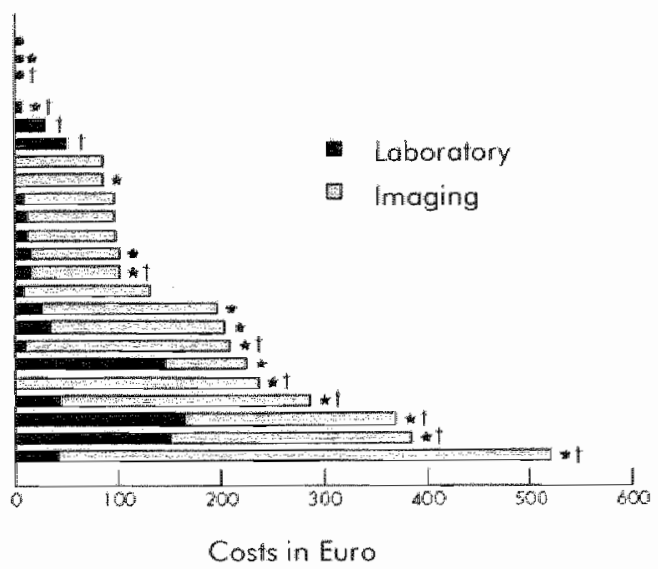

Figure 6.2 Rheumatologists" costs spent for additional investigations

Every bar represents one rheumatologist; three rheumatologists (black circles) did not orderany additional investigations. * rheumatologists who diagnosed psoriatic arthritis; ' rheumatologists visited by a female patient.

Five rheumatologists diagnosed osteoarthritis for the male patient and none for the female patient. Striking differences in investigations requested were seen, especially in the radiographs ordered. Ten rheumatologists visited by the male patient ordered hand films alone and two ordered additional feet films, whereas $7 / 11$ rheumatologists visited by the female patient ordered a large variety of radiographs. The median costs in euros spent by those rheumatologists visited by the male patient were 97 (laboratory 9 , imaging 86) and for those visited by the female patient 209 (laboratory 29, imaging 200). Rheumatologists who made the correct diagnosis have a median working experience of 12 years and saw a median of 110 outpatients each week, which is about the same as those who made another diagnosis. Four of five female rheumatologists and $10 / 18$ male rheumatologists made the correct diagnosis. Two of four rheumatologists working in a teaching hospital and $12 / 19$ working in non-teaching hospital diagnosed psoriatic arthritis correctly. 


\section{Discussion}

Detailed information was obtained about the real daily clinical practice behavior of 23 Dutch rheumatologists. The validity of the data was assured because the SPs remained incognito for all meetings with the rheumatologists during the study. Reliability of the "patients" in performing their role and in scoring of the checklist was sufficient and has been reported extensively elsewhere. ${ }^{\text {? }}$

The results on the checklist items show a considerable amount of variation in performance between rheumatologists, and only a few items were performed by all of them. The checklist is process oriented and used in a non-normative way. The variation in scores among rheumatologists reflects a difference in number of items performed during the consultation. Higher checklist scores do not of themselves mean that these rheumatologists are of a higher standard. A large variety of imaging tests and laboratory tests were ordered. As a consequence, costs for these investigations varied enormously among rheumatologists.

Rheumatologists who diagnosed psoriatic arthritis had higher scores on the checklist than rheumatologists who made another diagnosis because the checklists were tailored to diagnose psoriatic arthritis. The main difference was that the rheumatologists diagnosing psoriatic arthritis inspected the skin at locations specific for psoriasis lesions twice as often as the other rheumatologists, who did not seem to pay attention to these locations. Most of the rheumatologists who did not establish the correct diagnosis told the patients that they had osteoarthritis. In our opinion, this differential diagnosis is, to some extent, understandable because both patients presented with DIP joint problems and in the male patient this was the only presenting symptom.

The male SP visited all five rheumatologists who diagnosed osteoarthitis. They based their diagnosis of osteoarthritis solely on the clinical presentation of the complaints, because radiographs and laboratory tests were ordered only after the diagnosis. Hand films of the malle patient (Figure 6.1) do not show any osteophytes or other specific clues for osteoarthritis, but loss of cartilage, formation of cysts and erosions can clearly be seen. Although the radiological picture is not completely specific for the diagnosis psoriatic arthritis, we think that the combination of complaints, a positive family history for psoriasis and negative for osteoarthritis, does merit the diagnosis psoriatic arthritis for this 55 year old male patient. One rheumatologist who was visited by the male patient and who strongly requested him to attend for a follow-up visit to discuss the results of the hand films changed her initial diagnosis from osteoarthritis to psoriatic arthritis. We think that the rheumatologists should have noticed the psoriasis lesions and at least mentioned psoriasis as a separate diagnosis from osteoarthritis. Therefore, when a patient presents with DIP joint swelling, inspection for hidden skin signs is critical. 
Rheumatologists with the diagnosis psoriatic arthritis spent more on additional laboratory and imaging tests. Almost all rheumatologists made the diagnosis at their first meeting with the patient. Therefore, these investigations were carried out to confirm the diagnosis or establish the extent and severity of the disease, and not primarily for diagnostic purposes.

To summarize, there is a considerable amount of variation in practice performance among rheumatologists visited by an SP presenting psoriatic arthritis. Rheumatologists focusing on striking features, in this case the DIP joint artrithis, sometimes seem to forget "the hidden (skin) symptoms". Rheumatologists making the correct diagnosis spend more on laboratory and imaging tests, which are not primarily intended for diagnostic purposes but to record the extent and severity of the disease. These detailed data on real practice performance on psoriatic arthritis should assist discussions about appropriateness of care and the development of general guidelines. The results can be used as a needs assessment tool for targeted continuing medical education programs whenever performance is substandard. 


\section{References}

1. Lomas J, Anderson GM, Domnick-Pierre K, Vayda E, Enkin MW, Hannah WJ. Do practice guidelines guide practice? $N$ Engl J Med 1989:321 1306-11.

2. Davis $D A$. Thamson MA, Oxman $A D$, Haynes $R B$. Changing physician performance. $A$ systematic review of the effect of continuing medical education strategies. JAMA $1995: 274: 700-5$.

3. Barrows HS. An overview of the uses of standardized patients for teaching and evaluating clinical skills. AAMC. Acad Mled 1993;68:443-51.

4. Rethans JJ, Westin $S$, Hays R. Methods for quality assessment in general practice. Fam Pract 1996:13:468-76.

5. Gorter S, van der Lindien S, Brauer J, van der Heijde D, H. H. Rethans J-J, et al. Rheumatologists' performance in daily practice. Arthritis Care Res 2001:45:16-27.

6. Gorter S, Rethans $\mathfrak{J} . J$, Scherpbier A, van der Heijde D. Houben H, Vleuten van der $C$, et all. A review of methodologies in writing case specific checklists for standardized patientbased assessument in internal medicine. Acad Med 2000;75:130-7.

7. Gorter S, Rethans $J$ J, Scherpbier $A$, van der Linden $S$, van Santen-Hoeufft, wan der Heijde $D$ et al. How to introduce incognito standardized patients into outpatient clinics of specialists in rheumatology. Med Teach $2001 ; 23: 138-44$. 


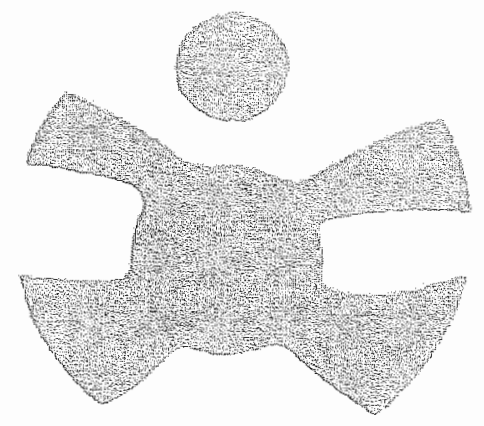

Reproducibility of clinical performance assessment in practice using incognito standardized patients

Simone Gorter, Jan-Joost Rethans, Désirée van der Heijde, Albert Scherpbier, Harry Houben, Cees van der Vleuten, Sjef van der Linden

Medical Education 2002;36:827-32 


\section{Abstract}

Background. The reproducibility of authentic assessment methods has been investigated for objective structured clinical examinations (OSCEs) and video assessment in general practice, but not for assessment with incognito standardized patients.

Purpose. To investigate the reproducibility of assessment with incognito standardized patients.

Method. A total of 27 Dutch rheumatologists in 16 hospitals were each visited by eight incognito standardized patients presenting with different rheumatological disorders. After each visit, the standardized patient completed a case-specific checklist containing items on medical history, physical examination and management. Over a 20-month periad, 254 incognito visits took place, of which 201 were first visits. The standardized patient was detected by the rheumatologist in 2 cases onlly. These encounters were not included in the analysis. Generalizability theory was used to investigate the reproducibility of the assessment.

Results. One fifth of the variance can be attributed to variation between rheumatologists. The largest variance is due to the variation in difficulty among cases. A reproducible assessment requires 3 hours of testing time (6 cases) if it is obtained through a norm referenced interpretation of scores and 7 hours of testing time (14 cases) if it is obtained through an absolute interpretation of scores.

Conclusion. The reproducibility of performance assessment in clinical practice by incognito standardized patients is similar to that of other authentic measurements for the assessment of clinical competence and performance. 


\section{Introduction}

Research and development concerning assessment of clinical competence have been characterized by increasing efforts to design methods of authentic assessment. ${ }^{1}$ The success of the objective structured clinical examination (OSCE) and its widespread use are due to the combination of authenticity and standardized test taking conditions. ${ }^{2}$ The OSCE, however, provides an indirect measure of performance only "because it involves simulated clinical encounters and represents an abstraction from the real clinical situation. ${ }^{3}$ It still requires extrapolation from test condition to the real world. In terms of Miller's competence pyramid, the OSCE does not bridge the gap between 'showing how' under artificial test conditions and actually "doing' in daily clinical practice. ${ }^{5}$ There is evidence of discrepancies between 'competence' ('what a doctor is capable of doing') and "performance' ('what a doctor does in daily practice"). ${ }^{6}$ Apparently, even the authentic OSCE requires extrapollation from test conditions to real world conditions, thereby detracting from the validity of the measurement. Less extrapolation would be necessary if assessment could be performed by unobtrusive or unnoticed direct observation and measurement of doctors' performances in daily practice.

The potential difficulty in assessment in daily clinical practice lies in the inherent non-standardized nature of test conditions. Patient case-mix poses an almost insurmountable difficulty with assessment in actual clinical practice. It has been identified as one of the reasons for the hopeless unreliability of any conventional global rating by supervisors who evaluate actual clinical performance..$^{7.8}$ The lesson to be learned from all psychometric evaluations of clinical competence measurements is that sufficient sampling is necessary to achieve reproducible scores." It has consistently been demonstrated that the clinical context lcase content/ patient) is a dominant factor which affects the reproducibility of the measurement. This means that any type of measurement will require a large sample across clinical contexts. Other factors that affect reproducibility, such as examiner variability or variability caused by different patients playing the same role, are either less influential or can be neutralized through effective sampling in an efficient test design. ${ }^{10}$ Even the "objective" OSCE requires a large sample of stations, i.e. at least 4 hours of testing time, before minimally reproducible scores are obtained. "We therefore estimated that, with an appropriate sampling strategy, authentic assessment in clinical practice might well yield reproducible measurements. ${ }^{12}$ This is supported by recent evidence from a study by Ram and colleagues. ${ }^{13}$ In a study of video assessment of a random sample of 16 taped non-standardized consultations in general practice, Ram et al. 
obtained reproducibility coefficients of about 0.80 . Each consultation was rated by one rater and a different observer. Testing time was approximately 3 hours.

Another direct method for assessing performance in clinical practice is the incognito standardized patient method. ${ }^{14.15}$ This method makes use of standardized patients (SPS) who consult a doctor as if they were a real patient. Although the doctor is informed that an SP may show up at some time, he or she does not know when to expect them. The SPS are extensively trained to portray their clinical scenario in a highly standardized way. They have also been trained to score the doctor's performance on a checklist after the encounter. Incognito SP-based assessment provides a highly authentic evaluation of performance in daily practice. The standardization of the SP role may suggest some degree of artificiality, but studies have shown that doctors are unable to distinguish SPS from real patients. ${ }^{16}$ Not surprisingly, studies using incognito SPs typically report very low detection rates. ${ }^{17,18,20}$

In this study we investigated the reproducibility of incognito SP-based assessment. So far, studies on the reproducibility of this method have focused on SP consistency or SP accuracy in role-playing. ${ }^{21,22}$ To our knowledge, there are no published studies reporting an analysis of the overall reproducibility of incognito SP-based assessment involving repeated visits by different SPS portraying different cases. In light of the above discussion on the reproducibility of authentic methods, and the encouraging results of the video assessment method, we set out to determine the reproducibility of the incognito SP-based method. This study reports an analysis of a data set obtained from 22 Dutch rheumatologists, each of whom saw 8 different incognito SPs presenting with different clinical conditions. Each case was presented by one of two SPs who were specially trained to portray a specific case.

\section{Method}

\section{Subjects}

Out of a total of 127 Dutch rheumatologists, 116 were asked to participate. The remaining 11 rheumatologists were involved in the development of the study. They either participated in the development of the checklists for rating the visits or in the preparatory training sessions with the SPs. A total of $57(49 \%)$ of the invited rheumatologists gave written consent. For logistical reasons, 27 rheumatologists, spread throughout the Netherlands, were selected for participation in the study. Consent was obtained from the boards of the hospitals where the participating rheumatologists practiced. A total of 22 of the 27 
rheumatologists were each visited by 8 incognito SPs. Details of rheumatologists' characteristics have been published elsewhere. ${ }^{19}$

\section{Instruments}

Eight patient roles were developed (Table 7.1). Each case was based on a real patient who had presented in an outpatient ward of a university hospital. Sixteen SPs were recruited, and each role was portrayed by 2 SPS. Some SPS were real patients who presented their own stable rheumatological condition. All SPs were extensively trained to play their role consistently and to score the rheumatologist's performance accurately on a case-specific checklist. The face validity of the presentations of the cases by the SPs was judged to be sufficient by 4 rheumatologists. The SPs practiced checklist scoring using methods described elsewhere ${ }^{20}$ until an acceptable level of accuracy (85\% agreement) was achieved. Specific checklists were developed for each case by a panel of 11 rheumatologists. The number of items varied from 50 to 75 . The items asked for information on the medical content of the visit. Each list included items on history taking, physical examination and management. The panel also identified key items considered to be essential components of a rheumatologist's consultation on a particular case. On average the key items accounted for $55 \%$ of all items on a checklist. The SPs completed the checklist immediately after the consultation.

Table 7.1 Mean percentage scores and standard deviations of the rheumatologists' $(n=22)$ performances in each of the 8 cases

\begin{tabular}{lccc} 
& \multicolumn{2}{c}{ Case } \\
Lateral epicondylitis & Mean & Standard Deviation \\
Fibromyalgia & 49 & 16.0 \\
Ankylosing Spondvitis & 63 & 12.0 \\
Polymyalgiat heumatica & 54 & 10.0 \\
Rheumatoid arthritis & 73 & 10.0 \\
Hemochromatosis arthropathy & 34 & 9.4 \\
Psoriatic arthritis & 65 & 17.0 \\
Osteoporosis & 52 & 8.5 \\
& 46 & 9.8
\end{tabular}

\section{Procedure}

Each role was played by 2 SPs. The SPS were randomly allocated to the rheumatologists. No rheumatologist was visited by the same $S P$ twice, unless an appointment had been made for a follow-up visit. General practitioners from the area of the hospitals attended by the SPs participated 
in the study by writing referral letters to the rheumatologists for the SPS. The participating theumatologists were asked to complete a detection form if they suspected a patient of being an SP. We assumed validity as long as the SPs remained undetected. Arrangements were made with the participating hospitals to ensure that the SPS remained under cover. Results of additional investigations ordered for SPS by the rheumatologist, such as lab tests and reports of radiological investigations, as well as real radiographs were simulated and care was taken that the rheumatologist received these results in the manner customary for that hospital. A detailed description of the study methods and the feasibility of introducing incognito SPS in secondary care has been published elsewhere. ${ }^{20}$ In 2 cases SPS were unmasked. In both cases this was due to administrative mistakes rather than non-authentic patient portrayal. Appointments for follow-up visits were made in 53 consultations. The patient concerned kept the appointment and completed one checklist for both visits. In this way a total of 254 visits took place over the period between July 1998 and February 2000. It was estimated through logbook analysis that a consultation took about 30 minutes.

\section{Statistics / analysis}

For each case, the number of actions performed by the rheumatologist was scored on the predefined case-specific checklist. This number was expressed for each encounter as a percentage of the total number of actions listed on the checklist. This process was also carried out for essential key items. In this way, 2 percentage scores were calculated for every rheumatologist for each of 8 cases. The correlation between the overall score and the essential score was 0.97 . As this would inevitably vield very similar reproducibility estimates, it was decided to report the overall score only. The average case score was the mean score for an individual theumatologist across 8 cases.

We investigated the level of reproducibility using generalizability theory. ${ }^{23} \mathrm{~A}$ simple, all-random person-by-case design was used for estimating variance components. The design may have been slightly biased due to the fact that each role was played by 2 SPS. Differencies between SPs may have inflated the variance of the 'person' component. 'This confounding effect was not preventable. Reproducibility coefficients were estimated from the variance components using a norm-referenced perspective lgeneralizability coefficients) and a domain-referenced perspective (dependability coefficients) as functions of the number of cases. From a norm-referenced perspective, scores are valued relative to each other; from a domainreferenced perspective, scores are interpreted in an absolute manner. A reproducibility coefficient can be interpreted as the expected correlation 
with a hypothetical other measurement involving a random sample of different patients and cases, assuming that the scores are valued relative to each other (generalizability coefficient) or relative to an absolute standard (dependability coefficient).

\section{Results}

Due to unforeseen logistical problems (long waiting list, temporary stops on new patients, absence of referral letters, etc.) some consultations were unavallable for analysis. The results of all cases seen by 22 of the rheumatollogists were available and these were included in the analysis. Therefore, $176(8$ cases for each of the 22 rheumatologists) of the 201 first visits were included in the analysis. As results of follow-up visits were supplementary to those of first visits, the first and related follow-up visit were analyzed as one visit. Table 7.1 provides descriptive statistical data on the total scores per case. Table 7.2 reports the estimated variance components. Most of the variance is associated with cases.

Table 7.2 Estimated variance components, standard errors and percentage of total variance

$\begin{array}{lccc}\text { Source of Variance } & \begin{array}{c}\text { Estimated Variance } \\ \text { Camponent }\end{array} & \begin{array}{c}\text { Standard } \\ \text { Eror }\end{array} & \begin{array}{c}\text { Percentage of Toltal } \\ \text { Variance }\end{array} \\ \text { Persons }(\mathrm{P}) & 74.14 & 25.82 & 19.17 \\ \text { Cases }(\mathrm{C}) & 206.57 & 99.65 & 53.42 \\ \text { P } x \text { C } \text { error } & 105.96 & 12.28 & 27.40\end{array}$

Table 7.1 shows that the mean number of items performed across cases varies considerably. The various clinical problems apparently present quite different challenges to individual theumatologists. The second largest variance component is the general error term, which represents approximately one quarter of the total variance. Usually, this component is the largest in clinical competence measurements. The remaining one fifth of the variance is attributable to the variance between rheumatologists. This indicates the ability of the measurement to differentiate between doctors. As the purpose of the instrument is to differentiate between rheumatologists, this is considered a desirable variance. Although it is, as usual, the smallest component, it cannot be called small in an absolute sense. The general error term ( $P \times C$, error) represents undesirable variance, or error variance, both in the norm-referenced and the domain-referenced score interpretations. From the domain-referenced perspective the case variance is also considered part of the error variance. The standard errors are quite large for all variance components. This is due to the relatively 
small sample sizes on which these estimations are based $(22$ doctors and 8 cases).

Table 7.3 reports the generalizability and dependability coefficients as a function of a (hypotheticall number of cases.

There is a sizable difference between the 2 types of reproducibility coefficients. This is due to the large case variance component, which is entered in the dependability coefficients. The sample size of 8 cases used in this study produced values of 0.86 and 0.69 , respectively. If an arbitrary value of 0.80 is regarded as a minimum reproducibility coefficient, 6 cases may suffice for norm-referenced scores, whereas about 14 cases are needed for an absolute score interpretation.

Table 7.3 Reproducibility coefficients using a norm-referenced (generalizability coefficients) and a domain-referenced score interpretation (dependability coefficients) as functions of the number of cases and estimated testing time

Number of cases
2
4
6
8
10
12
14
16

Estimated testing
time (in hours)

1

2

3

4

5

6

7

8

Generalizability
coefficient

0.61

0.76

0.82

0.86

0.89

0.90

0.92

0.93
Dependability coefficient
0.35

0.52

0.62

0.69

0.73

0.77

0.79

0.81

\section{Discussion}

This study has two methodological weaknesses. The first concerns the use of 2 different SPs for each case. Differences between rheumatologists due to differences between these SPS are erroneously taken as person variance or desirable variance. This could not be prevented for practical reasons. However, the inflation is likely to be small since the SPs were trained to portray their role and score the checklist very accurately and in the same way. It has been shown that differences between SPs do not statistically interfere with doctors' performances. ${ }^{21}$ The second problem is more serious and concerns the small sample size of the doctors. Naturally, this originates from the huge logistical demands of this study. As a consequence of the small sample size, standard errors of the estimated variance components are sizable and the data should be interpreted with some caution.

The most notable finding in relation to the variance components obtained was the large variance caused by the differences between the cases in terms of the extent of the challenge posed to doctors. This may be due to 
the sampling problem mentioned. Usually, the general error term is larger than the variance associated with cases. The person component was relatively large. As a result, the reproducibility coefficients were quite acceptable. With a relative score interpretation a relatively small sample of approximately 6 cases suffices to achieve a reproducibility coefficient of 0.80 . Many more cases are needed for an absolute interpratation of the scores. Naturally, when the cases present considerable differences in degree of difficulty, as in this study, a large sample of cases is required in order to achieve a generalization of the results of performance on random samples of other cases. Our data indicated that approximately 14 cases would be needed to obtain a reproducibility coefficient of 0.80 .

A more salient finding than the difference between the 2 score interpretations and their effect concerns the overall level of reproducibility found in this study. The purpose of this study was to investigate whether this direct performance assessment method could yield reproducible findings. The answer to this question is affirmative, provided the sample of cases is large enough.

We also wanted to know how the reproducibility of this method compares to that of other methods. When we compare the reproducibility coefficients at comparable testing times, the values found with this method are by no means worse than the values reported in OSCE assessment. "Furthermore, the norm-referenced reproducibility coefficients appear to be considerably better. In order to compare our method with the practice video assessment format we compared our dependability coefficients with the values reported by Ram et al. ${ }^{13}$ With the video assessment instrument, real patients were randomly used, all cases were dissimilar and case difficulty was automatically included in the error term. Our reproducibility data are slightly worse at comparable testing times. However, we wish to emphasize that these reproducibility coefficients should not be interpreted too absolutelly, because of the noise in the estimates. Finding of comparability between the results is much more compelling than finding of observed differences.

The information collected in our study related only to the medical content of the consultation and did not include attitudinal and communication skills. However, we think that data on attitudinal and communication skills would yield a much more consistent pattern among different rheumatologists and might therefore result in even better reproducibility results.

Overall, this study has demonstrated that the method of assessing authentic practice performance using incognito SPS can vield scores that are as reproducible as those of other authentic measures of competence and performance. With a sufficiently large sample of measurements, reproducible measurement can be achieved with direct assessment of performance in daily clinical practice. 


\section{References}

1. Varn der Veuten CPM. The assessment of Professional Competence: Developments. Research and Practical Implications. Adv Health Sci Educ 1996;1:41-67.

2. Harden RM. Gleeson FA. Assessment of clinical competence using an objective structured clinical examination (OSCE). Med Educ 1979;13:41-54.

3. Rethans J-J. Westin S, Hays RH. Methods for quality assessment in general practice. Fam Pract 1996;13:468-76.

4. Kane MT. The assessment of professional competence. Eval \& the Health Profess $1992 ; 15: 163-82$.

5. Miller GE. The Assessment of Clinical Skills/Competence/Performance. Acad Med 1990;65: $\$ 63-7$.

6. Rethans J-J, Sturmans F, Drop R, van der Vleuten C, Hobus P. Does competence of general practitioners predict pertormance? Comparison between examination setting and actual practice. BMJ 1991;303:1377-80.

7. Streiner C. Clinical ratings-ward rating. In: Shannon S. Norman G, editors. Evaluation methods: a resource handbook. Hamilton: Program for Educatiomal Development MicMaster University: $1995 ; 29.32$.

8. Gray JD. Global rating scales in residency education. Acad Med 1996;21:555-63.

9. Swanson DB. A measurement framework for performance-based tests. lin: Hart I, Harden R, editors. Further developments in Assessing Clinical Competence. Montreal: Can.Heal Publications; $1987: 13-45$.

10. Van der Vleuten CPM. Norman GR. De Graaft E. Pitfalls in the pursuit of objectivity: Issues of reliability. Med Educ 1991;25:110-8.

11. Van der Vleuten CPM, D. Swanson D. Assessment of Clinical Skills With Standardized Patients: State of the Art. Teach Learn Med 1990:2:58-76.

12. Vu NV, Barrows HS. Use of standardized patients in clinical assessments: recent developments and measurement findlings. Educ Research 1994:23:23-30.

13. Ram P. Grol R, Rethans JU, Schouten B, Van der Vleuten CPM, Kester A. Assessment of general practitioners by video obserwation of communicative and medical performance in daily practice: issues of validity, reliability and feasibility. Med Educ 1999:33:447-54.

14. Rethans $J J$ Sturmans F, Drop MJ, Van der Vleuten CPM. Assessment of performance in actual practice of general practitioners. Br J Gen Pract 1991:41:97-9.

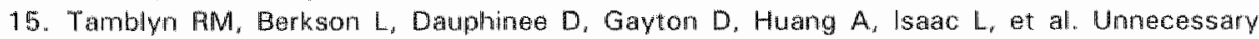
prescribing of NSAIDS and the management. Ann Intern Med 1997:127:429-38.

16. Norman GR. Tugwell P, Feightner JW. A comparison of resident performance on real and simulated patients. J Med Educ 1982;57:708-15.

17. Rethans $J$-J. Needs assessment in continuing medical education through standardized patients. J Cont Educ Health Proff 1998;18:172-8.

18. Baullens $J$. Rethans $J-J$. Goudhurys $J$ Buntinx $F$. The use of standardized patients in resaarch in general practice. Fam Piract 1997;14:58-62.

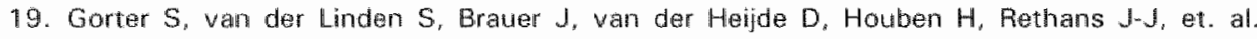
Riheumatologists" performance in daily practice. Arthritis Care Res 2001:45:16-27.

20. Gorter S, Rethans J-J, Scherpbier A, van der Linden Si, van Santen-Hoeufft M. van der Heijde D et all. How to introdtuce incognito standardized patients into outpatient clinics of specialists in theumatology. Med Teach 2001:23:138-44.

21. Tamblyn RM, Grad R. Gayton D, Petrella $L$. Reid $T$. Impact of inaccuracies in standardized patient portrayal and reporting on physician performance during blinded visits. Teach Learm Med 1997:9:25-38.

22. Vu NV "Marcy MM, Colliver JA, Verhulst SJ, Travis TA, Barrows HS. Standardized [simulated) patients" accuracy in recording clinical performance checklist items. Med Educ $1992: 26: 99-104$

23. Brennan RL. Elements of Generalizability Theory. Iowa: ACT Publications; 1983. 


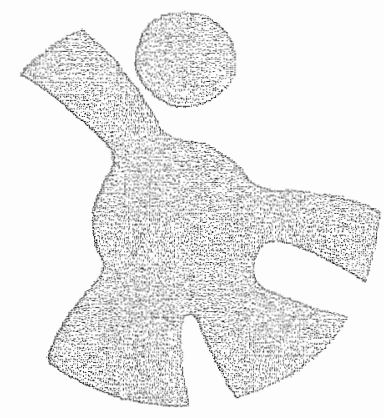

The role of a computerized case-based testing procedure in practice performance assessment

Lambert Schuwirth, Simone Gorter, Désirée van der Heijde, Jan-Joost Rethans, Jolanda Brauer, Harry Houben, Sjef van der Linden, Cees van der Vleuten, Albert Scherpbier 


\section{Abstract}

introduction. For postgraduate training of doctors there is a need for valid and reliable instruments to assess their daily performance. Various instruments have been suggested, some of which use incognito standardized patients (SPS). These methods are resource intensive. Computerized case-based testing (CCT) is logistically simpler and may still predict performance well. The research question was to evaluate the predictive validity of CCT for performance.

Methods. Fourteen rheumatologists were each visited by 8 incognito SPS presenting various rheumatological complaints, and scoring the performance of the rheumatologists using a predefined checklist. From this checklist a panel of experts identified essential items. In addition, these theumatologists sat a CCT test containing 55 cases with a total of 121 thems.

Results. High but negative correlations were found between the SP scores and the CCT scores. This was unexpected. Therefore, background variables on experience were used to compare the both methods. The correlation between these and CCT were high and positive and with the SP scores high and negative. This pattern did not differ when using the essential items of the checklist. Reliabilities of the SP scores were markedly high.

Discussion. CCT was not predictive for SP scores, but was related to working experience. Both instrument probably measure other things, and it cannot be said that either of the instruments was superior to the other, but each had its own strengths and weaknesses and should be perceived as incremental. The results underpin the assumption that for good performance assessment a variation of instruments is needed. The reproducibility of authentic assessment methods has been investigated for objective structured clinical examinations (OSCEs) and video assessment in general practice, but not for assessment with incognito standardized patients. 


\section{Introduction}

The role of doctors in the provision of high quality health care is essential. Therefore, most modern undergraduate and postgraduate training programs rely on high quality assessment procedures to ensure that their graduates are well equipped for the tasks they face in practice. These assessment procedures are often strongly focused on the measurement of competence. What matters in real practice, however, is not so much the competence of the doctor but his or her performance.' Although various definitions of competence and performance exist, they converge into the notion that competence indicates what people will do under optimal test conditions knowing that they are challenged, and performance indicates what people will do on average on a day to day basis in reall life unobtrusively.' Furthermore, it is generally accepted that possessing sufficient competence is a necessary requirement for sufficient performance, though it may not always be a sufficient requirement. Also, competence has a tendency to decrease when it is not reactivated regularly. To enable doctors to maintain their competence and performance two aspects are important. First, there is a need for good assessment methods to detect possible weaknesses and strengths. Second, relevant and accessible remediation procedures should exist. The current practice in this field of maintaining competence and performance is based on Continuing Medical Educational (CME) programs, which are organized by professional bodies within each discipline. Ideally these CME programs would closely fit the specific needs of each practicing physician, so that any existing deficiencies in practice performance can be remediated. However, there is hardly any evidence that these activities do result in better delivery of care. ${ }^{2}$ The contrary seems to be the case, physicians tend to attend mostly those courses dealing with topics ther like, and which they are already good at, and tend to ignore those, which aim at their deficiencies. Part of the explanation of this phenomenon is that physicians experience difficulties in accurately assessing their own needs for $\mathrm{CME}^{3}$ This underpins the need for assessment procedures to reliably and validly assess physicians' performance to be able to tailor CME activities to their individua! needs. Developing such types of assessment, however, is quite complicated; they should contain both competence and performance assessment, carefully balancing reliability, validity and resource intensiveness." In designing assessment methods for practice performance many different instruments have been suggested thus far. Some are indirect, and look at the evidences of performance, other are more direct and include observations. Indirect measures include chart reviews, assessment of lab ordering data, or prescription behavior. Direct measures may consist of video assessment of surgery hours, or the use 
of incognito standardized patients who visit the doctor and complete the consultation on a checklist. ${ }^{5}$ In one of our previous studies the performance of 27 Dutch theumatologists on eight different theumatological conditions was assessed using incognito $\mathrm{SP}_{\mathrm{S}}$, and detailed relevant performance data were obtained. A disadvantage of this approach is its complexity and resource intensiveness. Logistical factors limit the number of consultations that can be assessed. Since competence is an important factor in performance, and since competence is domain specific, it is logical to assume that this domain specificity limits reproducibility of the results. In addition, it is now generally accepted that in competence assessment there is no one superior instrument which could capture the "whole picture", so it is highly unlikely that this will be the case in performance assessment. Instead, in the current literature on practice performance assessment it is advocated to include multiple instruments, each tailored to the specific purpose of the assessment. ${ }^{7}$ So, there is a need for logistically simpler methods that can still provide information about performance. A relatively easy and cheap approach that assesses decision-making ability might prove to be a more valuable contribution to this. Computerized case-based testing (CCT) may be such a procedure ${ }^{8.9}$ It is based on the so-called key-feature concept, in which the candidate is presented large numbers of short, authentically described cases. ${ }^{10,11}$ In each case a limited number of questions is asked, aiming at essential decisions. Apart from its high feasibility and cost-effectiveness, its reliability and construct and content validity have been demonstrated in a number of studies. ${ }^{12,13}$ The aim of the present study is to investigate the value of CCT as a predictor for performance. The study is set up as a criterion validity study, with the results of the incognito SP visits as criterion.

\section{Methods}

\section{Subjects}

Twenty rheumatologists of a group of 27 whose day-to-day performance was assessed in a study using incognito standardized patients (SPs) consented to participate in the computerized case-based test (CCT). ${ }^{6.14}$ One rheumatologist dropped out during the first year of the study because of a long waiting list for new patients. Six rheumatologists of the performance study did not consent because of lack of time. Unfortunately, due to illness and early retirement 5 rheumatologists could no longer participate in the study. Of one rheumatologist information on working experience was lacking, so a complete data set was obtained for 14 rheumatologists. In addition to the results on CCT and the SP visits some background variables of the subjects were obtained. These are presented in Table 8.1. 
Table 8.1 Background characteristics of all subjects

\begin{tabular}{llrrrrc}
$\begin{array}{c}\text { Subject } \\
\text { nr }\end{array}$ & Gender & Age & $\begin{array}{c}\text { Years of } \\
\text { experience }\end{array}$ & $\begin{array}{c}\text { Number of patient } \\
\text { contacts per week }\end{array}$ & $\begin{array}{c}\text { Pho } \\
\text { yesino }\end{array}$ & $\begin{array}{c}\text { Teaching hospital } \\
\text { yesino }\end{array}$ \\
\hline 1 & Male & 37 & 6 & 12 & no & no \\
4 & male & 57 & 22 & 150 & no & yes \\
5 & female & 50 & 20 & 100 & no & yes \\
6 & male & 52 & 17 & 60 & yes & no \\
7 & male & 50 & 15 & 150 & no & yes \\
8 & male & 52 & 19 & 110 & no & yes \\
10 & male & 41 & 7 & 100 & yes & yes \\
15 & male & 50 & 13 & 25 & yes & no \\
16 & male & 53 & 20 & 105 & no & yes \\
22 & male & 42 & 5 & 120 & yes & yes \\
23 & male & 36 & 3 & 60 & no & yes \\
24 & male & 49 & 12 & 110 & yes & yes \\
25 & male & 47 & 12 & 150 & no & yes \\
26 & female & 44 & 9 & 75 & yes & no
\end{tabular}

\section{Performance assessment}

Sixteen standardized patients (SPs) were trained to authentically play a rheumatologic case (in total 8 cases). For each of these eight roles a specific checklist was developed. The items could be subdivided in 3 categories: history taking, physical examination, and diagnosis and management. In addition, a panel of 4 expert academic rheumatologists for each case were asked to identify essential items. Table 8.2 presents the content of the cases and the number of items.

Table 8.2 Total number of items and number of essential items per checklist

Role

Lateral humeral epidcondylitis

Fibronvalgia

Infommatory back pain:

Polvmyalgia rheumatica

Rheurnatold arthritis of the cervical spine

Mennochromatosis arthropathy

Psoriatic arthritus

Osteoporotic vertebral fracture
Total no. of items

$\begin{array}{ll}48 & 13 \\ 57 & 22 \\ 67 & 41 \\ 50 & 36 \\ 57 & 38 \\ 43 & 20 \\ 57 & 43 \\ 62 & 30\end{array}$

At the start of the study, participating rheumatologists were informed that sometime during the next year undercover SPs would visit them. Between July 1998 and February 2000, 26 rheumatologists working in 16 hospitals spread across the country, were each visited by eight incognito SPs. In total, 254 encounters took place, of which 201 first visits and 53 follow-up 
visits. SPs were not detected in all but two visits. Information on the medical content of each visit was obtained by having SPs complete a predefined and case-specific checklist immediately after the visit. Information regarding requested additional investigations was obtained from the hospital laboratory and/or radiology staff. Results of these investigations were simulated and sent to the rheumatologists in the usual way for that hospital. For each visit a total score was calculated by adding the correctly performed items from the checklist. Scores are presented as percentage obtained from the maximum score possible. An overall score across all cases was calculated per rheumatologist. For the essential items an "SP-essential score" was calculated.

Figure 8.1 Ms Jones, 68 years ald, rheumatold factor positive erosive nodular RA. She has been on methotrexate $7.5 \mathrm{mg}$ per week for 7 years, without synovitis or any complaints. Routine laboratory results:

$\begin{array}{lll} & 2 \text { months aga } & 2 \text { days ago } \\ \text { Haemoglobin } & 7.6 & 7.4 \\ \text { Trombocytes } & 340 & 345 \\ \text { Leucocytes } & 3.2 & 2.8 \\ \text { ESF } & 45 & 48 \\ \text { AP } & 90 & 88\end{array}$

$A P$

2 months ago 2 days ago

$\infty$

AP

GammaGT

90

88

$A S T$

41

$A L T$

35

Creatinine

31

39

35

94

Question: What is most probably the case?

You decide to perform a physical examination.

Question: Which signs should have your particular attention?

Next page

You have found a splenomegaly and signs of cutaneous vasculitis and you are strongly considering Felty's syndrome.

Question: What is the most appropriate medical (drug) treatment at this point? You may select more than one answer.
a) $\operatorname{stop} M \pi X$
bl stop MTX + start folic acid
c) continue MTX + start folic acid
d) increase the dosage of MTX
ef increase the dosage of MTX + start folic acid
f) temporarily lower dose MTX
g) lower the dosage of MTX + start folic acid
h) Azathioprime possibly combinated with prednisolione 


\section{Competence assessment}

The CCT was developed by a group of 9 rheumatologists according to the strategies as described by Schuwirth et al. The test consisted of 55 cases, including all disorders presented in the performance test described above. Each case was combined with a small number of questions asking for essential decisions. The test contained a total of 121 questions. Different question formats were used; the question format was determined based on the content of the question. An example of a case is shown in Figure 8.1. Since it was not possible to organize a meeting to assess all rheumatologists who participated in the performance study at one time, one of the researchers (JB) visited all participating rheumatologists to take the test on a laptop computer. The answers to the open ended questions were hand-scored by two raters independently. Scores on items were expressed in three possible categories: 0 points for an incorrect answer, 1 point for a correct answer, and 0.5 points for a partially correct answer. The total score was calculated for every rheumatologist by adding all points obtained. This final score is presented as the percentage of the maximum score possible.

\section{Statistics}

Descriptive statistics were computed for the scores on the SP-based checklists and the CCT-scores. Reliabilities were calculated using Cronbach's alpha. Between the scores on the SP-checklist both with the total scores and the score on the essential items, and the CCT scores, Pearson correlation coefficients were calculated. These were corrected for attenuation using the reliabilities of the tests.

\section{Results}

The 14 rheumatologists were visited by all 8 incognito SPs. This resulted in a total of 112 first visits. In Table 8.3 descriptive statistics and reliabilities are presented of all measures. In this table the scores on the CCT test included also open-ended questions that were hand scored afterwards by two independent raters. The inter-rater correlation was 0.793 . The scores on the open items were therefore entered as the mean of both raters. Table 8.4 presents the correlation coefficients between the total scores and scores on the essential items of the incognito SP test, and the scores on the CCT of the participating rheumatologists. 
Table 8.3 Descriptive statistics and reliabilities for the case-based test, the total SP-based assessment scores and the scores on the essential items

$\begin{array}{lccc}\text { Measure } & \text { Range } & \text { Mean (SD) } & \text { Alpha } \\ \text { Case-based test (CCT) } & 26.43-33.16 & 31.34(1.99) & 0.55 \\ \text { SP-total scare } & 30.60-72.42 & 53.54(9.62) & 0.86 \\ \text { SP-essential score } & 35.59-82.49 & 64.16(10.67) & 0.85\end{array}$

Table 8.4 Correlations between the scores on the SP-based total scores, the SP-based essential items scores and the Case-based test scores

Case-based test

Case-based test (CCT)

SP-total score

SP-essential score
$-0.379$

$-0.347$
SP-totall score

$-0.261 p=0.348$

1.00
SP essential score

$-0.236 p=0.397$

$0.946 \mathrm{p}<0.0001$

A notable feature in this table is the negative correlations between the SPscores (both on the total set of items and on the essential items) and the CCT results. Furthermore, the correlation between scores on the essential items of the checklist and the total scores is extremely high. The negative correlations were unexpected since at least moderate positive correlations were expected. To investigate these findings further it was then decided to use the background variables of the participants to calculate a measure of experience. This was done using the number of years in practice and the average number of patients seen per week. From this the total number of patients each rheumatologist had seen during his or her professional life was estimated. In the development of expertise the amount of practice experience is seen an important contributing factor. ${ }^{15.16}$ For this estimate we will use the term exposure. The correlation between exposure and the CCT scores is 0.636 . To estimate the true correlation a correction for attenuation was performed. For this the reliability of the exposure was set to 1.00 the disattentuated correlation was 0.858$)$. The correlation with SP total scores is -0.616 and with the essential items score -0.637 (disattentuated -0.664 and -0.695 respectively). All correlations were significant $(p<0.025)$.

\section{Discussion}

In an attempt to determine the criterion validity of CCT with respect to the outcome of an incognito SP-based examination negative correlations were found between both instruments. This was rather unexpected because at 
least a moderate positive correlation was expected. When both measures were compared to an estimate of experience, the correlation with the SPbased assessment was negative whereas the one with CCT was positive. Apparently the SP-based assessment and CCT do not provide similar information about the competence and/or performance of the candidate. One possible explanation for this could be that CCT is mainly focused at competence, that the SP-based examinations test performance and that both constructs are dissimilar. Considering current ideas about the relationship between competence and performance, however, this is highly unlikely. "More plausible explanations lie in the differences in content of the measures. The checklists the patient used in the SP-based examination focused strongly on all possible actions a candidate could take during the patient encounter. For assessment purposes the obvious way to score them would be to count the number of actions taken. This, however, is not in concordance with the literature on development of expertise. In this theory one important aspect of expertise is efficiency. ${ }^{15.19}$ Experts tend to need less information to come to the correct diagnosis and management. So more is not necessarily better. Although this may be obvious there are implications and side effects that are important. First, in terms of possible test development on the basis of SPS it is obviously not practical to design a formal test in which fewer actions taken will lead to a higher score. Second, a further content-based analysis (not reported here) was performed where only the decision items - such as diagnosis and management - were used. In this analysis the same correlational pattern was found. Third, the analysis using only the so-called essential items did not lead to different results. In fact, the high correlation between the essential items and the rest indicates that the 'essential' items did not behave psychometrically as essential items. This is not surprising, especially in view of the known idiosyncrasy of problem-solving ability, which increases with increasing expertise; each expert solves a problem using a different strategy, using different part of information, but they all arrive at a similar solution. Therefore, it is rather unlikely that experts would agree on what essential items are. A final puzzling finding is the high reliabilities found in the SPbased test. Considering the number of cases a low reliability would have been more logical. This is because in such tests almost always, high domain specificity can be demonstrated. This leads to low inter-case correlations and by this to a low reliability of tests with small numbers of cases. ${ }^{20}$ In the present SP-based examination, with only 8 cases, however. the Cronbach's alpha is high, and therefore the inter-case correlations must be high. This suggests that some sort of general consultation approach is being measured rather than the content of the problem-solving process. In other words, a candidate who gathers large amounts of information in one case is likely to do so in any other case, and vice versa, but this behavior is 
unrelated to the specific content of the case. In combination with the previous explanations this would lead to the conclusion that the SP-based examination in this setup did not measure the quality of the problemsolving process but rather its quantity. CCT correlated better with experience, but does that make it a better measure of performance? We think not. Firstly, it lacks the authenticity that the SP-based examination has. Secondly, and more importantly, the test is obtrusive; the candidate is well aware that his/her competence is being tested, which influences the performance and thus the score. Thirdly, there might be several factors related to the environment a doctor works in, which would influence whether or not the competence is being transferred into performance; the doctar may know what the right thing to do is, but may not be able to actually do this. Therefore, if CCT were the only instrument used to measure performance some important deficiencies may not be detected. Both methods do have advantages though. SP mased assessment is unobtrusive, at the highest level of authenticity, and based on patient perception. CCT is logistically simpler, cheaper, and has better content sampling qualities. Although our expectations were not met, some important lessons could be learnt from the results. SP-based assessment is a good instrument to describe what happens in real practice, in other words to gain insight on what actions doctors may take during a consultation. For this the instrument has been used successfully in other studies ${ }^{6}$. By this it can provide valuable information for the development of CME programs. It is unobtrusive and authentic, but the way it was set up in this study did not make it valuable to summatively assess what happens in practice, in other words to generalize from the sum scores to overall practice performance. Especially if it is intended to function in a summative assessment program its value can be improved to direct it at aspects that cannot be measured otherwise, such as establishing rapport, respect for the patient, communication, professionality, etc. CCT cannot test these aspects and should be used to test the competence of decision making rather than trying to predict performance. A general conclusion is that the combination of instruments is probably more useful than either of them allone. Both should rather be perceived as incremental and not as one replacing the other. A second conclusion would be that although an authentic test may appear to be automatically valid, authenticity (fidelity) does not guarantee validity. In matters of validity the content of the method may be even more important than its format. 


\section{References}

1. Rethans J, Norcini J, Bäron-Maldonado M, Blackmore D, Jolly B, LaDuca $T$, et al. The relationship between competence and performance: implications for assessing practice performance. Med Educ 2002;36:901:9.

2. Davis DA, Thomson MA, Oxman AD, Haynes RB. Changing physician performance. A systematic review of the effect of continuing medical education strategies. JAMA $1995 ; 274: 700-5$.

3. Jansen $J J$, Tan $L H$, van der Vleuten $C P$, van Luijk $S J$, Rethans $\mathbb{J} J$, Grol RP. Assessment of competence in technical clinical skills of general practitioners. Med Educ 1995;29/3): $247-53$.

4. Ram $P$. Comprehensive assessment of general practitioners [dissertation]. University of Maastricht, 1998.

5. Rethans JJ, Westin S. Hays R. Methods for quality assessment in general practice. Fam Pract 1996;13(5):468-76.

6. Gorter $S$, van der Linden S, Brauer J, Van der Heijde D, H. H, Rethans $J-J$, et al. Rheumatologists" performance in daily practice. Arthritis Care Res 2001:45:16-27.

7. Schuwirth L, Southgate L. Page G. Paget $N$, Lascop J. Lew S, et al. When enough is enough: a conceptual basis for fair and defensible practice performance assessment. Med Educ 2002;36:925-30.

8. Schuwirth LWT, Blackmore DB. Mom EMA, Van den Wildenberg F, Stoffers HEJM, Van der Vleuten CPM. How to write short cases for assessing problem-solving skills. Med Teach 1999:21/2):144-50.

9. Schuwirth LWT, Van der Vleuten CPM. De Kock CA. Peperkamp AGW, Donkers HHLM. Computerized case-based testing: a modern method to assess clinical decision making. Med Teach 1996;18/41:295-300.

10. Bordage G. An alternative approach to PMP"s: the "key-features" concept. In: Hart IR. Harden $\mathbb{R}$, editors. Further developments in assessing clinical competence, Proceedings of the second Ottawa conference. Montreal.: Can-Heal Publications Inc, 1987:59-75.

11. Page G, Bordage G. Harasym P, Bowmer I, Swanson DB. A new approach to assessing clinical problem-solving skills by written examination: Conceptual basis and initial pilot test results. In: Bender W, Hiemstra RJ, Scherpbier A, Zwierstra RJ, editors. Teaching and Assessing Clinical Competence, Proceedings of the fourth Ottawa conference. Groningen: Boekwerk Publications, Groningen. The Netherlands, 1990:403-7.

12. Bordage G, Brailovsky $C$. Carretier $H$, Page G. Content validation of key features on a mational examination of clinical decision-melking skills. Acad Med 1995;70/41:276-81.

13. Schuwirth LWT. An approach to the assessment of medical problem solving: Computerised Case-based Testing Idissertation. University of Maastricht, 1998.

14. Gorter SL, Riethans JuJ Scherpbier AJJA, wan der Linden S, Van Santen-Hoeuftt MHIM, $\checkmark a n$ der Heijdle DMFM, et al. How to introduce incognito standardized patients into outpatient clinics of specialists in rheumatology. Med Teach 2001:23:138-144.

15. Posner MI. What is it to be an expert? In: Chi MTH, Glaser R, Farr MJ, editars. The nature of expertise. Hilsdale. NJ, US: Lawrence Erlbaum Associates, Inc, 1988: kix-xxxwi.

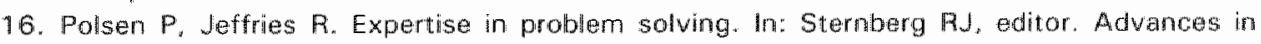
the psychology of human inteiligence. Hillsdale $\mathbb{N} J$ : Lawrence Erlbaum Associates, 1982: 367-411.

17. Chi MTH, Glaser $\mathbb{R}_{r}$ Rees $E$. Expertise in problem solving. In: Sternberg RJ, editor. Advances in the psychology of human intelligence. Hillsdale $N J$ : Lawrence Erlbaum Associates, 1982:7-76.

18. Glaser R, Chi MTH. Overwiew. In: Chi MTH, Glaser R, Farr MJ, editors. The nature of expertise. Hillsdale, NJ, US: Lawrence Erlbaum Associates, Inc, 1988:xv-kyviii. 
19. Regeth G. Norman GR. Issues in cognitive psychology: Implications for professional education. Acad Med 1998;719/:988-1001.

20. Swanson DB. A measurement framework for performance-based tests. In: Hart 1, Harden R. editors. Further dewelopments in Assessing Clinical Competence. Montreal: Can-Heal publications, $1987: 13-45$. 


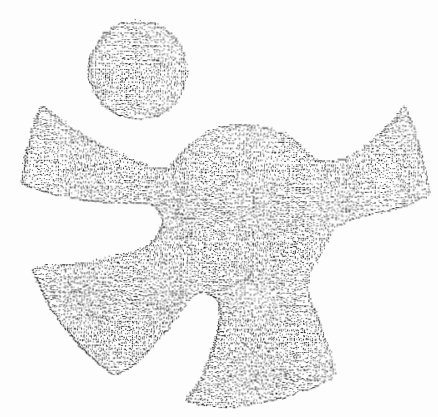

Doctor-patient interaction: standardized patients' reflections from inside the rheumatological office

Simone Gorter, Albert Scherpbier, Jolanda Brauer, Jan-Joost Rethans, Désirée van der Heijde, Harry Houben, Cees van der Vleuten, Sjef van der Linden 


\section{Abstract}

Objective. To assess appreciation and quality of doctor-patient interaction by exploring standardized patients opinions on aspects of the interaction between doctors and standardized patients.

Methods. A focus group interview was organized with standardized patients (SPs) who had completed 254 incognito visits to 26 Dutch rheumatologists in a study assessing rheumatologists' daily practice performance. 13 of 16 SPs attended the interview. The patients discussed aspects of interaction with the physicians. The interview was audio taped and literally transcribed Recurring themes were identified.

Results. Participants were on the whole very satisfied with the theumatological care received. Factors contributing to satisfied patients included "being approached as a person", "being treated respectfully" and "being given enough room to mention all complaints". On the other hand, standardized patients were struck by the variation in performance among the rheumatologists.

Discussion. Physicians may not be aware of the impact of their behavior on patients. Most critical comments of patients regarding communication and behavior were on small things, which should not be too difficult to change in daily practice. 


\section{Introduction}

Quality in doctor-patient interaction is important and has great influence on patient satisfaction. 'Among primary care physicians it has been shown that those without malpractice claims have better communication skills than physicians with claims. Those without claims laughed and used more humor, thereby encouraging patients to talk more and to express feelings and opinions. ${ }^{2}$ Effective communication between physicians and patients, both verbal and non-verbal, enhances patient satisfaction. ${ }^{34}$ Other factors such as hospital accessibility and waiting-room situations contribute to this as well. ${ }^{5}$ It is important to know which specific skills and attitudes contribute to patient satisfaction, because it has been shown that patient satisfaction can improve patient outcomes. ${ }^{6.9}$

It has been shown that patients are more satisfied if doctors pay attention to psychosocial issues and are not dominant in the conversation. ${ }^{10}$ Focus group interviews with real patients revealed that patients want to be respected and treated as individuals. ${ }^{11}$

Studies focusing on patient satisfaction usually deal with patients and their own primary care physicians. However, it is known that it is difficult for patients to evaluate their physicians since patients are emotionally involved in the consultation. Moreover, they are to a certain extent dependent on their doctors' actions. The use of patient reports is considered inadequate for assessing the quality of physicians. ${ }^{12}$

To overcome these problems standardized patients (SPs) can be used. SPs are real patients or thealthy persons trained to accurately play a role in a consistent way. ${ }^{13}$ They objectively evaluate physician's skills, are not emotionally involved and since they see different physicians in a standardized role, are able to compare physicians ${ }^{*}$ communication skills and behavior. Recently, in a large study we assessed rheumatologists' daily practice performance by sending 16 incognito SPs presenting 8 different rheumatological conditions, to 26 rheumatologists" outpatient wards." SPs stayed incognito for the duration of the study. In total 254 incognito visits took place, 201 first visits and 53 follow-up visits. The study focused on the medical content of the visits, with SPS completing case-specific checklists. ${ }^{15}$ As before, ${ }^{16}$ we noticed that the SPS also wanted to share with us non-medical aspects of the interaction with the rheumatologists. Thus, we decided to address a number of questions more systematically by organizing a focus group interview. These questions are: 1) what makes standardized patients like or dislike a rheumatologist, 2) is there any influence of situations in the waiting room or the doctor's office on an SP evaluation of the physician, and 3) does the experience of being a SP influence their opinion of physicians? 


\section{Methods}

\section{Participants}

Near completion of the project, all 16 SPs were invited by letter to participate in the focus group interview. Three were unable to attend the interview. The remaining 13 had a mean age of 55 (range 45-73), 6 were male, 9 had previous experience as SP in undergraduate medical curricula and 3 SPs were real patients (with no prior experience as SP). Two SPs had participated as incognito $S P$ in a previous study assessing general practitioners' performance. ${ }^{17}$

The SPs each presented one of the following 8 rheumatological conditions: ankylosing spondylitis, fibromyalgia, hemochromatosis arthropathy, lateral epicondylitis, osteoporotic vertebral fracture, polymyalgia rheumatica, psoriatic arthritis and rheumatoid arthritis.

\section{Focus group interview}

A focus group interview is a popular method for assessing and exploring opinions and perceptions. ${ }^{18}$ It is a group interview with a moderator encouraging people to talk with each other. The moderator does not ask each person to answer questions, but stimulates the group to comment on each other's experiences and points of view and to exchange anecdlotes. In this way, experiences and perceptions, that are difficult to capture in oneto-one interviews or quantitative research methods, can be explored. The strength of the focus group interview lies in its ability to observe the interaction (verbal and non-verbal) between participants. On the other hand, the researcher has less control over the issues and the discussion can surprisingly deal with other subjects than expected. ${ }^{18}$

\section{Procedure}

Thirteen SPs participated in the 3 hour during session, which was moderated by one of the researchers (AS). Three other researchers (SG, J-J $R$, JB) took notes and interrupted whenever the discussion became irrelevant. The discussion started with the 3 initial questions. During the course of the focus group interview, the group spontaneously raised additional issues concerning their experiences as SPS. 


\section{Data analysis}

The interview was recorded on audiotape and transcribed literally. The transcript was first compressed by two researchers individually (SG and JB) by deleting all superfluous and non-contributing remarks. Each of them identified recurring themes. A summary was sent to a third reviewer (AS) and all 13 participating SPS. They all agreed with the content and accuracy of the summary report.

\section{Results}

In addition to the 3 research questions, SPs spontaneously raised the following topics: the variation in performance between rheumatologists, the difference in physician behavior between first visit and next follow-up visit and the perceived effect on the consultation of the general practitioner's referral letter. The different themes will now be reported consecutively and illustrated by quotes of the participants. We present those quotes that we valued as common and striking. Since opinions and experiences were not always shared by most SPs, individual but striking quotes will be presented.

\section{What make SPs like or dislike a rheumatologist?}

In general, SPs liked the rheumatologists. Sometimes they were even surprised by their friendly way of approaching them, their patience and capability to listen to their stories. The reasons why SPs liked a rheumatologist are often for seemingly small things, such as going in person to the patient in the waiting room instead of calling them in from the office, or asking about the situation at home. Typical remarks included:

"It is how they treat you, how much time they have for you, how they explain things to you or show that they really understand your complaints..... For the first time in my life / thought, this man has probably been working hard since 7.30 this morning and I am his umpteenth patient today and even so he is joking or being very kind. I was really very impressed."

(female SP simulating fibromyalgia)

"It was little things that made me feel they really had time for me. I remember a doctor who seemed to be just going through the routine, but when she noticed something that I had written on my hand, she said:" Do vou also write things an your hand, I used to do that." This kind of remark 
shows that she really did see me, not just another case. And suddenly I liked her wery much."

(female SP simulating ankylosing spondylitis)

On the other hand, some events may make a physician suddenly appear unsympathetic. One of the SPs recalled the following experience:

"During the interview/thought he was very nice and then he was going to examine me and everything changed, I had to undress in a tiny cubicle with a curtain that did not close properly and then he received a phone call and he was asking endless questions of a colleague about conferences and research grants and all sorts of things .... then he started to examine me, and I was standing there barefoot on the cold floor, and he had another phone call, another colleague and again about money. It wasn't a short conversation either .... and there I was, turned towards him. I felt dreadfully uncomfortable, and I thought what shall I do, go and sit in the cubicle, remain standing here .... I have rarely felt so uncomfortable." (female patient simulating ankylosing spondylitis)

Showing respect is considered very important. The SPs interpret a serious approach by the rheumatologist as a sign of respect. This encourages the SPS to tell their story. However, it was sometimes difficult to judge the interaction, for example when the SP noticed that the physician missed a 128 lot of important information during the encounter (because he or she did not perform a full physical examination), but appreciated that the rheumatologist was very friendly. One remark regarding respectfulness:

"A person may explain things very clearly, but when they show no respect I find it very difficult to listen. Yes, as a patient my ears are closed. So to me respect is far more important than clarity".

(female SP simulating ankylosing spondylitis)

The influence of situations in the waiting room or the physician's office

Sometimes situations in a waiting room or physician's office influenced SPS' opinion on a rheumatologist. Other SPS experienced unpleasant situations, but these did not affect their evaluation of the rheumatologist. Some experiences:

"I sat in the same waiting room twice where nearby girls were typing and faxing and these girls were having fun! They walked in an out of the room 
and laughed themselves silly. That is all very nice of course, but when you are sitting in this waiting room as a real patient and in a lot of pain you don"t want to be there."

(male SP simulating hemochromatosis)

"I was in one waiting room which was totally cheerless. It was far too crowded and people had to wait for an hour and a half and the doctor was upset because there were so many patients... I don't like that at all." (male SP simulating hemochromatosis)

"What the doctor will be like or what the hospital will be like, I already know as soon as I have talked to the receptionist on the telephone. It may change because of the doctor, but often it is already fixed what I will think of him or her."

(female SP simulating ankylosing spondylitis)

"In one hospital the outpatient rheumatology ward was a long way away, it takes forever to walk there and l just think it is stupid."

(female real patient with rheumatoid arthritis)

"I was on the examination table when the secretary came in to put something on the table. And she gave me this loak like, oh, yes, there's someone on the examination table. It is very embarrassing when you are lying there in front of someone who has nothing to do with it." (female SP simulating ankylosing spondylitis)

Does the experience of being a SP influence SPS ${ }^{r}$ opinion of physicians?

SPS each had sometimes special reasons for participating in the project. One of the SP's who wanted to overcome her fear of going to a specialist commented:

"it really did help me!"

One of the real patients found that her own rheumatologist who was aware of the project now treats her differently and she appreciates this wery much: 
"He says, you're an expert now .... He makes special efforts for me, for instance, he ordered a new drug for me ...."

(female real patient with rheumatoid arthritis)

One patient expressed the opinion of most of the SPs as follows:

"I have a lot of respect now for their efforts and their attitude towards their patients."

(female SP simulating fibromyalgia)

\section{Additional topics raised}

\section{Variation in performance between rheumatologists}

The SPs in our project had the unique opportunity to compare rheumatologists' performance, since the SPs each played their standardized role about 13 times for as many different rheumatologists. The SPS spontaneously mentioned the variations between rheumatologists and were surprised by it. A real patient would not notice this, since most of the time real patients consult only one physician for a particular problem. Three striking remarks regarding this theme:

130 "What really fascinates me is that you see one doctor on Wednesday afternoon, for instance, and then the next one on Thursday morning and they come up with totally different things .... what these people discover on the physical examination,.... it is unbelievable. If they use this when they decide on the treatment ......" (female SP simulating fibromyalgia)

"I was given totally different results ranging from; "well, this is a textbook story lof ankylosing spondylitis), but it doesn't fit the X-ray", to:" yes, well the $X$-ray is clear (sacroilititis), but the story doesn't fit", while I had told them exactly the same story."

(female patient simulating ankylosing spondylitis)

The variation in performance among rheumatologists affected opinions on the medical profession. This is expressed by one of the SPs:

"There were lots of different treatments and one rheumatologist even saidand to be honest I agree with him - there are 24 different treatments for 
you .... so medical science as such, / have lost some of my respect for it." (male SP simulating lateral epicondylitis)

\section{Differences in physicians' behavior during first visit and follow- up visit}

The SPS were instructed to present specific complaints at the first visit and to present other complaints only when the physician asked about them or encouraged them to tell more. The SPS noticed that many rheumatologists approached them differently at the first visit as compared to the follow-up visit. During the first visit, much more time was spent on the patient"s history, whereas in the follow-up visit SPS were given fewer possibilities to present complaints. There was hardly any room for the patient to talk about complaints which he or she had forgotten to tell or did not have the opportunity to tell during the first visit. This problem was shared by many of the SPs participating in the focus group interview.

"If you didn't tell the doctor all your complaints on the first visit, it's too late, the verdict has been reached... I really think that patients should be told how important it is that you present all your complaints during the first visit, even though they may feel that it is all too much and that they had better tell things in small doses."

(female SP simulating fibromyalgia)

Sometimes SPS got the impression that at the follow-up visit rheumatologist had forgotten who they were. SPS really appreciated iff rheumatologists recognized them or showed to be well prepared for the visit.

"It makes me trust a doctor when he makes you feel that he has really looked at your $x$-rays and your record, that he has given it some serious attention."

(female real patient with rheumatoid arthritis)

One of the SPs had the following postive experience at follow-up:

"In my eyes he was the perfect doctor, on the follow-up visit he told me what he had writen down about me the first visit and he checked everything and / could tell some more right away. This is very polite and it doesn't even take that much longer..."

(female SP simulating fibromyalgia) 
Perceived effects of the general practitioner's referral letter on the consultation

All SPs knew the content of the referral letter they brought with them to the rheumatologist. Many of them noticed that the referral letter often guided the consultation. The rheumatologist focused on the complaints mentioned in the letter and did not give the SPs room to spontaneously come up with other complaints. SPs were concerned that a rheumatologist may miss the correct diagnosis when a patient is unable to relate complaints with each other and the general practitioner failed to mention one of these complaints in the referral letter.

"About the referral letter: It is just what the GP indicates and not a guideline..."

(fermale SP simulating fibromyalgia)

" think it is partly negative, the letter causes prejudice and then the specialist facuses on the one item stated in the letter. He or she could have found out much more if only they had looked more carefully and asked more questions."

(male real patient with psoriatic arthritis)

132 Another patient, presenting a typical case of polymyalgia rheumatica, did not experience this in a negative way. He said:

"Almost all specialists took note of the letter and then asked me to tell my story."

\section{Discussion}

This study expresses opinions of 13 SPs on some aspects of the human interaction between physicians and SPs by means of a focus group interview in a large project assessing performance of rheumatologists. ${ }^{19}$ The SPs were very enthusiastic about the rheumatologists. They found them very friendly and in their opinion most rheumatologists took enough time to listen to their stories. Approaching them as a person was very much appreciated by the SPs. It was not what they said, but the way in which they said something that made the SPS like or dislike the rheumatologist. Treating the patients respectful and giving them enough room to mention all complaints were some factors that contributed to satisfied patients. Many SPS had noticed that during the next follow-up visit it is often very difficult to express feelings or present other complaints. 
They were disappointed when this happened to them. For some patients contextual factors such as hospital convenience and accessibility or waiting room situations really made them have a different approach to the rheumatologist. The SPs were struck by variation in performance among the rheumatologist. Several of these issues will now be discussed in more detail.

Our SPs' concerns regarding the possibility to express all their complaints confirm an earlier study, which showed that physicians frequently miss important information that often influenced the development of diagnostic hypotheses. ${ }^{20}$

Almost all SPs had some negative experiences regarding accessibility, or crowded waiting rooms etc. This is in line with the study of Stern and MacRea, who organized focus groups with (real) patients visiting emergency rooms or ambulatory clinics. ${ }^{5}$ Patients who visited the ambulatory clinics also mentioned related factors such as nearby parking areas, and enough privacy in physician's office and examination room.

It might be important for physicians to know how they are being evaluated by patients. They should realize the impact of their behavior on their patients. Small things can have a great influence on a patient's opinion about his or her physician. Paying attention to patients' opinions will enhance mutual understanding. Patients can give valuable information ranging from hospital accessibility to very detailed information on the physician"s behavior. Patients' experiences can be used to improve the delivery of care.

We used incognito SPS to evaluate aspects of interaction with the rheumatologists. SPs are unique in their opportunity to compare different physicians. They are not emotionally involved with the physicians and not dependent on physicians' actions. On the other hand, it is possible that appreciation of a physician by someone with a real health problem might be different from appreciation by an incognito standardized patient simulating a disease. In the only study which has compared patient satisfaction rates with satisfaction rates by incognito SPs, a moderate correlation $(0.51)$ was found. ${ }^{21}$ We think that SPs do give valid information on these aspects of human interaction and that this information is comparable and additional to real patients' opinions.

Until recently only little attention has been paid to communication skills training during undergraduate and postgraduate training. CME activities should not only address technical aspects of medicine, but should address aspects of human interaction between patient and physicians as well. This can make physicians aware of the importance of good communication and interaction with their patients. ${ }^{22}$ In addition, daily practice should preferably involve patients' opinions on different aspects of care, since this is the way in which doctors are evaluated by their patients. Doctors can learn from patients' feedback. Especially since it has been shown that satisfaction 
influences patient outcomes in a positive way, it is worthwhile to invest in this kind of feedback. ${ }^{-6.9}$

While examining real patients' opinions about their own physician, patients' privacy should be guaranteed. Therefore, surveys are preferred and feedback should take place tailored to the individual rheumatologist. SP visits could take place at the same time. After each consultation, SPS should unmask themselves and give feedback or the researcher should do this, also immediately after a consultation. This would add value to feedback by surveys and physicians would have the opportunity to respond immediately.

In our study many comments of patients on communication and behavior are related to small things, which should not be so difficult to change. 


\section{References}

1. Silverman J, Kurtz S, Draper J. Skils for communicating with patients. Oxon: Rodcliffe Medical Press Itd, 1998.

2. Levinson W. Roter DL, Mullooly JP, Dull WT, Frankel RM. Physician-patient communication. The relationship with malpractice claims among primary carre physicians and surgeons. JAMA 1997:277:553-9.

3. Kaplan SH, Hreenfield S, Wace JE. Assessing the effects of physiciar-patient interactions on the outcomes of cilhronic diseases. Med Care 1989:27:5110-27.

4. Walker DJ, Griffiths 10 , Leon CM. Referrals to a rheumatology unit: an evaluation of the views of patients, general practitioners, and consultants. Ann Rheum Dis 1991,50:926 9.

5. Stern A. MacRea SK. Quality Care begins with patient-friendly environments. Health Forum J 1999:53-4.

6. Stewart MA. What is a successful doctor-patient interview? A study of interactions and outcomes. Soc Scil Med 1984;19:167-75.

7. Rost KM, Flavin KS, Cole K, McGill JB. Change in metabolic control and functional status after hospitalisation. Diabetes Care 1991;14:881-9.

8. Egbert LD, Batitt GE, Welch CE, Bartlett MK. Reduction of postoperative pain by encouragement and instruction of patients. N Engl I Med 1964;270:825-7.

9. Levinson W. Physician-patient communication: a key to malpractice prevention. JAMA 1994: 273:1619-20.

10. Bertakis KD, Roter D, Putman SM. The relationship of physician medical interviewing style to patient satisfaction. J Fam Pract 1991:32:175-81.

11. Delbanco TL. Enriching the doctor-patient relationship by inviting the patient's perspective. Ann Intern Med 1992:116:414-8.

12. Wensing $M, G$ rol $R$, Smits $A$. Quality judgements by patients on general practice care: a literature analysis. Soc Sci Med 1994;38:45-53.

13. Barrows HS. An overview of the uses of standardized patients for teaching and evaluating clinical skills. AAMC. Acad Med 1993;68:443-51.

14. Gorter SL, Rethans J-J, Scherpbier AJJA, van deir Linden S, Van Santen-Hoeufft MHHM, Van der Heijde DMFM, et al. How to introduce incognito standardized patients into outpatient clinics of specialists in rheumatology. Med Teach 2000; 23:138-44.

15. Gorter S, Rethans J-J, Scherpbier A, van der Heilde D, Houben $H$, Vleuten van der $C$, et at. A review of methodologies in writing case specific checklists for standardized patient based assessment in internal medicine. Acad Med 2000; 75:1130-7.

16. Rethans JU, Drop R, Sturmans F, van der Vleuten C. A metlyod for introducing standardized (simulated) patients into general practice consultations. Br \& Gen Pract $1991: 41: 944-6$.

17. Rethans JJ. Sturmans F, Drop R, wan der Vleuten $C$. Assessment of the performance of general practitioners by the use of standardized (simulated) patients. Br $J$ Gen Pract $1991 ; 41: 97-9$.

18. Morgan DL. Focus Groups as Qualitative Research. Newbury Park, London, New Deihi: Sage Publications; 1988.

19. Gorter $S$, van der Linden $S$, Brauer J, Van der Heijde D, Houben H, Rethans J-J, ot al. Rineumatologists ${ }^{4}$ performance in daily practice. Arthritis Care Res 2001;45:16-27.

20. Ramsey $\mathbb{P G}$. Curtis JR, Paauw DS, Carline JD, Wenrich MD. History-taking and preventive medicine skills among primary care physicians: An assessment using standardized patients. Am J Med 1998:104:152-8.

21. Tamblyn $R$, Abrahamowicz M, Schnarch $B$, Colliver JA, et al. Can ständardized patients predict real-patient satisfaction with the doctor-patient relationship? Teach Learn Med $1994: 6: 36-44$.

22. Frederikson L, Bull P. An appraisal of the current status of communiciation skills training in British Medical Schools. Soc Sci Med 1992:34:515-22. 
Chapter
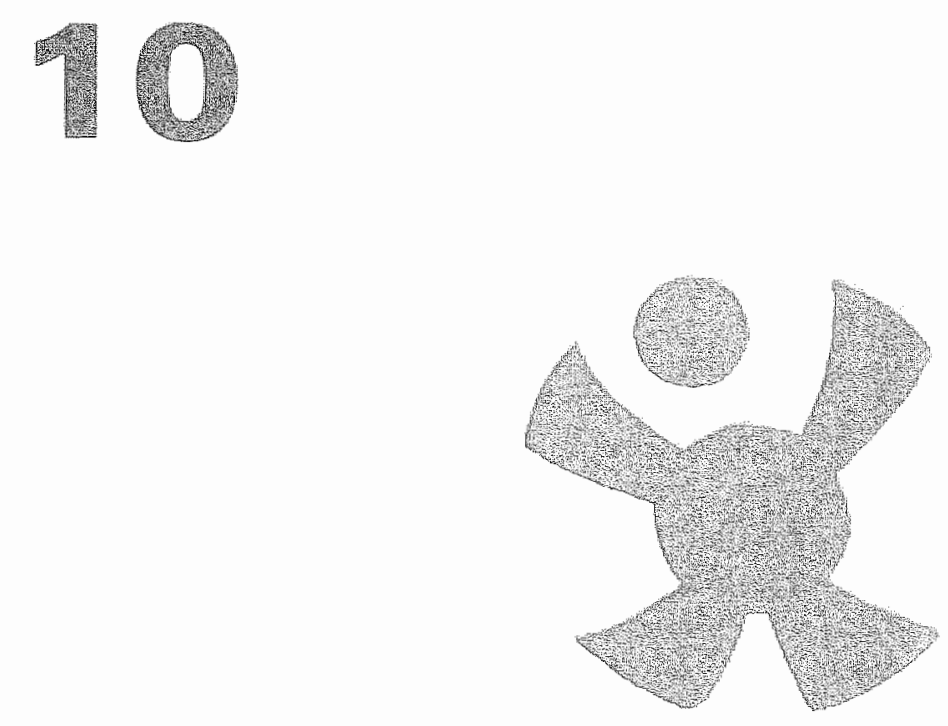

Conclusions and recommendations for further research 
\begin{tabular}{l}
0 \\
$\frac{8}{ \pm}$ \\
$\frac{0}{0}$ \\
$\frac{\pi}{0}$ \\
\hline
\end{tabular}

138 
In this chapter the results from the research questions stated at the beginning of this thesis will be reviewed in light of the previous studies. Thereafter, the relevance of the data obtained and experiences during this project will be discussed. In addition, some remarkable findings are highlighted. In the last part of this chapter recommendations for implementation of the study results and further research will be made.

\section{1) Is it feasible to introduce incognito standardized patients in secondary care?}

The results show clearly that it is feasible to introduce incognito standardized patients (SPS) into specialists" outpatient clinics and to organize follow-up visits. In only two out of 254 visits $(<1 \%)$ SPS were detected by the rheumatologists. Although the SP-method is an appropriate way to provide data on authentic practice performance, it is very demanding logistically, especially regarding the simulation of real radiographs. Co-operation of people from the "workfloor" is absolutely necessary to succeed. For feasibility reasons, we think that introducing incognito SPS into specialists' outpatient clinics could be organized as a kind of "service on demand" for specialists asking for medical audit, in special projects and not for large scale use. Information retrieved from the visits could then be used as a needs assessment tool for continuing medical education.

\section{2) How reproducible is the incognito standardized patient- method?}

Assessing reproducibility in the incognito SP-based method means gathering information on test length and number of cases needed to obtain reproducible results. A reproducible assessment implies that with the same method but using a randomly different sample of SPs and cases, similar results will be obtained. Reproducibility can apply to the group as a whole, or to individuals' performances. Compared to other but less standardized methods assessing authentic performance, the incognito SP-based method surprisingly yields equal reproducible results. When a relative score interpretation is applied, 6 cases ( 3 hours testing time) are needed to obtain a reproducible assessment, whereas 14 cases 17 hours testing timel are necessary for a reproducibility coefficient of 0.80 when scores are interpreted in an absolute manner. So, in this study while assessing performance of 22 rheumatologists in a direct way with 8 different cases and using a relative scoring system, reproducible results are obtained. 


\section{3) How is the performance and variation in performance among a Dutch group of rheumatologists when confronted with the same eight incognito standardized patients?}

A considerable amount of variation was found among rheumatologists. This involves the entire consultation: medical history, physical examination and management part, as well as costs spent for additional laboratory and imaging tests per rheumatologist. In addition, rheumatologists with more working experience perform fewer items on the checklists.

\section{4) What is the ability of a written competence test to predict daily clinical performance as assessed by incognito standardized patients?}

High but negative correlations were unexpectedly found between the SP scores and the CCT scores. The correlation between work experience and CCT was high and positive and with the SP scores high and negative. Thus, CCT was not predictive for SP scores. Both instrument probably measure other things, and it cannot be said that either of the instruments was superior to the other, but each had its own strengths and weaknesses and should be perceived as incremental. The results underpin the assumption that for good performance assessment a variation of 140 instruments is needed.

\section{5) How do incognito standardized patients appreciate the doctor-patient interaction?}

The results show that it was the way in which a doctor said something that made a SP more inclined to like or dislike a doctor. Being respected as a person was very much appreciated, as well as taking time to listen to the stories the SPs told. There were some patient concerns on the possibility to express all complaints and also about privacy in the physician's office. However, in general SPs were very enthusiastic about the rheumatologists. Since small things might have great influence on a patient's opinion about his or her physician, it might be important for physicians to know how they are being evaluated by patients. This might enhance mutual understanding. We think that patients" experiences and perceptions can be used as important resources to improve the delivery of care. 


\section{Relevance of the results}

In some respects this study is an unusual one. In the first place, it is the first study sending incognito SPs into specialists" outpatient wards and trying to measuring what is really going on in day-to-day practice. Secondly, the fact that it is feasible to organize such a study is a remarkable one on its own. Rheumatologists were willing to participate and many people working in different departments in different hospitals actively contributed to the data collection.

We have found substantial variation in performance when the care was assessed by using standardized, incognito SPs. This variation accounted for all aspects of the visit; the medical history, physical examination and management part. It is known that variation in the delivery of care exists among professionals. ${ }^{1}$ However, this has never been investigated in such a direct and unobtrusive way as we did. Until now, only indirect data from real practice behavior have been collected. For example, data on the mortality of certain medical procedures, or for example HbA1c as a laboratory outcome measure for success in treatment of patients with diabetes. By sending incognito and SPs into actual daily practice, comparing physicians' performances on identical cases is possible.

There are many reasons to collect data on real practice behavior. Since performance in real practice has proven to differ from what doctors say they do, insight into daily practice behavior offers information on what really is going on in day-to-day practice. Many guidelines have been developed on what doctors say they do or based upon results of strictly organized RCTs, and hence these may not perfectly fit real practice. Implementation of guidelines have not proved to be very successful. Developing guidelines while taking into account real practice might result in better suiting guidelines and be easier implemented into daily practice. ${ }^{2}$

The variation found in this study could be used to investigate and debate the appropriateness of the delivery of care. The process of discussing the reasons behind performance and identifying appropriate performance is in itself an educational activity for those doctors involved. If gaps in medical performance are found, targeted intervention on this subject could be arranged to improve performance, followed by repeated assessment in real practice to control for actual improvement. These different steps aiming to improve performance and hence quality in the delivery of care together form the so-called Quality Assurance circle. ${ }^{2}$

Assuring quality of care is becoming more and more important. Evidence based medicine involves the application of epidemiological data to one's own practice. It also involves translation of data from large trials to individual practice performance and taking into account budget constraints, patient preferences and pathophysiological insights. This also includes the 
critical reassessment of one's own experience under the influence of new information. ${ }^{3}$

Patients are nowadays more knowledgeable and have an increasing influence on decisions in practice performance. While evaluating performance, patients opinions and experiences should be included as well. They can provide unique data, such as hospital accessibility, but also on patient-doctor interaction. This aspect of providing care, i.e. communication and attitudinal skills, has shown to be of importance in the doctor-patient interaction and hence, is an important aspect of appreciation by the patient. ${ }^{4}$ Earlier research proved that real patients" opinions on these aspects of care correlate with SPs' opinions on doctor-patient attitudinal and communication skills. ${ }^{5}$ The SPs who participated in this project offered unique information on aspects of the consultation that were not measurable by peers or other non-patients. Information regarding hospital accessibility, convenient waiting rooms or politeness of doctors were often reported.

Transparency in daily practice is desired, not only by consumers, but also by the legislative parties and insurance companies. In our country practices are evaluated by peer visits every five years. This activity is a form of self regulation and is organized by the scientific medical societies and coordinated by a national organization. ${ }^{6}$ Recertification, as in many countries, is based upon points gained by attending a certain amount of hours in accreditated Continuing Medical Education (CME) activities such as conferences and workshops. Only the proof of attending such an activity suffices for accreditation. ${ }^{6}$ However, evidence exists that these forms of CME hardly result in improvement of daily practice performance and hence better patient outcome? A mix of different activities characterized by active participation of the attendees, such as locoregional discussion groups or feedback or working with opinion leaders, has a better chance for achieving change in medical practice. ${ }^{8}$

In the United Kingdom, recently, the Standing Committee on Postgraduate Medical Education (SCOPME) advised to give doctors sufficient time for learning and for professional development. ${ }^{9}$ The emphasis in revalidation shifted towards the role of professional education. This new assessment program is proactive and designed to demonstrate that the performance of doctors is acceptable. It is an assessment form that includes performance related outcome measures, while taking into account perspectives of providers, consumers and funders of health care. It is a more comprehensive assessment of practice performance, including for example outcome measures such as peak expiratory flow rates in asthma care, aspects of "humanity" such as respect; decision-making; cost-effectiveness and results of illness prevention activity. Each physician has to show a portfolio including all different aspects of performance once every few years to a regional revalidation panel. ${ }^{10}$ When performing substandard, their 
learning needs are assessed with observations in daily practice, such as consultations with real and SPS, medical record review, and an extended interview based on their personal portfollio." "1

\section{Recommendations for implementation and further research}

By sending eight incognito SPs into rheumatologists ${ }^{\prime}$ outpatient clinics, detailed information was obtained on their actual performance, such as how many rheumatologists asked for the occurrence of uveitis, how many examined the joints of the lower extremities, but also how many doctors requested certain lab tests or X-rays. So, an inventarisation was made on the performance of a group of rheumatologists when presented with standardized cases. This offered us the unique possibility to compare performances among doctors. So we did by providing feedback to the participant, while presenting his or her performance mirrored to the whole group's performance. However, we were not able to (and did not want tol identify good and bad performing doctors. As in rheumatology little work has been done on the development of guidelines, identifying appropriate practice is a difficult task. In addition, by asking experts in the field on how to perform best in practice would not result in a satisfactory consensus. This is known as idiosyncrasy of the development of expertise, meaning that experts develop expertise in their own and unique way. ${ }^{12}$

Our data on real practice performance may be used to discuss appropriateness of care. Reasons why variation occurred or what is best practice performance in a certain case should be the issue in the discussion. These should take place in small groups, taillored to participants' own practice and whenever possible confronting them with their own performance. Gaps in medical performance might be found as a result of those discussions and tailored education could be organized whenever needed. In our study, the substantial variation found in requesting radiographs in the case ankylosing spondylitis, or the decision to start anti-osteoporotic therapy in the case osteoporotic fracture, could be examples of subjects to be discussed in one of those discussion groups. If changes in actual practice performance are desired, it has been shown that activities on loco regional scale and as closely as possible related to actual practice have best chances to succeed. Later on these discussions mav be lifted to a higher (regional/ national) level, which then may result in the development of guidelines. Finally the ultimate goal of these activities should be to improve the quality of care in daily practice as reflected in better patient outcomes. It would be interesting to investigate whether rheumatologists participating in those discussion groups provide better care and have better patient outcomes than those who do not participate. 
In undergraduate medicine, SPs are more and more introduced in many settings both with summative as well as formative goals. ${ }^{13}$ In North America SPS are presented to residents, house officers and primary care physicians to assess their performance. ${ }^{14-16}$ Some of these assessment procedures are unobtrusively carried out. ${ }^{17.18}$ in our country, real practice performance of a group of general practitioners in the most southern part was assessed by incognito SPs. ${ }^{19}$

It would be most challenging to introduce incognito SPS as a routine educational activity in daily outpatient practice. However, the logistics of this study were very complicated and therefore an adjusted version of this method is preferred when used on a regular base. SPS might incognito be introduced into outpatient wards and unmask themselves at the end of the consultation, thereby preventing complicated tasks for the organizing team, such as simulating $X$-rays and laboratory results. Different aspects of performance such as human interaction or reasons to request additional investigations might be discussed between SP and the doctor that has been visited. When unobtrusive camera's were to be installed a peer, or in case of residents a faculty member, could join the discussion, ${ }^{20}$ or the information could be carried on to be discussed at a later moment. Of course, this kind of assessment should not be reserved for rheumatologists only, but hopefully for the whole medical profession.

Revalidation in the Netherlands is based on gaining points by visiting accredited CME activities such as workshops and conferences. Since 144 doctors tend to attend those courses they are already good at, it can be questioned whether the goal of revalidation, improving quality in the delivery of care, can be achieved. ${ }^{21,22}$ Needs assessment should take place and doctors should follow those courses they are not good at. In addition, as mentioned before, little evidence exists that passive forms of CME do contribute to better practice performance. ${ }^{7}$ We would recommend a system of revalidation based on needs assessment of performance related outcome measures. Physicians performing insufficiently on certain aspects should be stimulated to follow targeted education. This implies performance assessment to evaluate the needs for education. Developments in the UK regarding revalidation could well be used as an example, since it will be performance based. For the purpose of needs assessment in reall practice, incognito SPS could well be used to assess for example human interaction skills or inventarisation of requests for additional investigations. However, before performance assessments take place, the medical profession or scientific societies should have agreed on criteria of good and bad performance on the subject to be assessed. These criterila should be set up first and be performance based. But, a lot of work still has to be done on this subject. Doctors have different ways in dealing with exactly the same patients. Reasons why variation occurs should be investigated and in this 
way it might be possible to identify best practice performance. This process could lead to the development of guidelines, identification of learning needs and criteria for good and bad performance. And finally, with the introduction of targeted education on learning needs, this can lead to improvement in the quality of care.

The incognito SP method is a measure of performance that can offer detailed and unique information on some aspects of the medical visit including patients' perceptions of received care. Especially SPs' views on the human interaction skills of rheumatologists and the serious way they took their job really impressed Us. SPS should be introduced into the education of practicing physician. Not only for certification purposes, but especially as a formative educational tool. 


\section{References}

1. Eddy DM. Variations in physician practice: the role of uncertainty. Heath affairs 1984: 74.89.

2. Lawrence $M$, Schoffield T. Medical audit in primary care. U.S.A. : Oxford University Press; 1993.

3. Gezondheidsraad. From implementation to learning. The importance of a dialogue between practice and science in health care. The Hague: Gezondheidsraad; 2000. Report No.: 2000/18E.

4. Stem A. MacRea SK. Quality Care begins with patient-friendly enwironments. Health Forum Journal 1999:53-4.

5. Levinson $W$. Physician-patient communication: a key to malpractice prevention. JAMA 1994: 273:1619-20.

6. Swinkels JA. Reregistration of medical specialists in the Netherlands. BMJ 1999;319:1191-2.

7. Davis DA, Thomson MA, Oxman AD, Haynes RB. Changing physician performance. A systematic review of the effect of continuing medical education strategies. JAMA 1995:274: 700-5.

8. Lomas J, Anderson GM. Domnick.Pierre K, Vayda E, Enkin MW. Hannah WJ. Do practice guidelines guide practice? N Engl J Med 1989;321:1306-11.

9. Blight d. Assuring specialist practice. Med Educ 1998;32:341-2.

10. Southgate L, Hays RB, Norcini JJ, Mulholland H. Ayers B, Woolliscroft J, et al. Setting performance standards for medical practice: a theoretical framework. Med Educ 2001: 35:474-81.

11. Southgate L. James Mackenzie Lecture 1993. Freedom and discipline: clinical practice and the assessment of clinical competence. Br J Gen Pract 1994:44:87-92.

12. Schmidt HG, Norma GR, Boshuizen HPA. A cognitive perspective on medical expertise: theory and implications. Acad Med 1990;65:611-21.

13. Barrows HS. An overwiew of the uses of standardized patients for teaching and evaluating clinical skills. AAMC. Acad Med 1993;68:443-51.

14. Calhouln JG, Woolliscroft JO, ten Haken JD. Internal medicine house officers" performance as assessed by experts and standardized patients. I Med Educ $1987: 62: 754-60$.

15. Camey PA, Dietrich AJ, Freeman DH, Jr., Mott LA. A standardized-patient assessment of at continuing medical education program to improve physicians" cancer-control clinical skills. Acad Mad 1995; 70:52-8.

16. Gordon JJ, Saunders NA. Sanson Fisher RW. Evaluating intern's performance using simulat d patients in casualty departiment. Med $J$ Aust 1989:151:18-21.

17. Hutchinson B, Woodward CA. Norman GR. Abelson J, Brown JA. Provision of preventive Care to unannounced standardized patients. Can Med Assoc J 1998;27:185-93.

18. McLeod PS, Tamblyn RM. Gayton D, Grad R, Snell L. Berkson L, et al. Use of standardized patients to assess between-physician variations in resource utilization. JAMA $1997 ; 278: 1164-8$.

19. Rethans JJ. Sturmans F, Drop R, van der Vleuten C. Hobus P. Does competence of general practitioners predict their performance? Comparison between examination setting and actual practice. BMJ 1991;303:1377.80.

20. Ram $P$, var der Vleuten $C$, Rethans JJ, Grol R. Aretz K. Assessment of practicing family physicians: comparison of observation in a multiple-station examination using standardized patients with observation of consultations in daily practice. Acad Med $1999 ; 74: 62 * 9$. 
21. Southgate $L$. Pringle M. Rewalidation in the United Kingdom: general principles based on experience in general practice. BMJ 1999:319:1180-3.

22. Jansen JJM, Grol RPTM, Crebolder HFJM, Rethans JW, Vleuten van der CPM. Failure of feedback to enhance self-assessment skills of general practitioners. Teach Learn Med $1998 ; 10: 145-51$. 
Chapter
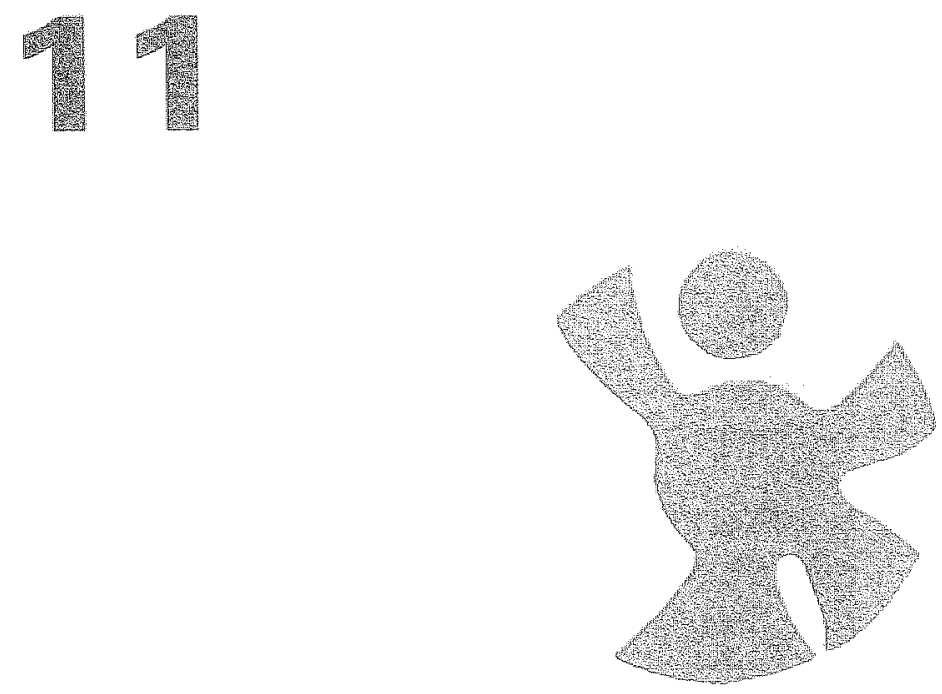

Summary 
$=$
$\frac{5}{9}$
$\frac{2}{0}$
$\frac{5}{0}$

150 


\section{Summary}

Cost effectiveness and quality in the delivery of care have become keyissues in current times of budgetary constraints and increasing costs in health care. Transparency in health care, therefore, has become an important issue. One way to obtain transparency is to provide data about performance in daily practice. Since it is known from earlier research that physicians perform differently from real practice when they know they are being observed, authentic practice performance is assessed when this takes places in a unobtrusive way. This thesis describes the authentic performance of a group of Dutch rheumatologists in day-to-day clinical practice, by using incognito standardized patients (SPs). The rheumatologists were each visited on their outpatient wards by eight incognito SPs, presenting eight different rheumatological conditions. As long as the SPS stayed incognito, validity of the method, i.e. authentic practice performance, was achieved. In this way, a total of 254 incognito visits took place, of which 201 first visits and 53 follow-up visits. Detailed information was obtained on the medical content of each visit and ordered laboratory and imaging tests. In this chapter a summary of the separate chapters will be presented.

Aim of the study was to investigate the feasibility of introducing incognito SPS into specialists' outpatient clinics and the occurrence of follow-up visits. Reproducibility of the incognito SP-based method in specialist care was the second aim of the study. We also wanted to describe the variation in performances of the participating rheumatologists on the eight cases presented by the incognito SPs and try to find explanations for abserved variation. The predictive value of a written competence test (less burdensome to organize) to this incognito SP-based assessment was investigated. Furthermore, the SPS' opinions on non-medical aspects of the interaction between them and the rheumatologists were explored.

In chapter 1, the general introduction, the relevance for assessment in real practice is highlighted. Furthermore, the background of the SP-based assessment is described and a brief review of current literature is given. In addition, the occurrence of practice variation and its educational value is briefly discussed, the logistical demands of this project and the abilities of other instruments to predict practice performance are briefly mentioned and SPs' opportunity to assess non-medical aspects of the consultation, such as communication and attitudinal skills is described. Finally, the research questions of this project are reported.

Chapter 2 provides a review of the literature on the development of casespecific checklists for SP-based assessments in internal medicine. In order to be able to draw conclusions from a SP-based assessment, the 
development of checklists that are used to register the content of the visit, is crucial to the validity and reliability of the assessment. In this chapter, attention is drawn to validity aspects of this development process, such as who developed the checklists, which development procedure was used; whether or not the development process was based on data from the literature or on data resulting from consensus procedures; what scoring system was used and whether or not the checklist was published. A total of 29 relevant articles were found in the literature. Only 12 of these articles reported specifically on the development of the checklist. In general there were three procedures used for developing checklists: panel of experts, the investigators themselves, and the use of responses from expert physicians to written protocols. No article indicated that authors exclusively relied on data from the literature to compose their lists and only four articles made the checklist available. The scoring systems varied considerably among articles and depended on the purpose of the SP-physician encounter. It was concluded that the development process of the checklists needs to be more fully described to enable readers to evaluate validity of the studies.

The feasibility of introducing incognito SPs into specialists" outpatient clinics is described in chapter 3 , by using the results of the first year of the practical part of the study. Introducing SPs into hospital setting requires arrangements that are quite different from those in primary care, a setting in which incognito SPs have been introduced before. For example, since in our country patients can only see a specialist after referral from a general practitioner, general practitioners' cooperation was needed in writing referral letters. More than one year before the first SP would enter practice, rheumatologists glave informed consent. By the time the first SP entered practice we presumed that the rheumatologists were not expecting them anymore. Many efforts were needed to coordinate the visits. Results of requested additional investigations had to reach the rheumatologists in the usual way, so co-operation from people working in laboratories and radiology departments was essential. Simulating real radiographs proved especially problematic, since rheumatologists had to receive the radiograplins they had ordered which had to be exactly the same, except for the hospital labels, as the radiograph that has been ordered by another rheumatologist from the other side of the country. The SPs remained undetected in $98 \%$ of the visits. In summary, introducing incognito SPS into specialists' outpatient clinics with follow-up visits has proven possible, but demands many efforts to obtain the detailed information about real practice performance. We think this is not a method for general use, but more as a kind of "service on demand" when physicians ask for medical audit.

Chapter 4 describes the variation in performance for all eight cases among the 27 Dutch rheumatologists who were visited by the incognito SPs. 
Considerable variation was seen among rheumatologists when presented with the same SPs. Costs for ordered laboratory and imaging investigations varied both among cases as well as among individual theumatologists. Practice variation is poorly understood. Uncertainty, lack of agreement on optimal treatment, legal implications promoting defensive medicine. economic constraints and peer pressure are among factors that might contribute to the observed variation. Few rheumatologist characteristics were investigated and of these only years of working experience partly explained the number of items performed on the checklist. We think that comparable degrees of variation exist in other health care settings and therefore, that the results will be generalizable and useful in discussions on the appropriateness of delivery of care by rheumatologists and can be used as a needs assessment tool for continuous medical education or the development of guidelines.

Intra-doctor variation may occur when a physician performs differently when facing exactly the same problem, or when different cases are presented to one physician and his or her performance on one case does not predict performance on another case. Inter-doctor variation can be found when different physicians are presented with the same case. Physicians' personal or background characteristics may explain part of the accurring inter-doctor variation and is one of the issues investigated in chapter 5. There is considerable variation in scores among cases as well as among rheumatologists. Scores are expressed in percentage of the maximum possible score and a separate score is calculated beforehand by a group of rheumatologists for those items considered essential for that case (key-items). The years of working experience as a rheumatologist significantly negatively correlates with the case score on the key-items and the total case score. However, with increasing working experience, the ratio between key-item score and total item score remains the same, which means that experts do not perform better on the items considered most important by a group of rheumatologists. Our finding that expert physicians perform fewer items has been found before. However, it has now been shown that this also holds for actual practice. An explanation why these experts do not perform better on predefined key-items might be that physicians develop expertise in their own way, depending on their training and individual experience. Hence, it is difficult to predict those items, due to this idiosyncratic development of physician's expertise.

In chapter 6 the results of the case on psoriatic arthritis is presented. Twenty-three rheumatologists were each visited by two incognito SPs (real patients; one female, one male), which stayed incognito for all encounters for the duration of the study. Fourteen rheumatologists diagnosed psoriatic arthritis correctly and inspected the skin for psoriatic lesions more of ten than those who did not diagnose correctly. The correct diagnosis was more 
frequently missed among rheumatologists visited by the male patient, presenting with clear DIP-joint arthritis, compared to the female patient who had a history of DIP-joint arthritis, tendinitis and carpal tunnel surgery. In addition, those rheumatologists with the correct diagnosis spent more costs on additional laboratory and imaging tests. They did so after the diagnosis was made, probably to confirm the diagnosis and to document the extent of the disease. To summarize, again, a considerable amount of variation is found between rheumatologists in performance this time on a psoriatic arthritis case. Those rheumatologists focusing on striking features (clear DIP-joint arthritis) sometimes seem to forget "the hidden" (skin) symptoms.

The reproducibility of authentic assessment methods have been investigated for OSCE's (Objective Structured Examinations or station examination) and video assessments in practice, but this has never been done for incognito SP-based assessment in specialists care. Chapter 7 , therefore, investigates this issue by analyzing the results of 22 rheumatologists. who were all visited by eight incognito SPs each. Scores on the checklist completed by the SP at the end of each visit were entered into generalizability analysis. One fifth of the variance is attributable to the variance among rheumatologists, whereas the largest variance component is the difference in difficulty among cases. In a norm-referenced score interpretation, three hours (six cases) of testing time is required for a reproducible assessment, whereas seven hours (14 cases) in an absolute scoring system. These reproducibility findings are equal to reproducibility findings in OSCE assessment and other authentic measures of competence and performance.

Practice variation in delivering care is a well-known phenomenon and promoting good clinical practice also means reducing undesired variation. Insight into daily clinical practice and linking data from real practice to patient outcome will facilitate defining standards for good clinical practice and developing guidelines to improve the delivery of care.

In Chapter 8 the predictive validity of a computerized case-based test (CCT) for performance was investigated. Fourteen of the 26 participating rheumatologists in the SP-based assessment, completed a CCT containing 55 cases, with a total of 121 items. High but negative correlations were found between the SP scores and the CCT scores. This was unexpected. The correlation between work experience and CCT was high and positive and with the SP scores high and negative. Thus, CCT was not predictive for SP scores. Both instrument probably measure other things, and it cannot be said that either of the instruments was superior to the other, but each had its own strengths and weaknesses and should be perceived as incremental. The results underpin the assumption that for good performance assessment a variation of instruments is needed. 
In chapter 9, it is the SPS themselves who present their opinion on the rheumatologists they have visited. Effective communication Vverbal and non-verbal) between physicians and patients, hospital accessibility and waiting room situations are among factors enhancing patient satisfaction. It is important to know which specific skills and attitudes contribute to enhanced patient satisfaction, because it has been shown that patient satisfaction can improve patient outcome. Therefore, appreciation and opinion on the interaction between doctors and our SPS is investigated. A focus group interview was organized to explore the experiences and perceptions of the SPS. Thirteen of 16 SPs participated and the following questions were set beforehand: 1) what makes SPS like or dislike a rheumatologist, 2) is there any influence of situations in waiting room or the doctor's office on the evaluation of the physician and 3) does the experience of being a SP influence their opinion of physicians? During the focus group interview the following topics spontaneously raised: the variation in performance between rheumatologists, difference in physician behavior between first and follow-up visit and the perceived effect on the consultation of the general practitioner's referral letter. In this article, the different topics are illustrated by quotes from the participants. The SPS were very enthusiastic about the rheumatologists. Approaching them as a person was very much appreciated. However, there were some concerns for example regarding the possibility to express all their complaints and privacy in physician's office. We think that doctors can learn from patients' feedback and that they should involve patients' opinions on different aspects of care. Most of the comments were related to small things, which should not be so difficult to change. 


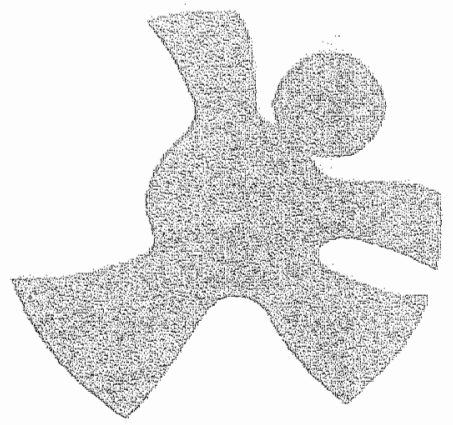

\section{Samenvatting}


$\frac{1}{0}$
$\frac{1}{0}$
$\frac{1}{0}$

158 


\section{Samenvatting}

In de huidige tijd van budgettering en stijgende uitgaven in de gezondheidszorg, zijn kosten-effectiviteit en kwaliteit van zorg populaire begrippen geworden. Transparante zorg wordt steeds belangrijker. Eén van de manieren om de zorg transparanter te maken, is het verkrijgen van informatie over het handelen in de praktijk. Dit wordt performance fvan gezondheidszorgverleners) genoemd. Daarbij is het van belang om het echte handelen in de dagelijkse praktijk vast te leggen. Eerder onderzoek heeft aangetoond dat artsen anders handelen wanneer ze weten dat ze geobserveerd worden. Dit proefschrift beschrijft het echte handelen in de dagelijkse praktijk van een groep nederlandse reumatologen, die op hun spreekuur bezocht werden door incognito gestandaardiseerde patiënten (SPS). De deelnemende reumatologen werden ieder door acht incognito SPs bezocht, waarbij iedere SP een andere reumatologische aandoening presenteerde. De validiteit van deze methode, dat wil zeggen meting van het echte handelen in de dagelijkse praktijk, werd gewaarborgd, zolang de SPs incognito bleven. In totaal vonden tijdens deze studie 254 bezoeken plaats, waarvan 53 vervolgbezoeken. Er werd gedetailleerde informatie verzameld over medisch inhoudelijke aspecten van het bezoek en aangevraagd laboratorium- en röntgenonderzoek. In deze samenvatting vwordt de inhoud van de diverse hoofdstukken weergegeven.

Het doel van de studie was om de haalbaarheid te onderzoeken van het introduceren van incognito SPs op spreekuren van medisch specialisten, ook tijdens vervolgbezaeken. Reproduceerbaarheid van de incognito SPmethode in de $2^{\text {de }}$ lijn, was een volgende doelstelling. Daarnaast wilden we de variatie in handelen van de deelnemende reumatologen zoals vastgelegd door acht incognito SPs registreren en waar mogelijk verklaringen voor deze variatie proberen te vinden. Van een logistiek minder ingewikkelde toets, een schriftelijke competentie toets, werd de voorspellende waarde onderzocht op het handelen in de praktijk zoals gemeten met incognito SPS. Tevens werden de meningen van de SPS geëxploreerd met betrekking tot niet-medische aspecten van interactie tussen reumatoloog en SP.

In hoofdstuk 1, de algemene inleiding, wordt de relevantie van het meten in de dagelijkse praktijk belicht. Daarnaast wordt ingegaan op de achtergrond en ontwikkeling van SPs voor onderwijs en onderzoek en wordt er een kort overzicht van de literatuur gegeven. Daarnaast wordt het woorkomen van variatie in handelen en haar onderwijskundige waarde besproken, de logistieke eisen die aan onderzoek met SPs worden gesteld, alsmede de mogelijkheid van andere meetinstrumenten om het handelen in cle praktijk te voorspellen. Ook wordt besproken dat door gebruik te maken van SPis de gelegenheid bestaat niet-medische informatie over het bezoek aan de arts 
te verkrigen. Het gaat dan a.a. over attitude en communicatievaardigheden. Tenslotte worden de onderzoeksvraagstellingen gepresenteerd.

Hoofdstuk 2 geeft een overzicht van de literatuur over de ontwikkeling van casusspecifieke checklists op het gebied wan Interne Geneeskunde voor metingen met SPs. Om conclusies te kunnen trekken, is het belangrijk dat de wijze waarop de checklists zijn opgesteld beschreven wordt. Alleen in dit geval kun je lets over de validiteit en de betrouwbaarheid van een studie zeggen. In dit hoofdstuk wordt aandacht geschonken aan aspecten van validiteit, zoals "wie ontwikkelden de checklists"; "op welke wijze werd dit gedaan": was het proces van checklist ontwikkeling gebaseerd op gegevens uit de literatuur of op gegevens uit consensus procedures; welk scoringssysteem werd gebruikt, en of de checklist gepubliceerd was. In totaal werden 29 relevante artikelen gevonden, waarvan er 12 het proces van checklist ontwikkeling beschreven. Uiteindelijk werden er drie procedures gevonden voor het ontwikkelen van checklists: expertpanel, de onderzoekers zelf, en het gebruiken van reacties van experts op vooraf ontwikkelde checklists. In geen enkel artikel werd vermeld dat de auteur zijn checklist volledig met gegevens uit de literatuur opstelde. In slechts vier artikellen werd de checklist gepubliceerd. De gehanteerde scoringssystemen varieerden enorm en waren afhankelijk van thet doel van de SP-meting. Om de validiteit van de studies te kunnen beoordelen is het belangrijk dat het ontwikkelingsproces van de checklist goed beschreven wordt.

De haalbaarheid van het introduceren van incognito SPs op poliklinieken van medisch specialisten tijdens het eerste jaar van de studie wordt beschreven in hoofdstuk 3. De introductie van incognito SPs in het ziekenhuis vergde andere voorbereidingen dan de introductie in de huisartsenpraktijk, waarmee reeds ervaringen waren opgedaan. In Nederland wordt bijvoorbeeld een patiënt door een huisarts verwezen naar een specialist. Dit betekende dat er een verwijsbrief aanwezig moest zijn van een voor die speciallist bekende huisarts. In onze studie participeerden bijna 100 huisartsen. De deelnemende reumatologen gaven een jaar voordat de eerste incognito SP de praktijk ingestuurd werd, reeds toestemming voor deelname aan de studie. Op deze manier hoopten wij dat de reumatologen niet meer op hun qui-vive waren woor een bezoek door een incognito SP. De inspanningen die nodig waren om de bezoeken incognito te houden waren behoorlijk. Resultaten van aangevraagd aanvullend onderzoek moesten op een voor die reumatoloog "normale" wijze gepresenteerd worden. Dit betekende samenwerking met mensen uilt de laboratoria en röntgenafdelingen. Met name het simuleren van röntgenfoto's was moeilijk. De ffoto moest natuurlijk voor iedere reumatoloog identiek zijn, hoewel de labels daarentegen per ziekenhuis varieerden. In $98 \%$ van de bezoeken bleven de SPs incognito. Samenvattend kan worden gezegd dat het 
introduceren van incognito SPS op spreekuren van medisch specialisten werkzaam in ziekenhuizen mogelijk is, dat ook vervolgconsulten incognito kunnen plaatsvinden, maar dat het erg veel inspanningen vereist de bezoeken te laten slagen. Wij denken niet dat de SP-methode een methode is die overal ingezet kan worden voor het meten van performance, maar eerder gebruikt moet worden als een "service on demand" "bijvoorbeeld als er gericht gevraagd wordt naar een evaluatie van handelen in de praktijk.

Hoofdstuk 4 beschrijft de variatie in het handelen van de 27 deelnemende nederlandse reumatologen met betrekking tot de acht casus. De reumatologen die bezocht werden vertoonden een behoorlijke mate van variatie in hun handelen. Kosten voor aangevraagd laboratorium, of röntgenonderzoek varieerden, zowel tussen de verschillende casus als tussen de individuele reumatologen. Variatie in handelen in de dagelijkse praktijk wordt slecht begrepen. Onzekerheid, gebrek aan bewijsvoering met betrekking tot optimale behandeling, defensief handelen in verband met mogelijke juridische stappen, druk wan collega's en economische bezwaren zouden factoren kunnen zijn die bijdragen aan de gevonden variatie in handelen. Er werden enkelle kenmerken van de reumatologen onderzocht, waarvan alleen het aantal jaren werkervaring als reumatoloog voor een deel de gevonden variatie kon verklaren. Omdat dergelijke gevonden variatie in handelen zeer waarschijnlijk ook op andere settings in de gezondheidszorg van toepassing is, denken we dat generalisatie van deze resultaten mogelijk is. Uiteraard zijn de resultaten bruikbaar voor discussies tussen reumatologen over kwaliteitswerbetering en kunnen de resultaten van dit onderzoek mogelijk gebruikt worden als een instrument voor het meten van specifieke behoeften voor nascholing of voor het ontwikkelen van richtlijnen.

Dokters variëren in hun handelen als ze verschillende casus krijgen voorgelegd; dit staat bekend als casusspecificiteit. Intra-dokter variatie treedt op als een arts op verschillende wijzen handelt wanneer hij exact hetzelfde probleem tegenkomt. Inter-dokter variatie kan optreden als dezelfde casus worden voorgelegd aan een verschillende artsen en iedere dokter anders handelt. Dit wordt onder andere besproken in hoofdstuk 5 . Achtergrondvariabelen off persoonlijke eigenschappen van artsen zouden mogelijk een deel van de gevonden variatie in handelen verklaren. Er werd een behoorlijke variatie gewonden in scores, zowel tussen de diverse casus, als tussen de reumatologen. Scores werden uitgedrukt in percentage van de maximaal te behalen score, en een aparte score wordt berekend voor de zogenaamde key-items. Deze score werd berekend uit de items die door de meerderheid van een groep reumatologen als essentieel beschouwd werden. Dit vond plaats voorafgaande aan de bezoeken door de SPs. Het aantal jaren werkervaring als reumatoloog correleerde significant negatief met de totale casus score en de score op de keymitems. Echter, met 
toegenomen werkervaring bleef de ratio tussen key-item score en totale casus score ongeveer gelijk, wat betekende dat experts niet beter scoorden op de items die door een groep reumatologen als essentieel werden gedefinieerd. Onze bevinding, dat experts minder items verrichtten werd reeds eerder beschreven. Dit werd nu ook bevestigd voor het handelen in de dagelijkse praktijk. Een verklaring voor het feit dat experts niet beter op de essentiële items scoren, kan zijn dat experts hun ervaring op hun eigen manier opdoen, afhankelijk van hun training en individuele ervaring. Door de idiosyncrasie van deze expertise is het moeilijk het handelen op dergelijke items te voorspellen.

In hoofdstuk 6 worden de resultaten van een casus over artritis psoriatica beschreven. Drieëntwintig reumatologen werden ieder bezocht door twee incognito SPs ("echte" patiënten: 1 man en 1 vrouw). Veertien reumatologen stelden de juiste diagnose artritis psoriatica en onderzochten duideiijk vaker de huid op psoriasis lesies dan de reumatologen die de diagnose artritis psariatica niet stelden. De juiste diagnose werd vaker gemist door de reumatologen die bezocht waren door de mannelijke SP. Hij presenteerde zich met artritis van het distale interfalangeale gewricht (DIPgewricht), terwijl de vrouwelijke SP een anamnese had van een artritis van een distaal interfalangeaal gewricht in het verleden, een tendinitis en een operatie in verband met een carpaal tunnel syndroom. De reumatologen met de juiste diagnose gaven meer geld uit aan aanvullend onderzoek. Dit aanvullend onderzoek werd aangevraagd nadat ze de diagnose gesteld hadden, waarschijnlijk om de diagnose te bevestigen en de uitgebreidheid van de aandoening te documenteren. Samenvattend kan worden gezegd dat er een behoorlijke variatie in handelen aanwezig is tussen de verschillende reumatologen die allen werden bezocht door een gestandaardiseerde patiënt met artritis psoriatica. De reumatologen die hun aandacht met name richtten op de artritis van het DIP-gewricht, leken soms de "verborgen" (huid) symptomen te missen.

De reproduceerbaarheid van methoden als OSCE's 1Objective Structured Clinical Examination ofwel stationsexamen) en video-metingen in de praktijk, is al eerder beschreven, maar bij SPs in de dagelijkse praktijk was dit nog niet bekend. In hoofdstuk 7 werd dat gedaan door de resultaten van 22 reumatologen te onderzoeken die allen door acht incognito SPS bezocht waren. De checklists werden na afloop van het consult door de SPS ingevuld. Met de scores op deze lijsten werd een generaliseerbaarheidsanalyse uitgevoerd. Eén vijfde van de gevonden variatie kon worden toegeschreven aan de variatie tussen reumatologen, de grootste variatie aan de variatie in moeilijkheidsgraad tussen casus. Bij een genormeerde score-interpretatie was 3 uur testtijd ( 6 casus) nodig voor een reproduceerbare meting, terwijl 7 uur testtijd (14 casus) nodig was bij een absolute score interpretatie. Deze resultaten zijn vergelijkbaar met de 
resultaten over betrouwbaarheid zoals die gevonden zijn in studies bij OSCE's en andere authentieke compietentie- en performance metingen.

Variatie in handelen is een bekend fenomeen en het stimuleren van "good clinical practice" betekent ook ongewenste variatie verminderen. Inzicht in het handelen van de dagelijkse praktijk en het combineren van deze data met uitkomstmaten van patiënten zal het definiëren van standaarden voor "good clinical practice" en het ontwikkelen van richtlinen om de kwaliteit van handelen te verbeteren, vergemakkelijken.

in hoofdstuk 8 werd de predictieve waarde van een "computerised casebased-test (CCT)" voor een performance meting onderzocht. Veertien van de 26 reumatologen die deelnamen aan de praktijk-meting met incognito SPS maakten een CCT die bestond uit 55 casus met een totaal van 121 items. Onverwacht werden hoge, maar negatieve correlaties gevonden tussen de scores van de praktijkmeting en die van de CCT. De correlatie tussen werkervaring en CCT score was positief en hoog, de correlatie tussen werkervaring en praktijkscore negatief en hoog. De score van de CCT was niet voorspellend voor de score van de praktijkmeting. Waarschijnijk meten beide instrumenten iets anders, en is de één niet beter dan de ander. Beide meetinstrumenten hebben hun voor-en nadelen, maar bieden gecombineerd uitgebreidere informatie. Deze resultaten ondersteunen de gedachte dat voor een degelijke meting van performance diverse instrumenten noodzakelijk zijn.

In hoofdstuk 9 komen de SPs zelf aan het woord. Zij geven hier hun mening over de reumatologen die ze bezocht hadden. Met 13 van de 16 SPs die aan de praktijkmeting hadden geparticipeerd, werd een focusgroep interview georganiseerd. De groep werd drie vragen vaorgelegd. Ten eerste: waarom vindt een SP een reumatoloog aardig of niet aardig? Ten tweede: beïnvloeden situaties in de wacht- of spreekkamer de mening van een SP over de reumatoloog? En ten derde: heeft de ervaring van het participeren aan dit onderzoek als SP invloed op hun denken over artsen in het algemeen? Tijdens de discussie werden bovenstaande punten uitwoerig met eigen ervaringen geillustreerd en werden tevens een aantal andere zaken spontaan door de groep naar voren gebracht; zoals de variatie in handelen van de verschillende reumatologen bij dezelfde presentaties, het verschil in benadering van dezelfde reumatoloog tijdens het eerste consult en het vervolg consult, en het effect van de verwijsbrief van de huisarts op de consultvoering door de reumatoloog. Over het algemeen waren de deelnemers aan het focusgroep interview zeer tevreden over de ontvangen reumatologische zorg. Factoren die bijdroegen aan deze tevredenheid waren onder andere: "een persoonlijke benadering door de reumatoloog", "respectvol behandeld worden", en "voldoende ruimte krijgen om alle klachten te vermelden tijdens het consult". De patiënt persoonlijk uit de wachtkamer halen of informeren naar de thuissituatie werd als zeer positief 
ervaren. Echter, een gordijn dat niet goed het omkleedhokje afsluit, een doktersassistente die de onderzoekskamer binnen komt lopen, of een uitvoering telefoongesprek met een collega tijdens het spreekuur worden als zeer vervelend ervaren. Opvallend was dat de SPs onder de indruk waren van variatie in het (medisch-inhoudelijk) handelen tussen de diverse reumatologen bij een zelfde casus. De benadering door de reumatoloog tijdens het vervolgconsult werd door de gestandaardiseerde patiënten vaak als slechter ervaren. Het merendeel van het commentaar van deze patiënten op communicatie en attitude van de reumatologen had betrekking op relatief "kleine zaken", die gemakkelijk te verbeteren zijn. Deze feedback is waardevol om verbeteringen te bereiken in de alledaagse praktijk. Het is aan te bevelen dat artsen in de praktijk deze feedback kunnen krijgen. Misschien heeft dat wel meer impact dan het volgen van vele cursussen. 
Dankwoord

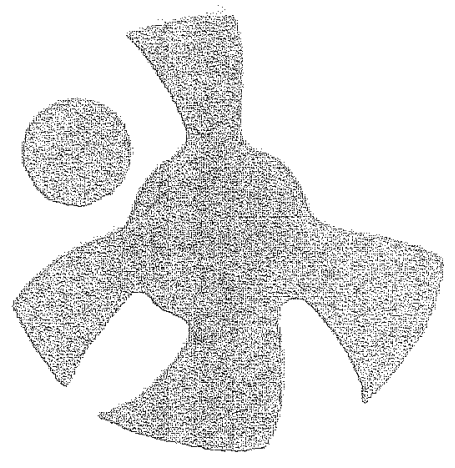




\section{Dankwoord}

Dit proefschrift is mogelijk gemaakt door de enthousiaste en waardevolle medewerking van velen. Ik wil graag, nu de eindstreep in zicht is, in het bijzonder de volgende personen bedanken.

Mijn promotoren en co-promotor; Désirée van der Heijde, Albert Scherpbier en Jan-Joost Rethans.

Beste Désirée, ik heb met veel plezier met je samengewerkt en veel geleerd van jouw duidelijkheid, heldere kijk op het project en op mijn schrijfwerk. Je bent een prima promotor! Dank je wel.

Albert, jouw tomeloze enthousiasme deed me keer op keer versteld staan. Het tempo waarmee je een artikel corrigeerde was niet bij te houden en aan nieuwe creatieve ideeën bij jou geen gebrek.

Jan-Joost, compromotor, maar zeker ook goede vriend. Jij nam het grootste deel van de begeleiding voor je rekening. In de eerste periode van mijn aanstelling betekende dit het uitwerken van het onderzoek, het aanvragen van subsidie en mij op weg helpen in de wereld van onderzoek en gestandaardiseerde patiënten. Later begeleidde je de witwerking van het project in de dagelijkse praktijk en het schrijfwerk. Met werkelijk heel veel plezier werk ik met je samen en hoop dit in de toekomst nog vaak te kunnen doen..

Jolanda Brauer, lieve Jolan, zonder jou was het project beslist niet geslaagd. Jouw gezellige, en vlotte babbel en jouw gave om alles in goede banen te kunnen leiden, hebben er voor gezorgd dat de bezoeken door de SPs zonder grote problemen verliepen. Jij bent diegene die dagen in donkere kamers van de röntgenafdeling doorbracht om foto's te kopiëren, die als schoondochter van een SP het land mee doorreisde, maar bovenal mijn maatje in ons project was. Wat hebben we gelachen. Als ik ooit nog eens de kans krijg, werk ik graag weer met je samen. Jolan, hartstikke bedankt!

Daarnaast wil ik de overige leden van de begeleidingscommissie bedanken; Professor Sjef van der Linden. Professor Cees van der Vleuten en Harry Houben. Beste Sjef, jij neemt een bijzondere plaats in bij dit onderzoek. Uren hebben we gebrainstormd over de incognito bezoeken van de SPS, over wat er allemaal mis zou kunnen gaan, waar we allemaal aan moesten denken. Bijna incognito bezochten we de directies van de 16 deelnemende ziekenhuizen, waarvoor we regelmatig uren per trein onderweg waren. Sjef, bedankt voor je hulp, ik kijk uit naar mijn opleidingstijd bij de reumatologie onder jouw supervisie. Beste Cees, jou will ik bedanken voor je steun bij dit project en bij het schrijven van diverse artikelen. Je hebt de bijzondere gave mensen te stimuleren, en bent altijd bereid een helpende hand uit te steken. Hilervoor heel veel dank. Harry, als perifeer reumatoloog in het Atrium MC 
Heerlen was je altijd erg enthousiast voor het project. Bedankt voor je hulp in diverse fasen van het project.

Marijke van Santen, je was geen officieel lid van de begeleidingscommissie, maar hebt me tijdens het project veel geholpen met je creatieve ideeen, het ontwikkelen van de toets en het trainen van de gestandaardiseerde patiënten. Ilk ben heel blij dat ik jou en Jolanda als paranimf aan mijn zijde heb staan. Dank je wel!

Lambert Schuwirth, beste Lammie, de laatste loodjes wegen het zwaarst, en dat hebben we geweten. Na jouw hulp bij het ontwikkelen van de computer toets hebben we nog uren achter je PC doorgebracht om de data te analyseren en te interpreteren. Het artikel is nu gelukkig af, hoewel ik onze brainstorm sessies wel mis. Bedankt voor je hulp.

Bij het schrijven van de casus, het ontwikkelen van de checklists, de computertoets, en het trainen vain de gestandaardiseerde patiënten was de hulp van diverse reumatologen uit Maastricht en elders onontbeerlijk. Ik wil hen allen bedanken vaor de goede hulp en prettige samenwerking. Een speciaal woord van dank gaat uit naar Toon Westgeest, reumatoloog te Eindhoven die onder andere als een incognito reumatoloog diverse casus heeft ondersteund.

En natuurlijk de hoofdrolspelers van het project; de gestandaardiseerde patï̈nten. Sjoerd Aerts, Esseline Olga Fabre, Margo Gaveel, Bea de Groote, Bertus Hüsken, Dhr Hollander, wijlen Elbert Keus, Marijke Kohinor, Wil Macco, Frits Martens, Jan Markus, Edith Meijer, Marcel Mol, Tineke Prins, Hans Schrumpf, Dion de Swart, Lorna Teunisse en Houkje Verhagen van der Weij. Ik wil jullie bedanken voor jullie inzet en enthousiasme. Jullie hebben daar uiteindelijk echt gestaan, voor de reumatoloog, en jullie rol gespeeld. Soms hebben jullie uren in de trein doorgebracht voor een bezoekje van een half uur. Het was een ongelooflijk leuke ervaring om met jullie te werken. De telefoontjes na afloop van de bezoeken en de soms bizarre situaties waarin jullie je een uitweg moesten zoeken zijn om nooit te vergeten. Met jullie waardevolle, kritische en leuke opmerkingen over het reilen en zeilen in de diverse praktijken hebben we uiteindelijk een heel artikel kunnen schrijven. Bedankt!

Het is bijzonder jammer dat een van de gestandaardiseerde patiënten, Elbert Keus, tijdens het project overledien is en de afronding ervan niet meer kan meemaken. Hij heeft met veel enthousiasme zijn rol gespeeld en vond dit project "een legitieme manier om mensen voor de gek te houden. ... ".

De mensen achter de schermen mag ik natuurlijk niet vergeten. In ieder ziekenhuis waren er contactpersonen op diverse afdelingen. Zij regelden werkelijk alles; van de invoer van de fake-laboratorium-resultaten, röntgenuitslagen, tot het maken van fake-ponsplaatjes en het verhinderen van het verzenden van rekeningen. Bedankt hiervoor! Zonder zo'n 100 meewerkende huisartsen was het niet mogelijk om de gestandaardiseerde 
patiënten incognito bij de reumatologen langs te laten gaan. Zij schreven niet alleen de verwijsbrieven, maar verzamelden ook netjes weer de brieven die door de reumatologen aan de huisartsen geschreven waren.

En natuurlijk alle vrienden, familie en diverse medewerkers uit de ziekenhuizen, bedankt voor het gebruiken van jullie adressen en thet opvangen van telefoontjes of doorgeslipte rekeningen voor de gestandaardiseerde patiënten.

Zonder de deelname van veel reumatologen in Nederland was dit onderzoek niet mogelijk geweest, jullie waren bereid om ons een kijkje in jullie keuken te laten nemen en daarnaast nog enthousiast om mee te doen aan de computertoets.

Beste Erik de Klerk, Guy Schulpen, Karin Bruynesteyn, Astrid van Tubergen en Astrid Wanders, mede-onderzoekers van de reumatologie, bedankt voor jullie steun en samenwerking. I heb onze thee-uurtjes wel gemist de afgelopen jaren!

Mereke Gorsira, jij bedankt voor je hulp bij de finishing touch van diverse artikelen.

Tiny Wouters, wanneer je gesignaleerd wordt bij jou op de kamer, samen turend naar een groot computerscherm, dan weet iedereen binnen de vakgroep dat het proefschrift bijna af is. Jouw oog voor detail en geduld hebben geleid tot een prachtige lay-out. Dank je wel!

Een proefschrift is pas echt af als er een kaft omheen zit. Annelies Weegels, jouw ontwerp van de kaft is betekenisvol en echt prachtig geworden.

Marianne, mijn zus. Lieve $M^{\prime}$ jantje, ook voor jou is dit jaar belangrijk; je zult je opleiding tot huisarts afronden. Utrecht is ver, maar nu het proefschrift af is en de drukke diensten voorbij zijn, is het beslist dichter bij.

Mijn ouders, lieve pappa en mamma. Ik wil jullie bedanken voor de stimulans, de ruimte en gelegenheid die ik heb gekregen om te gaan studeren en me te ontwikkelen tot wie ik nu ben. Mamma, bedankt voor je nuchtere kijk op vele zaken en je goede adviezen. Lieve pappa, jouw sociale begaafdheid en kennis over van alles en nog wat zijn benijdenswaardig. Het boekje is af! Ook voor jullie een zorg minder. Jullie zijn de liefste ouders van de wereld!

Lieve Jasper, mijn kleine kerel. Jouw vrolijkheid en energie maken van iedere dag weer iets bijzonders! Laten we veel leuke dingen gaan doen, zoals fietsen en naar de speeltuin.

Lieve Walther, je vindt het een geweldig leuk onderzoek, maar nu het eindelijk af is, vind je dat toch leuker. Bedankt voor je steun, je vertrouwen in het onderzoek en je relativerend vermogen als ik het weer even niet zag zitten. Het afgelopen jaar had veel te weinig gezellige momenten samen; was het niet mijn proefschrift, dan waren het wel de diensten. Eindelijk zijn de weekenden er nu voor jou en Jasper. 
Het proefschrift is af! Een heerlijk gevoel. 
Curriculum Vitae

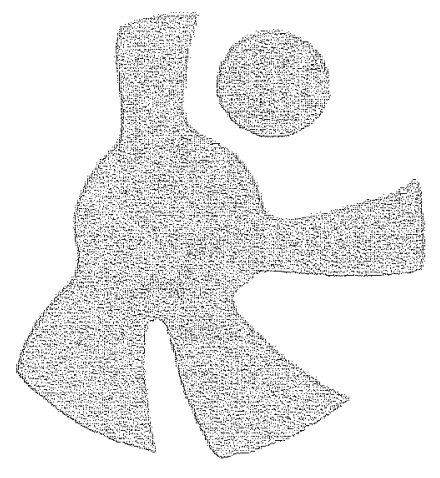




\section{Curriculum Vitae}

Simone Leonie Gorter werd geboren op 14 maart 1970 te Geldrop. In 1988 haalde zij haar VWO diploma aan het Strabrecht College te Geldrop. In datzelfde jaar startte zij met de studie Geneeskunde aan de Universiteit Maastricht, waar zij in 1995 haar artsexamen behaalde. Haar eerste kennismaking met de reumatologie had zij tijdens een stage reumatologie in het Universitair Ziekenhuis te Gent, België. Het jaar voor aanvang van haar co-schappen bracht ze door bij de werkgroep Reumatologie in het academisch ziekenhuis Maastricht, waar ze haar eerste onderzoekservaringen in de reumatologie opdeed. Van oktober 1995 tot september 2000 werkte zij eerst als AlO en later als arts-onderzoeker bij de werkgroep Reumatologie in het academisch ziekenhuis Maastricht aan haar promotieonderzoek. Voor een presentatie op het Gezond Onderwijscongres (GOC) over haar onderzoek ontving zij in 1999 de prijs voor de beste onderzoekspresentatie. Op 1 september 2000 startte zij met haar 3-jarige vooropleiding Interne Geneeskunde in het Atrium Medisch Centrum te Heerlen (opleiders dr FATh Lustermans en dr P Voogt), waarna ze 1 september 2003 is gestart met de opleiding tot reumatoloog in het academisch ziekenhuis Maastricht (opleider prof dr Sj van der Linden).

Simone Gorter woont samen met Walther van Mook en samen hebben zij een zoon Jasper. 